FACULDADE DE MEDICINA DE RIBEIRÃO PRETO

PROGRAMA DE PÓS-GRADUAÇÃO EM IMUNOLOGIA BÁSICA E APLICADA

\title{
ATIVIDADE DA FOSFOETANOLAMINA SINTÉTICA EM MELANOMA MURINO EXPERIMENTAL
}

Dissertação de Mestrado apresentada a Faculdade de Medicina de Ribeirão Preto da Universidade de São Paulo para obtenção do Título de Mestre em Ciências

Área de Concentração: Imunologia Básica e Aplicada

Orientado: Luciana Chain Veronez

Orientadora: Dr ${ }^{\mathrm{a}}$. Gabriela Silva Bisson

Ribeirão Preto 
Autorizo a reprodução e divulgação total ou parcial deste trabalho, por qualquer meio convencional ou eletrônico, para fins de estudo e pesquisa, desde que citada a fonte.

Veronez, Luciana Chain

Atividade da fosfoetanolamina sintética em melanoma murino experimental. Ribeirão Preto, 2012.

80 p. : il. ; $30 \mathrm{~cm}$

Dissertação de Mestrado, apresentada à Faculdade de Medicina de Ribeirão Preto/USP. Área de concentração: Imunologia Básica e Aplicada.

Orientadora: Bisson, Gabriela Silva

1. Fosfoetanolamina. 2. Melanoma. 


\section{FOLHA DE APROVAÇÃO}

\section{Luciana Chain Veronez}

“Atividade da fosfoetanolamina sintética em melanoma murino experimental”

Dissertação de Mestrado apresentada a Faculdade de Medicina de Ribeirão Preto da Universidade de São Paulo para obtenção do Título de Mestre em Ciências

Área de Concentração: Imunologia Básica e Aplicada

Orientadora: Dr ${ }^{\mathrm{a}}$. Gabriela Silva Bisson

Aprovada em:

Banca Examinadora

$\operatorname{Prof}(\mathrm{a}) . \operatorname{Dr}(\mathrm{a})$

Instituição: Assinatura:

Prof(a). Dr(a).

Instituição: Assinatura:

Prof(a). Dr(a).

Instituição: Assinatura: 


\section{DEDICATÓRIA}

Dedico este trabalho à minha família, mas principalmente: Aos meus pais, Felício e Ana:

"Teus braços sempre se abrem quando preciso de um abraço. Teu coração sabe compreender quando preciso de um amigo. Teus olhos sensíveis se endurecem quando preciso de uma lição. Tua força e teu amor me dirigiram pela vida e me deram as asas que precisava para voar".

(Samantha Bader)

Ao meu irmão e ao meu namorado, os "Felipes" da minha vida. 


\section{AGRADECIMENTOS}

Durante essa jornada, muitas pessoas entraram e passaram a fazer parte de minha vida colaborando direta ou indiretamente com minha formação pessoal e com a conclusão deste trabalho. Por esta razão, deixo aqui registrada minha sincera gratidão.

Agradeço à minha orientada Dra. Gabriela Silva Bisson, não só pela paciência, orientação, aprendizagem e contribuição em meu desenvolvimento profissional, mas principalmente pela confiança depositada e oportunidade oferecida no início do mestrado.

Aos meus queridos companheiros do LGBIO, com os quais acabei passando mais tempo que com minha própria família e que acabaram se tornando verdadeiros amigos. Cada qual com seu jeito peculiar com os quais sempre tive o que aprender. Agradeço pelo convício, pelas risadas e momentos de descontração, pelos apuros, sofrimentos, preocupações, apoio científico e emocional.

À Thaís Arns pela amizade e pelas inúmeras seções de desabafo! Pelas experiências e pelos inesquecíveis momentos hilários. Também aos meus amigos de infância e de faculdade que sempre torceram por mim.

Aos Drs. Sérgio Britto Garcia e Durvanei Augusto Maria por abrirem suas portas e, desde o início, aceitarem colaborar com nosso trabalho permitindo a realização das análises hematológicas e imunoistoquímicas essenciais para conclusão da dissertação.

À Dra. Evelin Capellari Cárnio por ceder seu laboratório e biotério para realização dos experimentos.

Ao Marcelo Eduardo Batalhão por sempre estar disponível quando precisei

de ajuda. À Rosângela Orlandin Lopes, pricipalmente pela paciência, atenção e ensinamentos técnicos de imunoistoquímica. 
À Fabiana Rossetto de Morais pela realização das análises de citometria de fluxo.

À Fundação de Amparo à Pesquisa do Estado de São Paulo (FAPESP) pelo bolsa de mestrado concedida.

À toda minha família pelo incentivo e apoio a cada nova etapa da minha vida. Vocês são muito importantes para mim, sou eu que tenho orgulho de vocês!

Especialmente aos meus pais, que mesmo não entendendo muito bem o que faço e a carreira científica que decidi seguir, nunca deixaram de me incentivar e apoiar. Obrigada por me fazerem ser o que sou hoje, pelas palavras, carinho, conselhos, amor e pelo colo que sempre estava a minha espera quando eu precisava. Minha admiração por vocês é imensa, obrigada por serem meu porto seguro! É em vocês que me inspiro, espero um dia ser um pouco do que são. Amo vocês!

Ao meu irmão querido, meu amigo e companheiro de todas as horas, por simplesmente existir na minha vida. Não precisamos falar nada, o simples fato de estarmos juntos já me fazia melhor nas horas em que eu mais precisava.

Ao meu namorado, por sempre estar ao meu lado e me incentivar mesmo quando o mau humor tomava conta de mim. Obrigada pela compreensão, por me ouvir sempre que alguma coisa dava errada e por me fazer entender que, as vezes, é preciso parar e respirar. Por me fazer rir nos momentos mais difíceis e comemorar comigo cada conquista! Te amo!

"Tudo o que um sonho precisa para ser realizado é alguém que acredite que ele possa ser realizado".

(Roberto Shinyashiki) 


\section{RESUMO}

VERONEZ, L. C. Atividade da fosfoetanolamina sintética em melanoma murino experimental. 80 f. Dissertação (Mestrado) - Faculdade de Medicina de Ribeirão Preto, Universidade de São Paulo, São Paulo, 2012.

O desenvolvimento de novas estratégias terapêuticas ao melanoma é de particular importância devido à sua baixa resposta aos tratamentos tradicionais. No presente trabalho, utilizamos modelo de melanoma murino experimental para estudarmos os efeitos da fosfoetanolamina (PEA) sintética sobre o desenvolvimento deste tumor. Nossos resultados demonstram que o fosfomonoéster apresentou efeito inibidor da proliferação de células da linhagem B16F10 in vitro, induzindo apoptose após estimulação por 24 a $72 \mathrm{~h}$. In vivo, o tratamento (via oral) de animais portadores de melanoma com diferentes doses de PEA (10, 20 e $40 \mathrm{mg} / \mathrm{Kg}$ ), durante 10 ou 20 dias consecutivos, resultou em volumes tumorais pelo menos 70\% menores que o de animais controle e diferenças macroscópicas consideráveis. PEA induziu, de maneira dose-dependente, aumento da apoptose e diminuição da proliferação de células tumorais. O tratamento resultou em alterações hematológicas como aumento do número de plaquetas, eritrócitos e leucócitos. Dentre os leucócitos, observou-se uma maior proporção de linfócitos e monócitos após 10 e 20 dias de tratamento, respectivamente. Em adição, PEA induziu uma maior produção da citocina pró-inflamatória IL-6 e das citocinas anti-inflamatórias IL-10 e TGF- $\beta$ e menores níveis da citocina pró-inflamatória IFN- $\gamma$. Os níveis de IL-1 $\beta$, IL-12p70 e IL-17 não foram alterados com o tratamento. Nossos resultados demonstram um papel inibidor da PEA sobre a progressão do melanoma, contribuindo para um melhor entendimento de sua atividade anti-tumoral.

Palavras-chave: fosfoetanolamina, melanoma. 


\begin{abstract}
VERONEZ, L. C. Activity of synthetic phosphoethanolamine in experimental murine melanoma. 80 f. Dissertation (Master) - Faculdade de Medicina de Ribeirão Preto, Universidade de São Paulo, São Paulo, 2012.

The low responsiveness of melanoma to traditional treatments together with its increasing incidence makes the development of new therapeutic strategies against this type of cancer extremely important. In this study, we used a murine melanoma model to evaluate the effects of synthetic phosphoethanolamine (PEA) on the development of this tumor. In vitro, PEA had an inhibitory effect on the proliferation of B16F10 cells, inducing apoptosis after 24 to $72 \mathrm{~h}$ stimulation. In vivo, oral treatment of melanoma-bearing animals with different doses of PEA $(10,20$ e $40 \mathrm{mg} / \mathrm{Kg})$ during 10 or 20 consecutive days resulted in reduced tumor volumes (at least 70\% compared to the control) and in expressive macroscopic differences. PEA also induced a dose-dependent increase of apoptosis and decrease in tumor cell proliferation. The treatment also resulted in hematological changes, such as increased numbers of platelets, erythrocytes and leukocytes. Among leukocytes, we observed a higher proportion of lymphocytes and monocytes after 10 and 20 days of treatment, respectively. In addition, PEA induced higher levels of the pro-inflammatory cytokine IL- 6 and of the antiinflammatory cytokines IL-10 and TGF- $\beta$, and it also induced a lower production of the proinflammatory cytokine IFN- $\gamma$. No differences were observed in the levels of IL-1 $\beta$, TNF- $\alpha$, IL-12p70 and IL-17 upon treatment. Our results demonstrate an inhibitory role of PEA in the development of melanoma, contributing to a better understanding of its antitumoral activity.
\end{abstract}

Key words: phosphoethanolamine, melanoma. 


\section{LISTA DE FIGURAS}

Figura 1. Efeitos da fosfoetanolamina comercial $\left(\mathrm{PEA}_{\mathrm{C}}\right)$ sobre a viabilidade de células de melanoma murino B16F10.

Figura 2. Efeitos da fosfoetanolamina comercial $\left(\mathrm{PEA}_{\mathrm{C}}\right)$ sobre a viabilidade de células de adenocarcinoma de cólon (HT-29) e mama (MCF-7) humanos

Figura 3. Efeitos da fosfoetanolamina comercial $\left(\mathrm{PEA}_{\mathrm{C}}\right)$ sobre a viabilidade de macrófagos murinos da linhagem RAW 264.7.

Figura 4. Quantificação de apoptose e necrose de células de melanoma murino B16F10 estimuladas com fosfoetanolamina comercial $\left(\mathrm{PEA}_{\mathrm{C}}\right)$.

Figura 5. Análise de ciclo celular de células de animais tratados com diferentes concentrações de fosfoetanolamina sintética.

Figura 6. Aspecto macroscópico dos tumores dorsais dos animais submetidos ou não ao tratamento com fosfoetanolamina sintética.

Figura 7. Efeito do tratamento com fosfoetanolamina sintética sobre o volume dos tumores dorsais de camundongos inoculados com células B16F10.

Figura 8. Perfil da progressão do volume tumoral e sobrevivência de animais inoculados com células B16F10 e tratados com fosfoetanolamina sintética.

Figura 9. Proliferação e morte de células tumorais de animais tratados com diferentes doses de fosfoetanolamina sintética.

Figura 10. Níveis de eritrócitos de animais tratados com diferentes doses de fosfoetanolamina sintética.

Figura 11. Níveis de plaquetas de animais tratados com diferentes doses de fosfoetanolamina sintética. 
Figura 12. Níveis de leucócitos do sangue de animais tratados com diferentes doses de fosfoetanolamina sintética.

Figura 13. Proporção relativa de leucócitos do sangue de animais inoculados com células B16F10 e tratados com fosfoetanolamina sintética.

Figura 14. Determinação da produção de citocinas por células de melanoma B16F10 estimuladas com PEA P.

Figura 15. Determinação da produção de citocinas pró-inflamatórias por células do baço dos animais experimentais.

Figura 16. Determinação da produção de citocinas anti-inflamatórias por células do baço dos animais experimentais 


\section{LISTA DE TABELAS}

Tabela 1. Grupos experimentais utilizados durante o experimento e suas respectivas inoculações e tratamentos.

Tabela 2. Peso corporal inicial e final dos animais dos sete grupos experimentais tratados por 10 dias durante o experimento. Os dados correspondem à média \pm desvio padrão da média.

Tabela 3. Peso corporal inicial e final dos animais dos sete grupos experimentais tratados por 20 dias durante o experimento. Os dados correspondem à média \pm desvio padrão da média. 


\section{LISTA DE ABREVIATURA}

ALP Alkyl phospholipid (Alquil fosfolipídeos)

APC Antigen Presenting Cell (Células Apresentadoras de Antígenos)

CDP Citidina difosfato

CTP Trifosfato de citidina

CTL Cytotoxic T Lymphocytes (Células T Citotóxicas)

DNA Deoxyribonucleic acid (ácido desoxirribonucléico)

DO Densidade óptica

EDTA Ethylenediamine tetraacetic acid (ácido etilenodiamino tetra-acético1)

HE Hematoxilina e Eosina

ELISA Enzyme-Linked Immunosorbent Assay (Ensaio de Imunoabsorção Ligado à Enzima)

FACS Fluorescence-activated cell sorting (seleção celular ativada por fluorescência)

FITC Fluorescein isotiocianate (Isotiocianato de fluoresceína)

IFN- $\gamma \quad$ Interferon gama

IL- $\quad$ Interleucina

MHC Major Histocompatibility Complex (Complexo Principal de Histocompatibilidade)

MMP-9 Matrix Metalloproteinase - 9

MTT 3-(4,5-Dimetiltiazol-2-il) 2,5-Difenil Brometo de Tetrazolium

NK Natural Killer

OMS Organização Mundial de Saúde 
PBS Phosphate Buffered Saline (solução salina-fosfato tamponada)

PCNA Proliferating Cell Nuclear Antigen (Antígeno nuclear de proliferação celular)

PE Phosphatidylethanolamine (Fosfatidiletanolamina)

PEA Phosphoethanolamine (Fosfoetanolamina)

PEAc Fosfoetanolamina comercial

RNAse Ribonuclease

RPMI Roswell Park Memorial Institute (meio de cultura celular)

TAM Tumor-associated macrophage (Macrófago associado ao tumor)

TGF- $\beta \quad$ Transforming growth factor - beta

Th T helper

TIL Tumor-infiltrating lymphocytes (linfócitos infiltrantes do tumor)

TNF- $\alpha \quad$ Tumor Necrosis Factor (Fator de necrose tumoral

Treg $\quad$ T reguladora

UV Ultravioleta 


\section{SUMÁRIO}

I. INTRODUÇÃO ..........................................................................................................................16

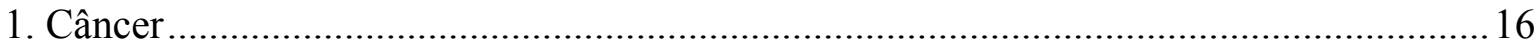

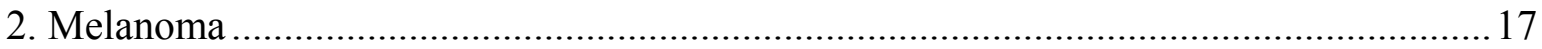

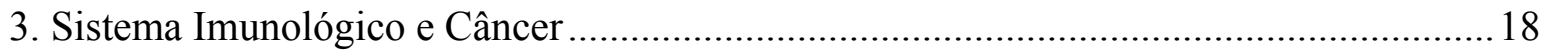

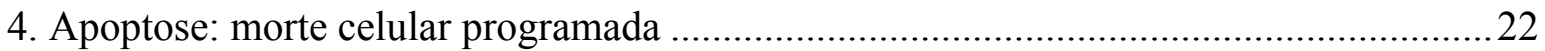

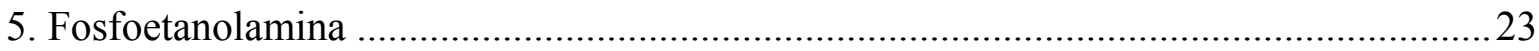

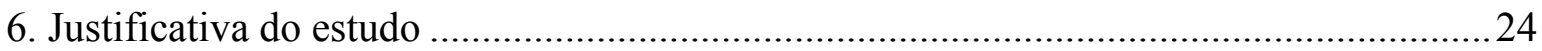

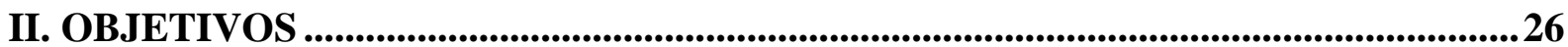

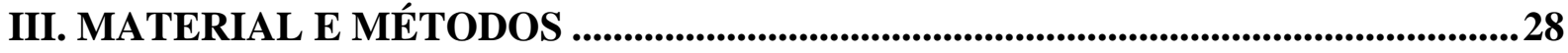

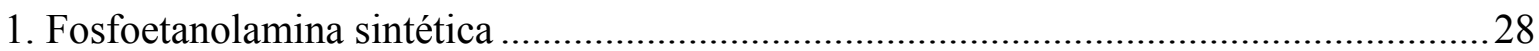

2. Cultura de células das linhagens B16F10, HT-29, MCF-7 e RAW 264.7 .....................28

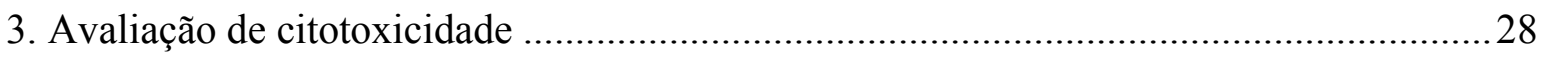

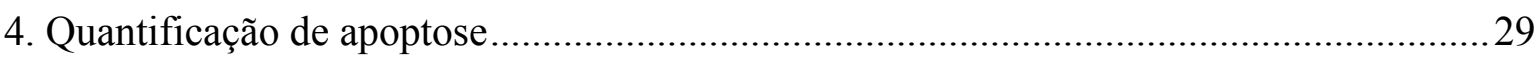

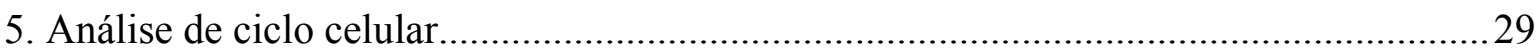

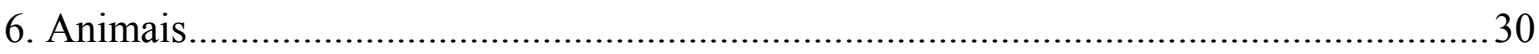

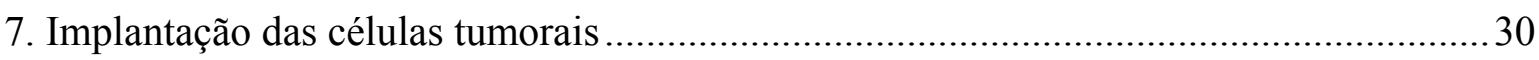

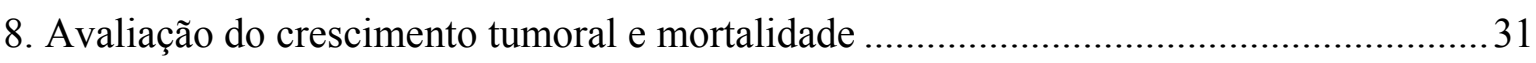

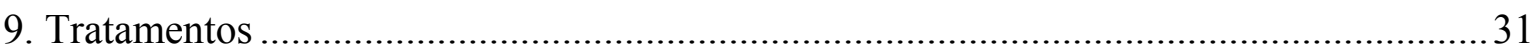

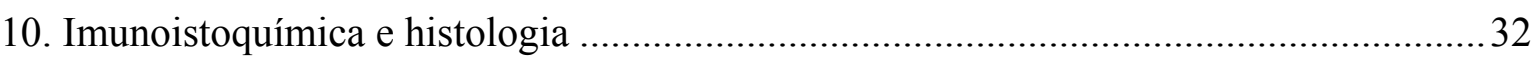

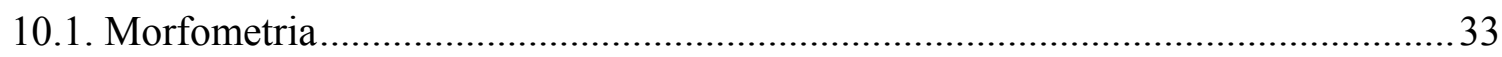

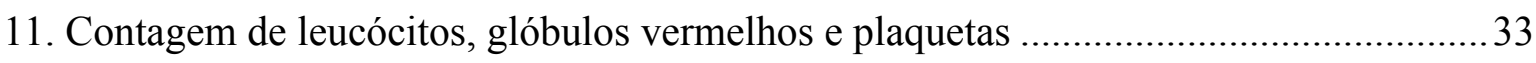

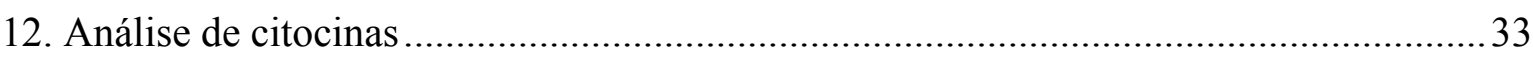

12.1. Obtenção de sobrenadantes da cultura de esplenócitos ...........................................33

12.2. Obtenção de sobrenadantes da cultura de células B16F10 ...................................... 34

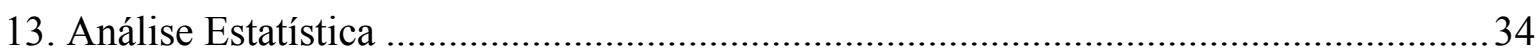

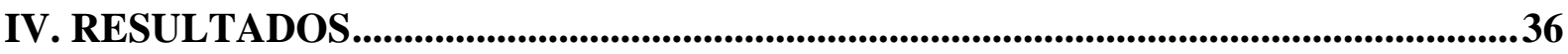

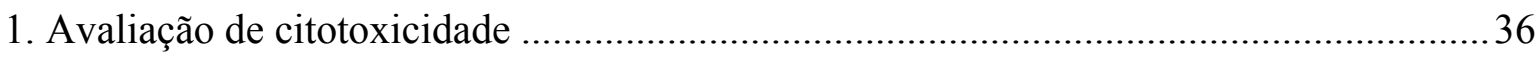

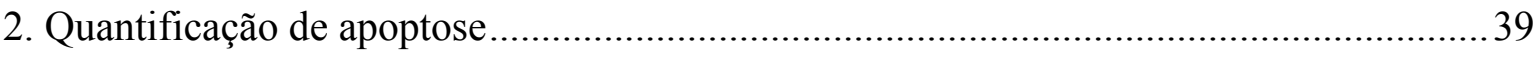

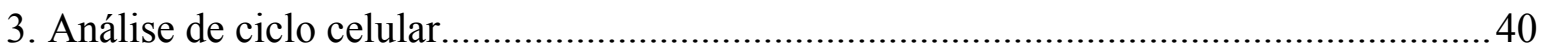

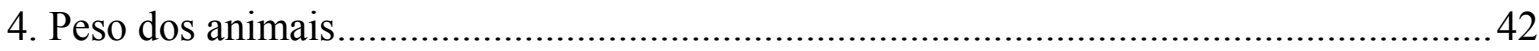




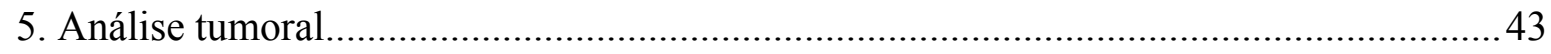

6. Análise imunoistoquímica de proliferação e morte das células tumorais .........................46

7. Contagem de leucócitos, glóbulos vermelhos e plaquetas .............................................. 48

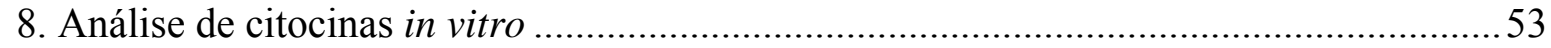

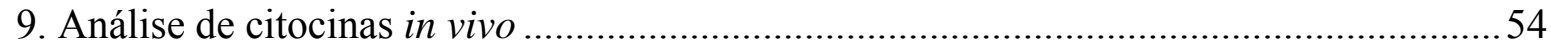

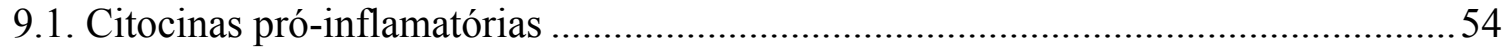

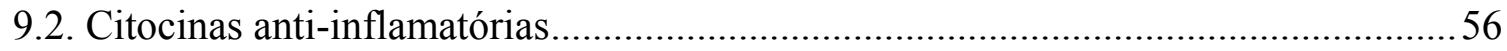

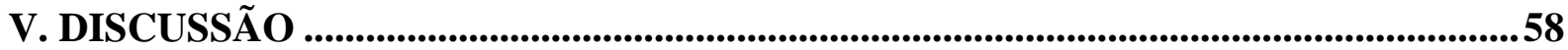

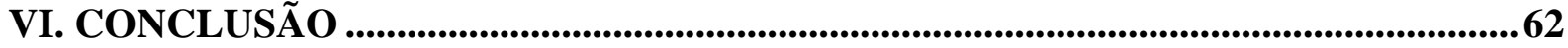

REFERÊNCIAS BIBLIOGRÁFICAS ….......................................................................64 64

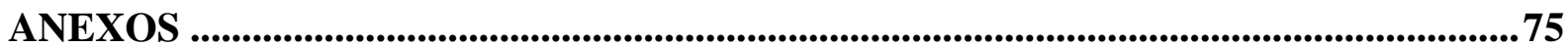

Anexo A - Imagens de secções de tumores de melanoma registradas com aumento de

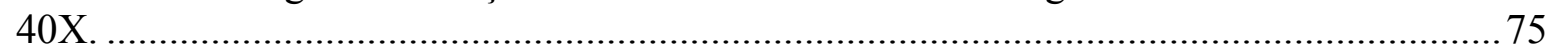

Anexo B - “Nanoassisted Laser Desorption-Ionization-MS Imaging of Tumors". ............76 


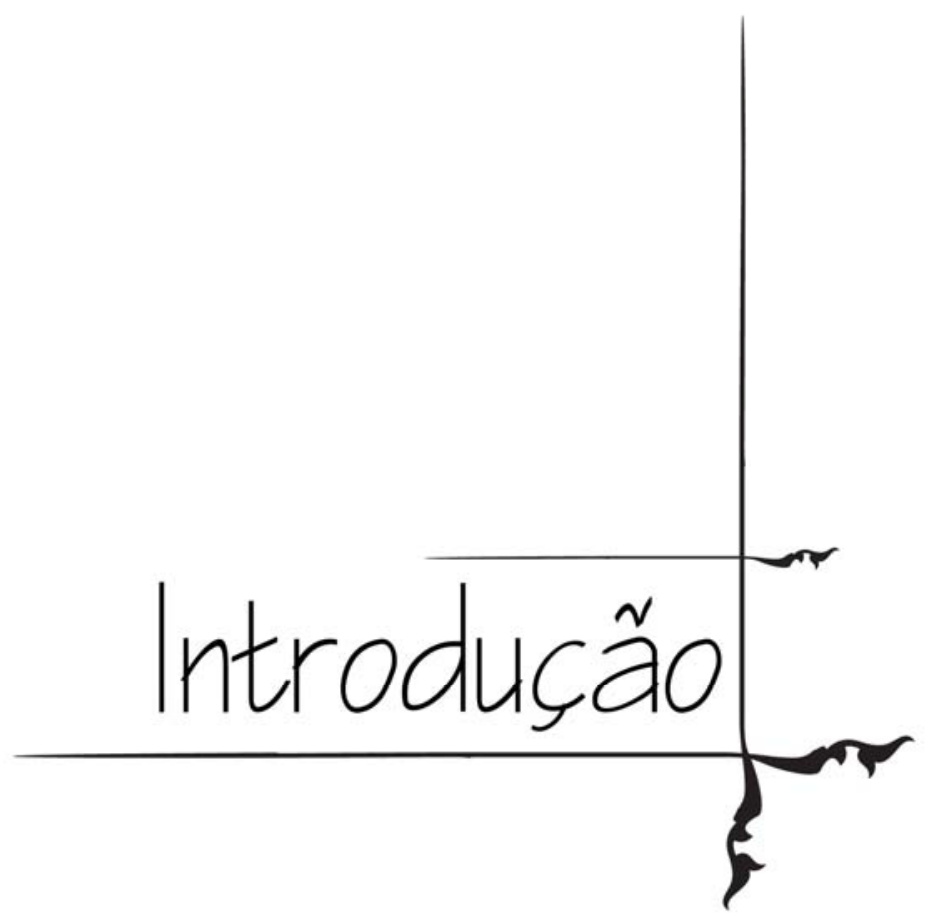




\section{INTRODUÇÃO}

\section{Câncer}

A oncogênese é um processo de várias etapas resultante de alterações genéticas, como mutações e alterações na integridade cromossômica, que podem conferir vantagens na sobrevivência e/ou crescimento em relação às demais células, levando à transformação de células normais em células malignas (Gout \& Hout, 2008; Grivennikov et al., 2010). Dessa forma, o câncer caracteriza-se como uma desordem hiperproliferativa, na qual as células tumorais apresentam defeitos nos mecanismos reguladores da proliferação celular e homeostase (Hanahan \& Weinberg, 2000; Lin \& Karin, 2007). Segundo Hanahan e Weinberg (2007), o desenvolvimento tumoral é a manifestação de seis principais alterações fisiológicas que ocorrem nas células: auto-suficiência na sinalização para o crescimento, insensibilidade aos sinais inibitórios de crescimento, evasão da morte celular programada (apoptose), potencial de replicação ilimitado, angiogênese, invasão e metástase.

Além de fatores genéticos, fatores ambientais tais como o álcool, cigarro, infecções, radiação ultravioleta e exposição a agentes carcinogênicos, também podem contribuir para o desenvolvimento do câncer (Czene et al., 2002). Alguns estudos têm sugerido a inclusão da dieta e hábitos alimentares como um destes fatores (Czene et al., 2002).

As principais formas de tratamento para o câncer ainda são as cirurgias, quimio e radioterapia (Grivennikov et al., 2010). Devido aos danos teciduais e a morte das células cancerígenas, os três casos induzem a formação de uma inflamação local ou sistêmica (Grivennikov et al., 2010). A cirurgia resulta na remoção da massa tumoral, enquanto a quimio e radioterapia causam a morte das células tumorais, principalmente por necrose, uma forma pró-inflamatória de morte celular (Vakkila \& Lotze, 2004). Entretanto, essas duas últimas formas de tratamento não matam somente as células cancerígenas, mas também as células envolvidas na defesa contra o câncer, tais como as células imunes e as células inflamatórias, comprometendo a resposta imune contra o câncer (Grivennikov et al., 2010). 


\section{Melanoma}

O câncer de pele é uma das malignidades mais comuns, cuja incidência tem aumentado rapidamente (Ilkovitch \& Lopez, 2008). Os cânceres de pele mais comuns podem ser categorizados em dois grupos principais: melanoma e não melanoma. $\mathrm{O}$ último grupo consiste primariamente de carcinomas basocelulares e carcinomas de células escamosas, os quais embora sejam raramente fatais, apresentam um rápido crescimento, podendo ser localmente e funcionalmente destrutivos (Ricotti et al., 2009). Conhecido como o câncer de pele mais fatal, com uma taxa de mortalidade cerca de três vezes superior que a do grupo anterior (Ilkovitch \& Lopez, 2008), o melanoma se desenvolve a partir de transformações malignas nas células produtoras de pigmento (melanina), denominadas melanócitos, os quais estão situados na camada basal da epiderme na pele humana (Chudnovsky et al., 2005).

A maioria dos cânceres de pele ocorre devido à exposição excessiva ao sol. A Sociedade Americana de Câncer estimou que, em 2007, mais de um milhão de casos de carcinomas basocelulares e de células escamosas, e cerca de 60 mil casos de melanoma, estariam associados à radiação ultravioleta (UV). Em geral, para o melanoma, um maior risco inclui história pessoal ou familiar de melanoma. Outros fatores de risco para todos os tipos de câncer de pele incluem: sensibilidade da pele ao sol, história de exposição solar excessiva, doenças imunossupressoras e exposição ocupacional (Ministério da Saúde, Instituto Nacional do Câncer, 2009).

O número de casos novos de câncer de pele não melanoma estimado para o Brasil no ano de 2010 é de 62.680 entre homens e de 671.490 nas mulheres. Quanto ao melanoma, as estimativas apontam para uma incidência mais baixa que a de cânceres de pele não melanoma (3.170 casos novos em homens e 3.060 casos novos em mulheres) (Ministério da Saúde, Instituto Nacional do Câncer, 2009). As maiores taxas estimadas em homens e mulheres encontram-se na Região Sul. A Organização Mundial da Saúde (OMS) estima que anualmente ocorram cerca de 132 mil casos novos desse câncer no mundo. Tem-se observado um expressivo crescimento na incidência desse tumor em populações de cor de pele branca (Ministério da Saúde, INCA, 2009).

O melanoma detectado precocemente e limitado à pele ou aos linfonodos é tratado primariamente por cirurgia. Entretanto, quando inoperável, até o momento a doença apresenta-se não curável e de mau prognóstico, em virtude da baixa eficácia dos tratamentos não cirúrgicos. O melanoma, além de altamente invasivo, usualmente é resistente à 
quimioterapia convencional (Nakayama, 2010) e a taxa de resposta a cada agente ou à combinação de agentes é de 15 a 25\% (Jilaveanu et al., 2009). O melanoma tem sido adotado como modelo para o estudo de imunologia de tumores e como plataforma para o estudo de novos agentes.

\section{Sistema Imunológico e Câncer}

O sistema imunológico é definido como o sistema responsável pela discriminação entre o próprio e o não próprio, cujos componentes inatos e adaptativos atuam conjuntamente a fim de gerar uma resposta efetiva (Ramirez-Montagut et al., 2003). Entretanto, a ausência de uma resposta imunológica (indução de tolerância) a componentes moleculares e celulares constitutivos do nosso corpo é de fundamental importância para evitar a geração de autoimunidade (Kim et al., 2007). Uma vez que as células tumorais são originadas de células constitutivas no organismo, as respostas a essas células são predominantemente tolerogênicas (Silveira, 2012). De fato, a maioria dos tumores apresenta baixa imunogenicidade (Dunn et al., 2005; Kim et al., 2007). Dessa forma, a geração de uma imunidade protetora ao câncer é extremamente complexa e um desafio aos imunologistas.

A partir da metade do século XX, com a utilização de modelos de tumores transplantados, evidências indicando a participação do sistema imunológico na regressão de tumores passaram a ser observadas (Ramirez-Montagut et al., 2003; Dunn et al., 2004; Kim et al., 2007). Tais observações sugeriram a existência de antígenos associados aos tumores resultantes da transformação maligna de células normais (proteínas expressas de maneira diferente e/ou aberrante) (Alb et al., 2012).

Lesões pré-malignas e cânceres precoces podem ser controlados ou eliminados pela vigilância imunológica (Shankaran et al., 2001), seguindo o paradigma do reconhecimento entre o próprio e o próprio alterado proposto por Houghton (1994), assim como a teoria da vigilância imunológica de Burnet e Thomas (Houghton, 1994; Burnet, 1957; Burnet, 1970; Burnet, 1971; Thomas, 1982). Nesta última, sugere-se que uma resposta imunológica dependente do timo atuaria como sentinela no reconhecimento e eliminação contínuos de células cancerígenas ou pré-cancerígenas no organismo (Burnet, 1957; Burnet, 1970; Burnet, 1971; Thomas, 1982). Todavia, a vigilância imunológica representa apenas uma dimensão da complexa relação entre o sistema imunológico e o câncer (Shankaran et al., 2001; Dunn et al., 
2004). Posteriormente, passou-se a empregar o conceito de "imunoedição", um processo dinâmico que inclui o envolvimento do sistema imune não só na formação, como também no desenvolvimento tumoral, representando uma extensão da vigilância imunológica (Shankaran et al., 2001).

O conceito que envolve a imunoedição é constituído de três fases, sendo denominado "os três Es da imunoedição": eliminação, equilíbrio e escape ou evasão (Dunn et al., 2002 e 2004). Inicialmente, células recém transformadas podem ser eliminadas pelo sistema imunológico e/ou por moléculas pró-inflamatórias, como células NK e a citocinas IFN- $\gamma$, caracterizando o processo de eliminação (vigilância imunológica), (Dunn et al., 2004; Kim et al.; 2007). Esta etapa pode ser completa ou incompleta, quando todas as células tumorais, ou apenas parte delas, são eliminadas (Swann \& Smyth, 2007). Nesta última situação, as células tumorais que não foram destruídas entram em equilíbrio com o sistema imunológico, sendo a pressão exercida por ele suficiente para controlar a progressão tumoral (Dunn et al., 2004; Swann \& Smyth, 2007; Kim et al., 2007). Variantes antigênicas com menor imunogenicidade (mutação no DNA e/ou alterações na expressão gênica), resistentes ou que suprimem as células efetoras do sistema imune, são selecionadas, culminando na fase de escape ou evasão (Dunn et al., 2004; Swann \& Smyth, 2007, Kim et al., 2007). Nesta última fase, o crescimento dos tumores não é mais contido pelas respostas imunológicas (Swann \& Smyth, 2007), em decorrência de diversos mecanismos de evasão imunológica empregados pelas células cancerígenas (Alb et al., 2012). Estes incluem a diminuição ou perda da expressão de moléculas de MHC classe I e moléculas coestimulatórias pelas células tumorais e a supressão e/ou anergia de células imunes efetoras (Becker et al., 1993; Algarra et al., 2000; Fujiwara et al., 2004).

No que concerne a imunidade inata, a atividade de células NK ("natural killer") é um dos principais mecanismos de eliminação de células cancerígenas (Torrezini \& Athanazio, 2007). As primeiras células transformadas são detectadas por essas células, as quais são ativadas dependendo do balanço entre os sinais fornecidos por seus receptores ativadores e/ou inibidores (Morandi et al., 2012). Pelo fato de seus receptores inibidores reconhecerem moléculas de MHC classe I, as células NK são capazes de identificar células alteradas como as células tumorais, as quais apresentam reduzida expressão dessas moléculas. Tal reconhecimento leva à ativação das células NK, culminando com a morte das células-alvo (Moretta et al., 1996, 2002; Lanier, 1998; Long, 1999; Biassoni et al., 2011. Dessa forma, a existência das células NK auxiliaria a imunidade adaptativa mediada por linfócitos $\mathrm{T}$ 
citotóxicos CD8+ (CTLs), não deixando que a queda da expressão de MHC classe I possa ser usada como mecanismo de escape de células transformadas (Moretta et al., 2002).

Outras células do sistema imune inato também participam das respostas contra tumores. Monócitos são recrutados do sangue periférico em resposta a quimiocinas secretadas pelas células cancerígenas e diferenciam-se em macrófagos (Mantovani et al., 1992). Estes fazem a interligação entre os sistemas imune inato e adaptativo, ativando, diretamente ou através de seus mediadores solúveis, células como linfócitos T e B (Finn, 2012). Os macrófagos associados a tumores (TAMs), como outras células efetoras do sistema imunológico, são células plásticas, com capacidade de assumir múltiplos fenótipos dependendo do microambiente em que se encontram (Hao et al., 2012; Wagner et al., 2012). Estas células passaram a ser normalmente considerados como células anti-inflamatórias M2, caracterizadas por um perfil de citocinas IL-10 $0^{\text {high }} / \mathrm{IL}-12^{\text {low }}$, embora também possam alterar seu fenótipo dependendo do estágio do tumor (Qian \& Pollard, 2010; Biswas et al., 2011) e/ou, simultaneamente expressar fatores pró-inflamatórios e imunossepressores (Kursmartsev \& Gabrilovich, 2005; Tsai et al., 2007). Ainda que sejam enfatizadas as funções pró-tumorais dos TAMs, estas células, quando ativadas de modo apropriado, se diferenciam em células com propriedades pró-inflamatórias (fenótipo M1), as quais secretam mediadores como TNF$\alpha$, IL-1 $\beta$ e MMP-9 (Hagemann et al., 2005), podendo matar células tumorais e eliciar reações destrutivas de tumores centradas nas paredes de vasos. Estudos sugerem que no melanoma cutâneo os TAMs são críticos para a progressão em direção a um fenótipo agressivo (Brocker et al., 1988).

Atualmente, entretanto, considera-se que o principal mecanismo da imunidade a tumores seja devido à resposta de células T (Mantovani et al., 2008). Essa resposta antitumoral pode ser resultante da morte direta de células tumorais por CTLs. Antígenos tumorais processados, através de apresentação cruzada por células apresentadoras de antígenos (APCs) e moléculas de MHC classe I, estimulam CTLs a reconhecerem e destruir as células tumorais (Ramirez-Montagut et al., 2003). CTLs oligoclonais reativos a tumores podem ser detectados no sangue ou entre os linfócitos infiltrantes de tumores (TILs) em pacientes com câncer (Andersen et al., 2001; Zhang et al., 2003; van Houdt et al., 2008). Inúmeras evidências indicam que TILs são capazes de controlar o crescimento tumoral (Yu \& Fu, 2006) e sua presença em tumores sólidos é considerada um indicador de bom prognóstico na sobrevivência de pacientes com câncer (Zhang et al., 2003; van Houdt et al., 2008). Entretanto, na maioria dos casos a resposta imune adaptativa contra células tumorais é 
extremamente fraca e ineficiente, uma vez que o próprio tumor e o microambiente circundante regulam negativamente as respostas de CTLs (apud Lorusso \& Ruegg, 2008).

Estudos recentes têm enfatizado a cuidadosamente orquestrada e intricada relação entre células tumorais transformadas e geneticamente instáveis e células normais locais ou derivadas da medula óssea. Com variações em composição, tamanho e distribuição, um infiltrado de leucócitos está presente na grande maioria dos tumores, se não em todos (Hold \& El-Omar, 2008). Tão relevante quanto o conteúdo desses leucócitos, é o perfil de mediadores imuno-moduladores solúveis, como as citocinas e quimiocinas, expressos por células do microambiente tumoral (Grivennikov et al., 2010).

As citocinas são moléculas solúveis que exibem efeitos regulatórios positivos e/ou negativos em vários tipos celulares (Papadakis \& Targan, 2000; Dinarello, 2000) e cujos níveis na circulação sistêmica podem refletir a atividade de tumores (Lee et al., 2012). Diversos trabalhos vêm correlacionando os níveis séricos e plasmáticos de citocinas com o prognóstico e significado clínico em vários tipos de cânceres (Mentor-Marcel et al., 2012; Matte et al., 2012; Lee et al., 2012; Yamada et al., 2012). Diferentes citocinas podem tanto promover, quanto inibir o desenvolvimento e a progressão do tumor (Lin \& Karin, 2007; Grivennikov et al., 2010). As citocinas tipicamente pró-inflamatórias IFN- $\gamma$ e IL-12 apresentam um importante papel na imunidade anti-tumoral (Luo et al, 2004; Lin \& Karin, 2007). IFN- $\gamma$, por exemplo, além de exercer efeito tóxico direto sobre células cancerígenas, apresenta atividade anti-angiogênica (Corthay et al., 2005), embora sua capacidade de promover a evasão tumoral às respostas imunológicas já tenha sido relatada (He et al., 2005). IL-12 tem como principal atividade anti-tumoral a indução e ativação de respostas Th1 e mediada por CTLs (Trinchieri, 2003). Por outro lado, citocinas como TGF- $\beta$ e IL-10 estão envolvidas na supressão da resposta imune (Yue et al., 1997; Yan et al., 2002). As células tumorais e os TAMs produzem grandes quantidades dessas citocinas e, dessa forma, estão implicados na supressão das funções efetoras de CTLs e indução da diferenciação de células T reguladoras (Tregs) no microambiente tumoral (Coussens \& Werb, 2002; Liu et al., 2007; Mantovani et al., 2009). Elevados níveis dessas de ambas as citocinas são verificados em pacientes com câncer (Dummer et al., 1995; Krasagakis et al., 1998; Ivanovic et al., 2006). Em adição, trabalhos também demonstraram efeitos anti-angiogênicos e imunoestimuladores da IL-10 (Vuoristi, 2007). Outras citocinas como TNF- $\alpha$ e IL-6 atuam induzindo angiogênese e metástase, favorecendo, consequentemente, o desenvolvimento tumoral (Thejass \& Kuttan, 2007). Porém, sinergicamente com IFN- $\gamma$, o fator de necrose tumoral (TNF- $\alpha$ ) também pode participar da ativação de macrófagos tumoricidas (Corthay et al., 2005). 
Em associação, as citocinas IL-6 e TGF- $\beta$ podem induzir a diferenciação de uma nova subpopulação de células $\mathrm{T}$, denominada Th17, recentemente identificada e caracterizada como produtora de IL-17 (Harrington et al., 2006; Yu et al., 2007; Wang et al., 2009; Yamada et al, 2012). IL-17 é considerada uma citocina pró-inflamatória por estimular a secreção de IL-6, IL-1 $\beta$ e TNF- $\alpha$ por macrófagos e células endoteliais, por exemplo (Fossiez et al., 1996; Jovanovic et al., 1998). Muitos trabalhos tem verificado a presença dessa subpopulação em diversos tipos de câncer, embora seu papel na imunidade a tumores ainda seja controverso (Tartour et al., 1999; Numasaki et al., 2005). A IL-17, produzida por linfócitos, promove o crescimento tumoral e angiogênese em modelo de câncer de mama, fibrosarcoma e adenocarcinoma de cólon (Numasaki et al., 2003; Du et al., 2012). Todavia, alguns trabalhos também verificaram inibição do crescimento tumoral pela ativação de CTLs induzida por IL-17 (Benchetrit et al., 2002; Martin-Orozco et al., 2009), além de erradicação de tumores em modelos de melanoma murino (Muranski, et al.; 2008).

\section{Apoptose: morte celular programada}

A morte celular pode se ocasionada de diferentes maneiras, dependendo do mecanismo pelo qual as células são estimuladas: células que sofrem algum dano externo são levadas a necrose; enquanto células induzidas a cometer um suicídio programado em decorrência de algum estímulo (interno ou externo) sofrem apoptose (Ghobrial et al., 2005). Este último, também chamado de morte celular programada, é o mecanismo pelo qual células indesejáveis, como aquelas com mutações potencialmente prejudiciais ou alterações no ciclo celular, são mortas visando controlar seu número e/ou proliferação, ou em resposta a danos não reparados do DNA (Fesik, 2005; Ghobrial et al., 2005). Qualquer alteração desse mecanismo pode romper o balanço entre a proliferação e morte celular, podendo levar a doenças como o câncer (Danial \& Korsmeyer, 2004; Fesik, 2005).

Vários estímulos como radiação UV e $\gamma$, quimioterápicos e sinais de receptores de morte podem iniciar o processo de apoptose (Krueger et al., 2001), culminando em algumas alterações morfológicas e bioquímicas características da mesma: inversão de folheto da membrana e exposição da fosfatidilserina, encolhimento das células, "blebbing" de membrana, picnose, condensação e marginalização da cromatina, contração do citoplasma, 
desintegração nuclear, fragmentação do DNA, formação de corpos apoptóticos (Tang \& Porter, 1997; Krueger et al., 2001).

Existem basicamente dois mecanismos pelos quais a apoptose pode ocorrer: um denominado extrínseco ou citoplasmático, o qual envolve o receptor Fas, um membro da superfamília de receptores do fator de necrose tumoral (TNF) e o outro, intrínseco ou mitocondrial que, quando ativado, leva a liberação do citocromo $\mathrm{C}$ da mitrocôndria e ativação do sinal de morte (Ghobrial et al., 2005). Ambos os mecanismos convergem na ativação de uma cascata de proteases chamadas caspases que clivam moléculas regulatórias e estruturais, culminando na morte da célula (Ghobrial et al., 2005).

\section{Fosfoetanolamina}

Os fosfolipídeos de etanolamina são componentes estruturais essenciais das membranas celulares e desempenham papéis regulatórios na divisão celular, sinalização, ativação, autofagia e fagocitose (Bakovic et al., 2007). A fosfoetanolamina (PEA), um monoéster cujo grupo R corresponde a NH2-CH2-CH2-, está presente literalmente em todos os tecidos e órgãos animais (Meister, 1965) e é precursora da fosfatidiletanolamina, um dos principais componentes das membranas.

As células eucarióticas possuem três mecanismos para a biosíntese de fosfolipídeos de etanolamina, fosfatidiletanolamina (PE) e PE-plasmalogenos. A via de Kennedy é responsável pela síntese de novo de fosfolipídeos de etanolamina. Como as células não sintetizam etanolamina, a via de Kennedy utiliza essa molécula produzida metabolicamente e (ou) a partir de lipídeos exógenos fornecidos com a alimentação (Dobrosotskaya et al., 2002). No mecanismo de síntese de novo, a etanolamina é primeiramente fosforilada pela etanolamina quinase em fosfoetanolamina (Lykidis et al., 2001). A fosfoetanolamina é então convertida em CDP-etanolamina pela CTP:fosfoetanolamina citidiltransferase. No estágio final dessa via, a CDP-etanolamina:1,2-diacilglicerol etanolaminafosfotransferase (Horibata \& Hirabayahi, 2006) cataliza a formação de fosfatidiletanolamina a partir de CDP-etanolamina e DAG. A fosfatidiletanolamina é o segundo lipídio mais abundante em mamíferos e apresenta diversas funções importantes na fisiologia celular (Vance, 2008).

Os fosfolipídeos distribuem-se de maneira assimétrica na membrana plasmática. Existem evidências indicativas de que nos estágios precoces da apoptose, a assimetria dos 
fosfolipídeos é perturbada (Balasubramanian et al., 2007). Especificamente, a translocação da fosfatidilserina e da fosfatidiletanolamina da superfície interna para a externa da membrana plasmática parece constituir um mecanismo fundamental através do qual as células apoptóticas são reconhecidas e eliminadas pelos macrófagos (Borisenko et al., 2003; Brouckaert et al., 2004). Em estudo recente, Yao e colaboradores (2009) demonstraram que a adição de fosfatidiletanolamina à cultura de células de hepatoma humano (linhagem HepG2) levou à diminuição do potencial de membrana mitocondrial e induziu a apoptose destas células. Em estudos com melanoma experimental, pesquisadores demonstraram uma redução expressiva da massa tumoral em animais tratados intraperitonealmente com a fosfoetanolamina, superior à observada com a administração de quimioterápicos comerciais, assim como da formação de metástases (Meneguelo, 2007; Ferreira et al., 2011 e 2012).

\section{Justificativa do estudo}

O melanoma é conhecido por sua baixa resposta aos tratamentos tradicionalmente adotados como quimio e radioterapia. Portanto, o desenvolvimento de novas estratégias terapêuticas é de particular importância.

Recentemente, alquilfosfolipídios (ALPs) sintéticos, tais como edelfosine, perefosine e miltefosine (Gajate et al., 2011), têm sido considerados promissores candidatos ao tratamento do câncer, sendo conjuntamente denominados de fosfolipídios antineoplásicos (Vink et al., 2007). Estes, diferentemente das convencionais drogas anti-neoplásicas, não tem como alvo o DNA das células, mas sim suas membranas, às quais eles se inserem interferindo na transdução de sinais e no metabolismo de lipídios, culminando na indução de apoptose (Vink et al., 2007; Alderliesten et al., 2011). No presente trabalho, investigamos se um dos precursores centrais na biossíntese dos fosfolípidos, a fosfoetanolamina, também apresentaria efeitos anti-tumorais.

Estudos realizados anteriormente por nossos colaboradores mostraram que a fosfoetanolamina sintética exerceu efeitos extremamente positivos no tratamento do melanoma experimental. Todavia, embora os efeitos anti-tumorais apresentados por PEA sejam promissores, o envolvimento do sistema imunológico e seus mediadores em tal efeito ainda é desconhecido, o que reforça a necessidade de investimentos em estudos adicionais. 


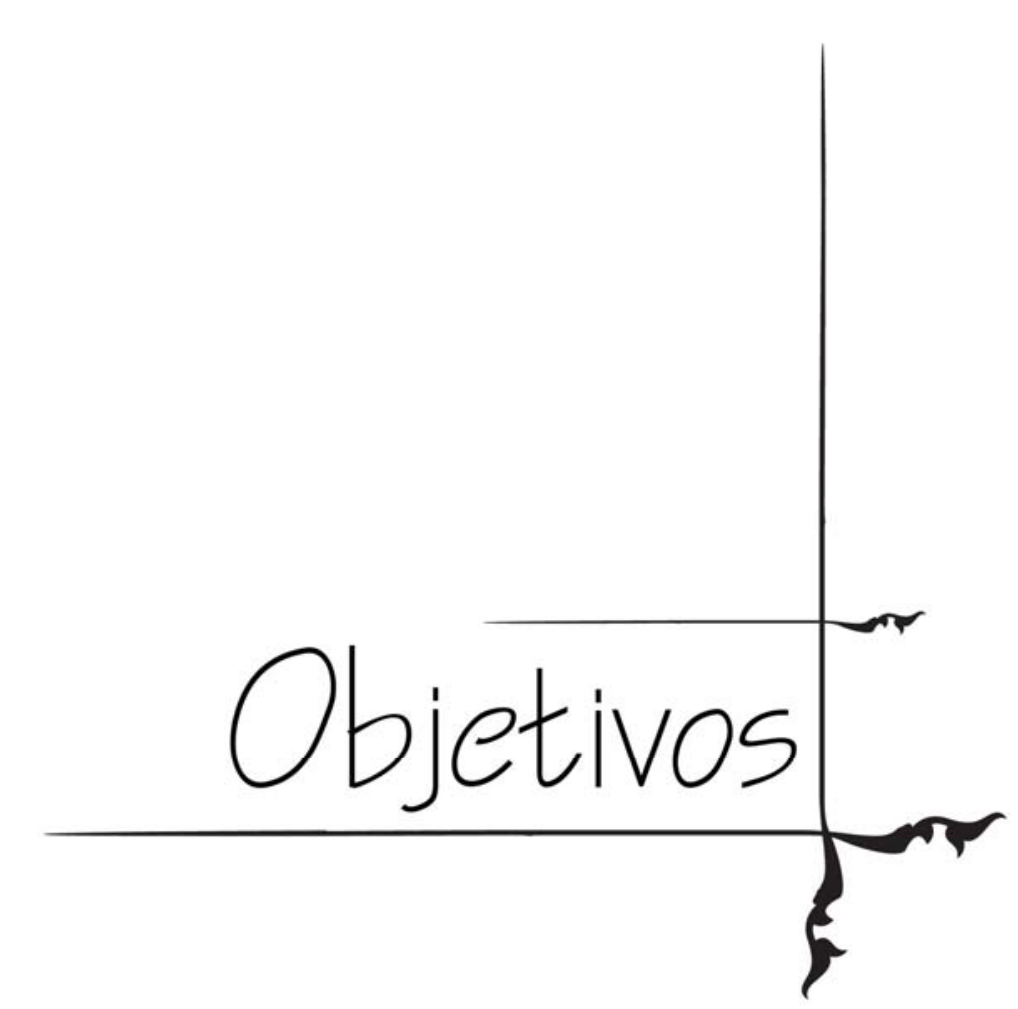




\section{OBJETIVOS}

O objetivo do presente trabalho foi avaliar a atividade da fosfoetanolamina sintética no desenvolvimento do melanoma. Para tanto, utilizamos modelo de melanoma experimental e investigamos:

1. Os efeitos da PEA sobre a viabilidade e a proliferação das células tumorais, determinados através de ensaios in vitro;

2. Os efeitos da administração da PEA sobre o crescimento tumoral in vivo;

3. As alterações hematológicas de animais portadores de tumor;

4. Os efeitos da administração da PEA sobre a sobrevida das células tumorais in vivo;

5. O perfil de citocinas (pró- ou anti-inflamatórias) produzidas por células do baço de animais portadores de tumor. 


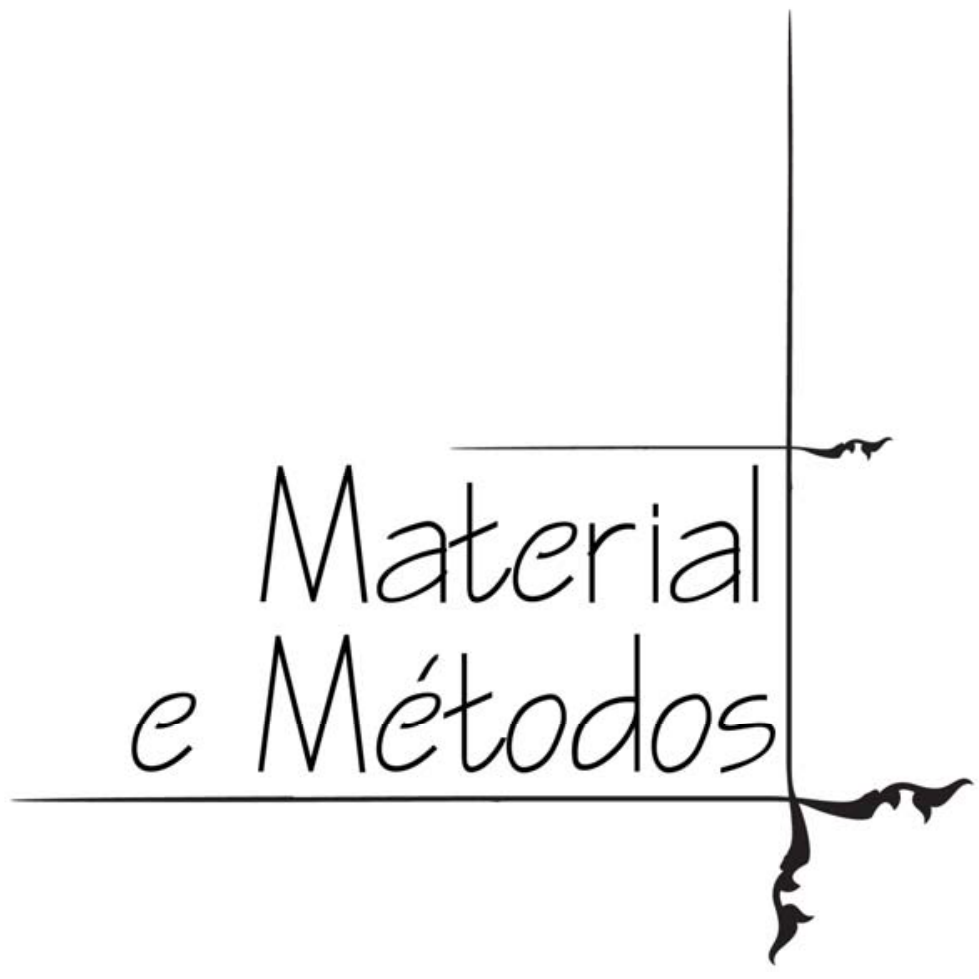




\section{MATERIAL E MÉTODOS}

\section{Fosfoetanolamina sintética}

A fosfoetanolamina (PEA) utilizada no estudo foi sintetizada pelo grupo liderado pelo Prof. Gilberto Orivaldo Chierice, do Instituto de Química de São Carlos da Universidade de São Paulo. A molécula foi diluída em solução salina a $0.9 \%$ e sonicada para a utilização no presente estudo. Para comparação, também foi utilizada uma formulação comercial (P0503 Sigma-Aldrich), a qual denominamos de PEAc.

\section{Cultura de células das linhagens B16F10, HT-29, MCF-7 e RAW 264.7}

As células das linhagens B16F10 (melanoma murino), HT-29 (adenocarcinoma de cólon humano), MCF-7 (adenocarcinoma de mama humano) e RAW 264.7 (macrófagos murinos contendo o gene repórter luciferase NF- $\kappa \mathrm{B}$ ), cedidas pelos Drs. Célio Lopes Silva (FMRP-USP), Celso Albuquerque Reis (IPATIMUP/Portugal), Roger Chamas (ICB-USP) e Dario Simões Zamboni (FMRP-USP), respectivamente, foram mantidas como monocamadas de cultura em meio RPMI 1640 (Gibco, Invitrogen) suplementado com 10\% de soro bovino fetal (Gibco, Invitrogen), $100 \mu \mathrm{g} / \mathrm{ml}$ de estreptomicina e 100 unidades/ml de penicilina, a $37^{\circ} \mathrm{C}$ em incubadora com $5 \%$ de $\mathrm{CO}_{2}$. O meio de cultura foi trocado a cada 2-3 dias e quando atingido $80 \%$ de confluência, as células foram removidas dos frascos de cultura através da adição de solução de tripsina $0.05 \%$ e repicadas.

\section{Avaliação de citotoxicidade}

Para avaliação de citotoxicidade foi utilizado o método colorimétrico 3-(4,5-Dimetiltiazol2-il) 2,5-Difenil Brometo de Tetrazolium (MTT) descrito por Mosmann (1983), que consiste em medir indiretamente a viabilidade celular pela atividade enzimática mitocondrial das células vivas. 
Células B16F10 foram semeadas em poços de uma placa de cultura de 96 poços num volume total de $200 \mu \mathrm{L} /$ poço contendo $1 \times 10^{4}$ células, estimuladas (triplicatas/concentração repetidas em três experimentos) com diferentes concentrações de PEAc $(0,3125$ a $10 \mathrm{mg} / \mathrm{mL})$ e períodos de incubação (24, 48 e 72h). O mesmo foi feito para as demais linhagens celulares, HT-29, MCF-7 e RAW 264.7. Poços contendo apenas células tumorais (sem estímulo) foram utilizados como controle. Após o período determinado, $0.05 \mathrm{mg}(10 \mu \mathrm{lde} 5 \mathrm{mg} / \mathrm{ml})$ do sal de MTT foi adicionado a cada poço da placa, sendo a mesma incubada a $37^{\circ} \mathrm{C}$ por $4 \mathrm{~h}$. Após esta etapa, o sobrenadante dos poços foi descartado e $100 \mu \mathrm{L} /$ poço de uma solução de triton $10 \%$ contendo álcool isopropílico (50\%) e ácido clorídrico $(0,5 \%)$ foram adicionados. Novamente, a placa foi mantida em estufa por mais uma hora a $37^{\circ} \mathrm{C}$. A absorbância das amostras foi medida em espectofotômetro a $570 \mathrm{~nm}$. A porcentagem de viabilidade foi calculada: viabilidade celular (\%) = DO570 (amostra) X 100 / DO570 (controle).

\section{Quantificação de apoptose}

A marcação com anexina- $\mathrm{V}$ revela o estágio inicial de translocação da fosfatidilserina da camada interna para a externa da membrana plasmática. Utilizamos kit comercial Anexina-VFITC (R\&D Systems), seguindo as instruções do fabricante. Brevemente, as células B16F10 foram incubadas por 24, 48 e/ou $72 \mathrm{~h}$ com as concentrações de PEA nas quais foram observadas diferenças estatísticas na viabilidade celular pelo ensaio de MTT, ou somente com meio de cultura RPMI como controle. Após estimulação, as células foram tripsinizadas, lavadas com PBS e ressuspendidas $\left(10^{5}\right.$ a $10^{6}$ células $\left./ \mathrm{ml}\right)$ em tampão de ligação. Solução de anexina-V e de iodeto de propídio foi adicionada à suspensão celular. Após 15 minutos de incubação a temperatura ambiente e no escuro, as células foram imediatamente submetidas à análise por citometria de fluxo (FACSCanto - BD) utilizando-se o programa FACSDiva versão 6.1.3.

\section{Análise de ciclo celular}

Da mesma forma que os ensaios de morte celular, as concentrações de PEA nas quais foram observadas diferenças estatísticas na viabilidade celular pelo ensaio de MTT foram 
testadas em células B16F10 para análise de ciclo celular. Células incubadas com meio de cultura RPMI foram utilizadas como controle. Após estimulação, as células foram tripsinizadas, lavadas com $1 \mathrm{~mL}$ de PBS contendo $5 \mathrm{mM}$ de EDTA e fixadas por uma hora a $4^{\circ} \mathrm{C}$ em $1 \mathrm{~mL}$ de etanol 70\% em PBS acrescido de $5 \mathrm{mM}$ de EDTA. Após lavagens, as células foram ressuspendidas em PBS, EDTA 5mM contendo 0.1\% de Triton X-100 (Sigma Aldrich), $100 \mu \mathrm{g}$ de RNAseA (Sigma Aldrich) e $25 \mu \mathrm{g}$ de iodeto de propídio (Sigma Aldrich) e incubadas no escuro por 15 min. As células foram então submetidas à análise por citometria de fluxo através do programa FACSDiva versão 6.1.3.

\section{Animais}

Foi utilizado um total de 70 camundongos C57BL/6, com aproximadamente $25 \mathrm{~g}$ no início dos ensaios, divididos em dois lotes de animais que diferiram quanto ao período de tratamento (10 e 20 dias). Os animais, provenientes do Biotério Central da Faculdade de Medicina de Ribeirão Preto, da Universidade de São Paulo (FMRP-USP), foram mantidos no biotério do Laboratório de Fisiologia da Escola de Enfermagem de Ribeirão Preto (EERPUSP).

\section{Implantação das células tumorais}

Para a inoculação nos animais, suspensão celular retirada dos frascos de cultura foi centrifugada e em seguida ressuspendida em PBS estéril de maneira a se obter solução contendo $5 \times 10^{5}$ células $/ \mathrm{mL}$. A viabilidade celular foi determinada através de exclusão por azul de trypan. Somente as suspensões que apresentaram pelo menos 95\% de viabilidade foram utilizadas para inoculação. Por fim, $5 \times 10^{4}$ células/animal $(0,1 \mathrm{~mL})$ foram injetadas subcutaneamente (s.c.) na região dorsal dos camundongos. 


\section{Avaliação do crescimento tumoral e mortalidade}

O crescimento dos tumores dorsais foi monitorado diariamente após implantação das células de melanoma B16F10, sendo mensurado semanalmente através da medida do diâmetro da massa tumoral sólida, cujo volume foi estimado através da fórmula para esferóides: $\mathrm{V}=0.52 \times$ (eixo maior) $\mathrm{x}$ (eixo menor) ${ }^{2}$. A mortalidade também foi acompanhada através de observação diária dos animais durante todo o período de experimentação.

\section{Tratamentos}

Todos os animais foram pesados antes da inoculação das células tumorais e ao término dos tratamentos. Aproximadamente 10 dias após a injeção das células tumorais, os camundongos foram tratados com PEA $(10,20$ e $40 \mathrm{mg} / \mathrm{Kg}-0.25 ; 0.5$ e $1 \mathrm{mg} / \mathrm{animal} / \mathrm{dia})$ via oral (gavagem, $100 \mu \mathrm{L}$ por aplicação) durante 10 e/ou 20 dias consecutivos. Animais controle foram tratados com PBS somente (controle negativo). Os camundongos foram divididos nos seguintes grupos experimentais ( $\mathrm{n}=7$ ou 10), resumidos na Tabela 1: Grupo 1 (controle). animais controle que receberam injeção s.c. de solução salina (ausência de células tumorais) e tratados com solução salina; Grupo 2 (somente PEA). animais que receberam injeção s.c. de solução salina (ausência de células tumorais) e tratados com PEA $(5.0 \mathrm{mg} / \mathrm{mL})$; Grupo 3 (não tratados). animais inoculados com células B16F10 e tratados com solução salina; Grupo 4. animais inoculados com células B16F10 e tratados com PEA $(2.5 \mathrm{mg} / \mathrm{mL})$; Grupo 5. animais inoculados com células B16F10 e tratados com PEA $(5.0 \mathrm{mg} / \mathrm{mL})$; Grupo 6. animais inoculados com células B16F10 e tratados com PEA $(10 \mathrm{mg} / \mathrm{mL})$; Grupo 7. animais inoculados com células B16F10 e tratados com PEAc $(5 \mathrm{mg} / \mathrm{mL})$.

Ao término dos tratamentos, os animais foram sacrificados, os tumores dorsais analisados, medidos e fotodocumentados e as lesões macroscópicas internas (metástases) identificadas. Amostras dos tumores dos diferentes grupos experimentais foram processadas para análise imunohistoquímica. Amostras dos baços foram preparadas para a dosagem de citocinas. O sangue dos animais foi coletado e utilizado para as análises hematológicas. 
Tabela 1. Grupos experimentais utilizados durante o experimento e suas respectivas inoculações e tratamentos.

\begin{tabular}{cccc}
\hline Grupos & Inoculação & Tratamento & N \\
\hline G1 (controle) & PBS & PBS & 7 \\
G2 (PEA somente) & PBS & PEA 20 mg/Kg & 7 \\
G3 (não tratados) & B16F10 & PBS & 10 \\
G4 & B16F10 & PEA $10 \mathrm{mg} / \mathrm{Kg}$ & 10 \\
G5 & B16F10 & PEA 20 mg/Kg & 10 \\
G6 & B16F10 & PEA $40 \mathrm{mg} / \mathrm{Kg}$ & 10 \\
G7 & B16F10 & PEA $20 \mathrm{mg} / \mathrm{Kg}$ & 10 \\
\hline
\end{tabular}

\section{Imunoistoquímica e histologia}

A proliferação e morte das células tumorais foram analisadas por imunoistoquímica, após marcação com anticorpos específicos para PCNA e caspase-3, respectivamente. Segmentos tumorais foram fixados em formalina tamponada e incluídos em parafina. Os blocos foram cortados serialmente (secções de $4 \mu \mu \mathrm{m}$ ) e usados para coloração imunohistoquímica. Os anticorpos primários foram obtidos do laboratório Novocastra (Newcastle, UK). A coloração imunohistoquímica foi realizada utilizando o método de detecção avidina-biotina do Kit de Detecção Universal Novostain (Novocastra Laboratories, Newcastle, UK) com algumas modificações. As secções foram processadas conforme anteriormente descrito (Mikesh et al., 2011; Chen et al., 2012). A reação positiva é mostrada como um precipitado marrom claro/marrom escuro no núcleo para PCNA e citoplasma para Caspase-3.

Para determinação das áreas necróticas dos tumores de melanoma, segmentos tumorais fixados em formalina tamponada e incluídos em parafina foram corados com hematoxilina e eosina (HE) para posterior exame histológico. 


\subsection{Morfometria}

Os 5 campos mais representativos de cada lâmina histológica foram selecionados e o número de células marcadas positivamente para cada fenótipo foi contado manualmente. As análises foram realizadas de forma independente e cega.

\section{Contagem de leucócitos, glóbulos vermelhos e plaquetas}

A contagem de glóbulos vermelhos, brancos e plaquetas no sangue foram realizadas em colaboração com o grupo de pesquisa do Prof. Dr. Durvanei Augusto Maria, do Instituto Butantan - São Paulo, SP.

\section{Análise de citocinas}

\subsection{Obtenção de sobrenadantes da cultura de esplenócitos}

Após o sacrifício dos animais, os baços foram removidos assepticamente e debridados. As amostras foram centrifugadas duas vezes a $1400 \mathrm{~g}$ por $15 \mathrm{~min}\left(4^{\circ} \mathrm{C}\right)$ e em seguida, tiveram as hemácias lisadas com tampão de cloreto de sódio $(\mathrm{NaCl})$. Novamente as células foram centrifugadas, isoladas e plaqueadas $\left(2 \times 10^{6}\right.$ céls/poço), sendo mantidas em meio de cultura RPMI 1640 suplementado com 10\% de soro bovino fetal, $100 \mu \mathrm{g} / \mathrm{ml}$ de estreptomicina e 100 unidades $/ \mathrm{ml}$ de penicilina, a $37^{\circ} \mathrm{C}$ em incubadora com $5 \%$ de $\mathrm{CO}_{2}$. Após estímulo com concanavalina A $(5 \mu \mathrm{g} / \mathrm{mL})$ por 24 a 48 horas, os sobrenadantes foram coletados e as concentrações de IL-12, IFN- $\gamma$, TGF- $\beta$, IL-10, TNF- $\alpha$, IL-6, IL-1 $\beta$ e IL-17 determinadas por ELISA, de acordo com instruções do fabricante (BD Bioscience - R\&D Systems, Minneapolis, USA). 


\subsection{Obtenção de sobrenadantes da cultura de células B16F10}

Assim como para os ensaios de morte celular, células B16F10 foram semeadas em poços de uma placa de cultura de 24 poços $\left(5 \times 10^{4}\right.$ células $/ \mathrm{mL} /$ poço $)$ e estimuladas com diferentes concentrações de PEAc $(0,3125$ a $10 \mathrm{mg} / \mathrm{mL})$ e durante diferentes períodos de incubação (24, 48 e 72h). Poços contendo apenas células tumorais (sem estímulo) foram utilizados como controle. Após os períodos determinados, os sobrenadantes foram coletados para posterior determinação, por ELISA, das concentrações das citocinas TGF- $\beta$, IL-10, TNF$\alpha$ e IL-6, de acordo com instruções do fabricante (BD Bioscience - R\&D Systems, Minneapolis, USA).

\section{Análise Estatística}

Para a análise estatística dos resultados foi utilizado o programa de computador Prism, versão 5.0 (Graph Pad Software inc). Os resultados foram analisados pelo teste de normalidade a fim de avaliar se os mesmos apresentavam distribuição Gausiana. $\mathrm{O}$ Test $\mathrm{t}$ (paramétrico) o de Mann-Whitney foram utilizados, respectivamente, para amostras que apresentaram e para as que não apresentaram distribuição normal. A probabilidade foi considerada estatisticamente significante se $\mathrm{p}<0.05$.

As análises dos resultados obtidos por citometria de fluxo foram realizadas utilizandose o programa FACSDiva versão 6.1.3. e/ou ModFit LT versão 3.3.11. 


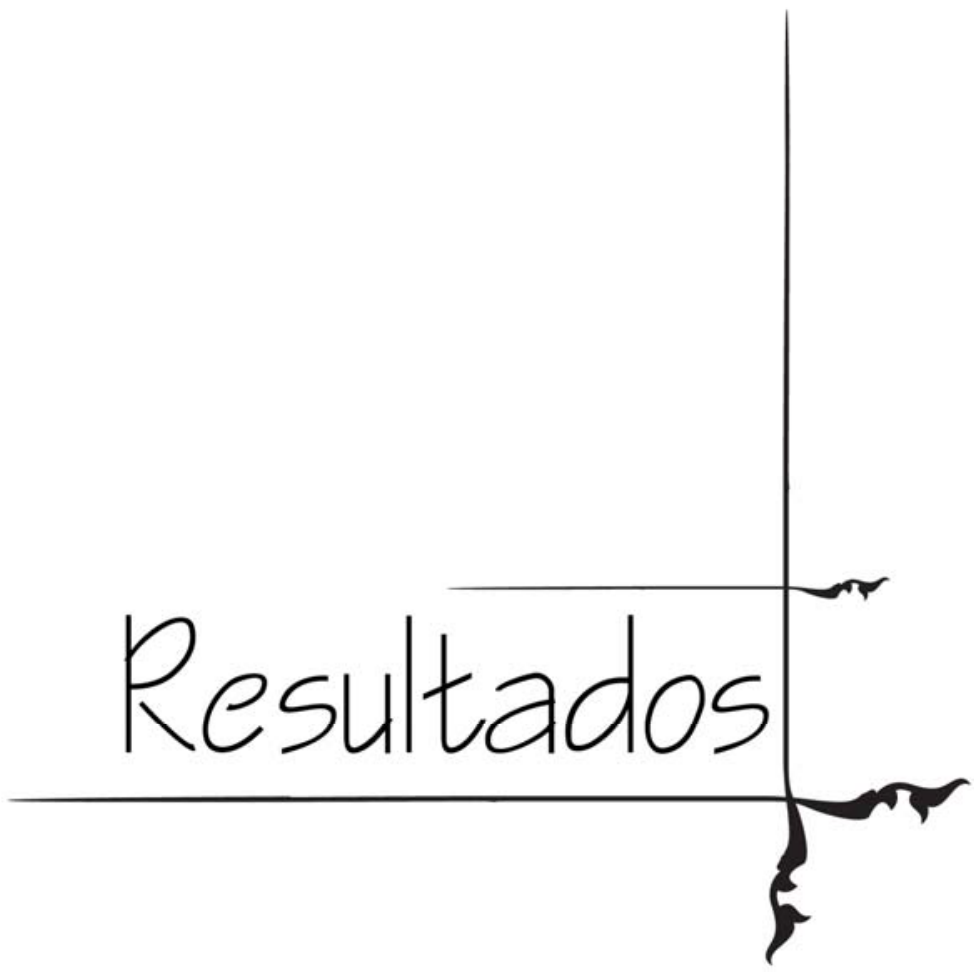




\section{RESULTADOS}

\section{Avaliação de citotoxicidade}

Conforme se observa na figura 1, a incubação das células B16F10 com as maiores concentrações de fosfoetanolamina comercial (PEAc - 2,5; 5 e $10 \mathrm{mg} / \mathrm{mL}$ ), durante 24 a 72 horas, levou à redução da viabilidade celular. Decorridas 24 horas de incubação com as maiores concentrações $(2.5 ; 5$ e $10 \mathrm{mg} / \mathrm{mL})$ de PEAc, cerca de 88,80 e $60 \%$ das células permaneceram viáveis, respectivamente (Figura 1A). Essas mesmas concentrações induziram, de forma mais intensa, redução na sobrevivência das células de modo que 86, 73 e 38\% estavam viáveis após 48 horas de estimulação (Figura 1B). Neste período de incubação, a menor concentração $(0,3125 \mathrm{mg} / \mathrm{mL})$ de fosfoetanolamina também levou à redução, de aproximadamente 18\%, da viabilidade das células (Figura 1B). Decorridas 72 horas de incubação, redução entre 13 e 47\% da viabilidade das células B16F10 foi verificada quando as mesmas foram tratadas com 0,625 e 1,25; 2,5 e 5; e $10 \mathrm{mg} / \mathrm{mL}$ de PEAc (Figura 1C). Neste mesmo período de incubação, somente a menor concentração testada $(0,3125 \mathrm{mg} / \mathrm{mL})$ não causou redução na viabilidade celular (Figura 1C).

A

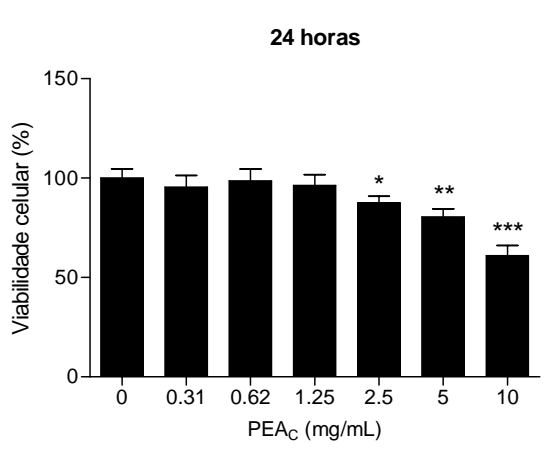

B

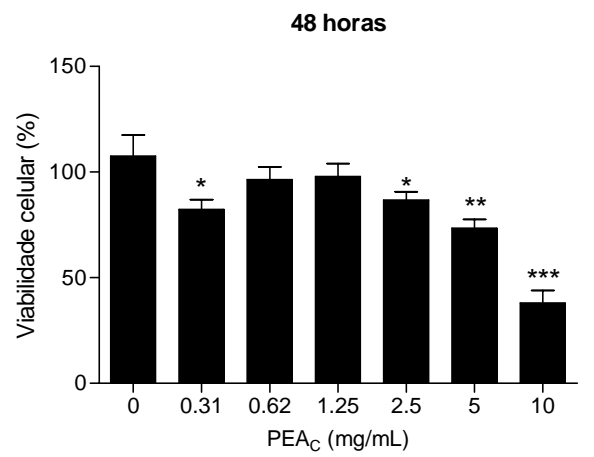

C

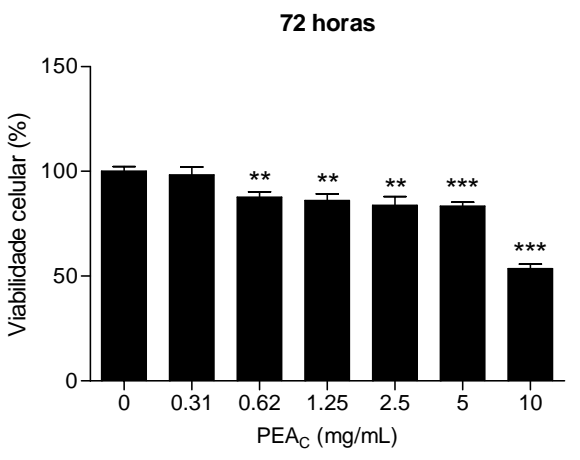

Figura 1. Efeitos da fosfoetanolamina comercial $\left(\mathrm{PEA}_{\mathrm{C}}\right)$ sobre a viabilidade de células de melanoma murino B16F10. Células B16F10 foram estimuladas com PEAc por 24 (A), 48 (B) e 72 (C) horas. A seguir, solução de MTT foi adicionada às células e quatro horas depois, as mesmas foram solubilizadas. Os resultados foram expressos como Média + EPM de quatro replicatas provenientes de três ensaios independentes após leitura da absorbância a $570 \mathrm{~nm}$. Amostra paramétrica, teste estatístico Test t. ${ }^{*} \mathrm{p}<0,05 ; * * \mathrm{p}<0,005 ; * * * \mathrm{p}<0,0001$. 
Da mesma forma, outras linhagens de células tumorais (HT-29 e MCF-7) foram avaliadas frente à estimulação com PEAc. Assim como observado para células B16F10, PEA levou à redução da viabilidade das células HT-29 e MCF-7 (Figura 2).

Com relação às células HT-29, verificamos que a redução da sobrevivência foi de, aproximadamente, 29 a 38\% após 24 horas de estimulação (com exceção da menor concentração testada, a qual não teve efeito nesse período - Figura 2A); e de 24 a 40\% após 48 horas (Figura 2B). Após 72 horas de estimulação, apenas as maiores concentrações de PEAc (2.5 a 10 mg/mL) levaram à redução, de 15 a 37\%, do número de células HT-29 viáveis (Figura 2C).

Em relação às células MCF-7, observou-se redução de 10 a 17\% da viabilidade após incubação com PEAc (10 mg/mL) durante 24 horas (Figura 2D). Decorridas 48 horas, a menor e a maior concentrações de fosfoetanolamina $(0,31$ e $10 \mathrm{mg} / \mathrm{mL})$ levaram à redução de 18 e 15\% da viabilidade celular (Figura 2E). Em período maior de estimulação com PEAc, viabilidade celular inferior a $90 \%$ foi verificada (Figura $2 \mathrm{~F}$ ).

Células não tumorais (macrófagos murinos da linhagem RAW 264.7) apresentaram-se mais resistentes aos efeitos da fosfoetanolamina. Nos diferentes períodos de incubação, somente a maior concentração de PEAc $(10 \mathrm{mg} / \mathrm{mL})$ levou à redução da viabilidade celular, de no máximo 30\% (Figura 3A, B e C). 
A

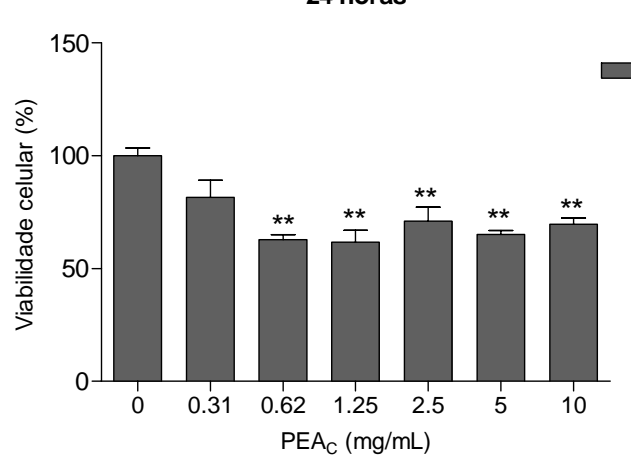

B

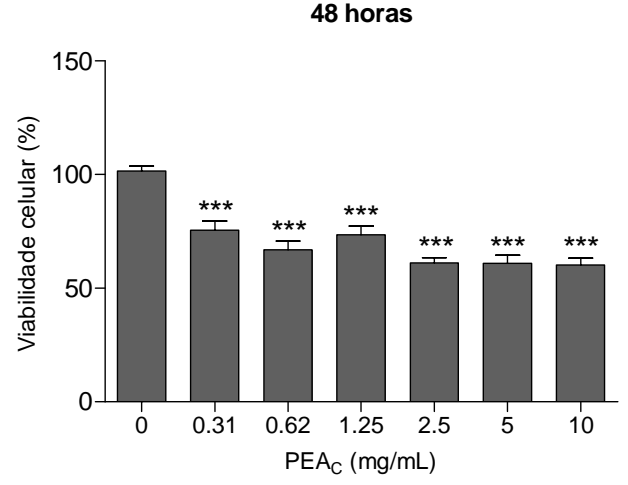

C

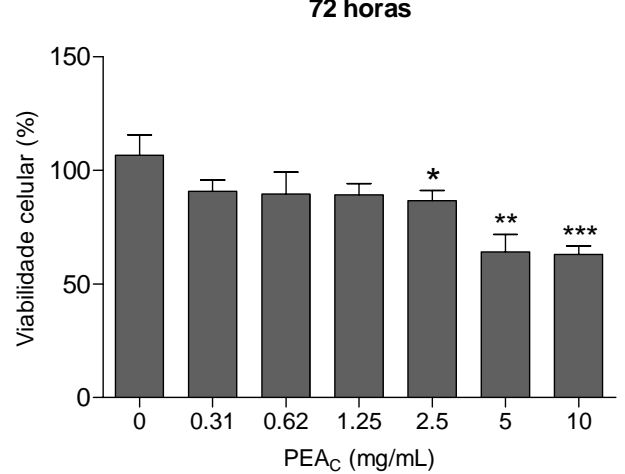

D 24 horas

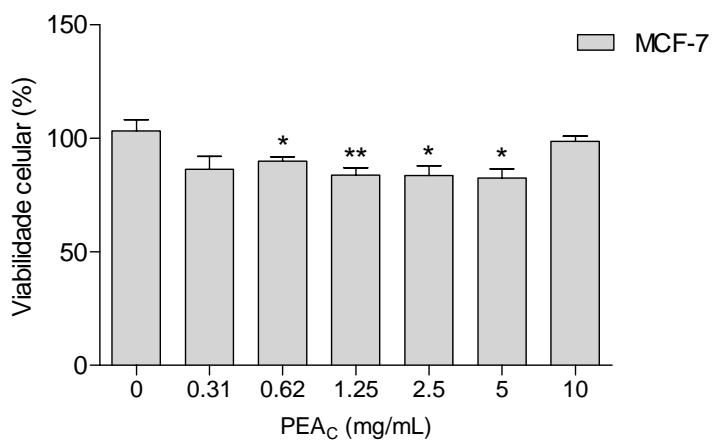

E

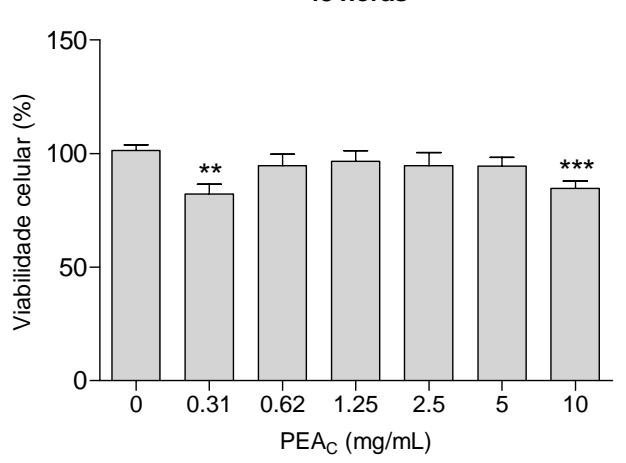

$\mathbf{F}$

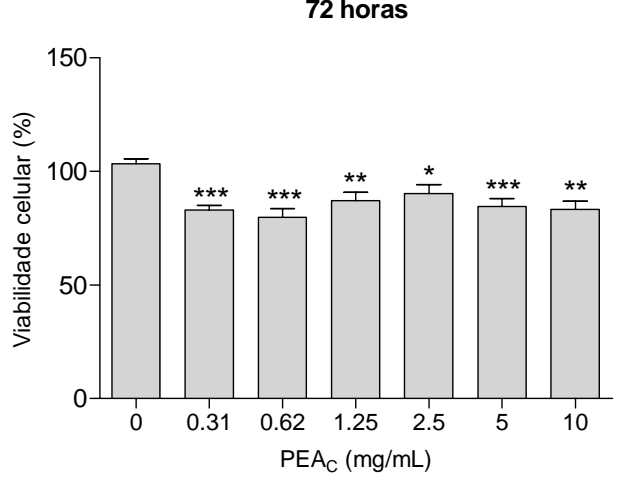

Figura 2. Efeitos da fosfoetanolamina comercial $\left(P E A_{C}\right)$ sobre a viabilidade de células de adenocarcinoma de cólon (HT-29) e mama (MCF-7) humanos. Células HT-29 e/ou MCF-7 foram estimuladas com PEAc por 24, 48 e 72 horas. A seguir, solução de MTT foi adicionada às células e quatro horas depois, as mesmas foram solubilizadas. Os resultados foram expressos como Média + EPM de replicatas provenientes de 2 ensaios independentes após leitura da absorbância a 570nm Amostras paramétricas, teste estatístico Test $t$; amostras não paramétricas, teste estatístico Mann-Whitney. ${ }^{*} \mathrm{p}<0,05 ; * * \mathrm{p}<0,01 ; * * * \mathrm{p}<0,0006$ 
A

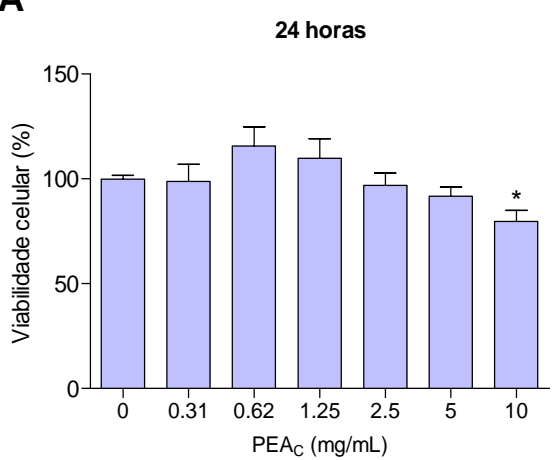

B

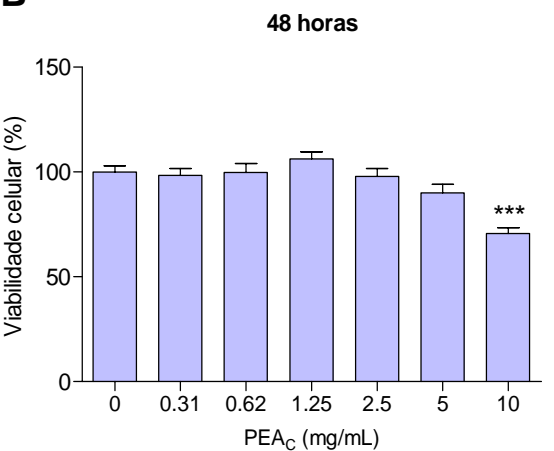

C

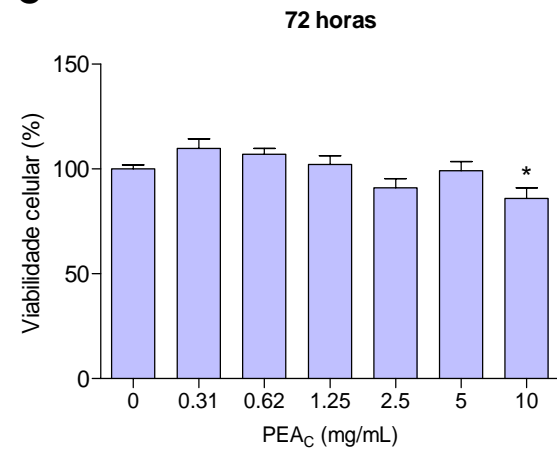

Figura 3. Efeitos da fosfoetanolamina comercial $\left(\mathrm{PEA}_{\mathrm{C}}\right)$ sobre a viabilidade de macrófagos murinos da linhagem RAW 264.7. Os macrófagos foram estimulados com PEAc por 24, 48 e 72 horas. A seguir, solução de MTT foi adicionada às células e quatro horas depois, as mesmas foram solubilizadas. Os resultados foram expressos como Média + EPM de triplicatas provenientes de 3 ensaios independentes após leitura da absorbância a 570nm. Amostra paramétrica, teste estatístico Test t. ${ }^{*} \mathrm{p}<0,05 ; * * * \mathrm{p}<0,0001$.

\section{Quantificação de apoptose}

Uma vez que a estimulação por PEAc exerceu um efeito inibitório da viabilidade das células B16F10, avaliamos, através de citometria de fluxo, se o fosfomonoester induziria morte celular por apoptose e/ou necrose. Para tanto, somente as concentrações de PEAc que apresentaram efeito inibitório sobre a viabilidade das células B16F10 nos ensaios de MTT foram testadas. Observamos que, em comparação às células incubadas somente com o meio de cultura, a estimulação com as maiores concentrações de PEAc, nos três períodos de tempo testados levou a aumento na porcentagem de células em apoptose. Aumentos de 2,3 a 3,6 vezes foram observados após a estimulação com $5 \mathrm{mg} / \mathrm{mL}$ de PEAc e de 4,8 a 8,7 vezes após a estimulação com $10 \mathrm{mg} / \mathrm{mL}$ de PEAc (Figura 4). A incubação por 24 horas com 2,5 mg/mL de PEAc induziu aumento discreto (1,8 vezes) na porcentagem de células apoptóticas (Figura 4A). As demais concentrações de fosfoetanolamina não alteraram a porcentagem de apoptose. Com relação à proporção de células necróticas, nenhuma concentração de PEAc alterou as taxas desse tipo de morte celular (Figura 4). 
A

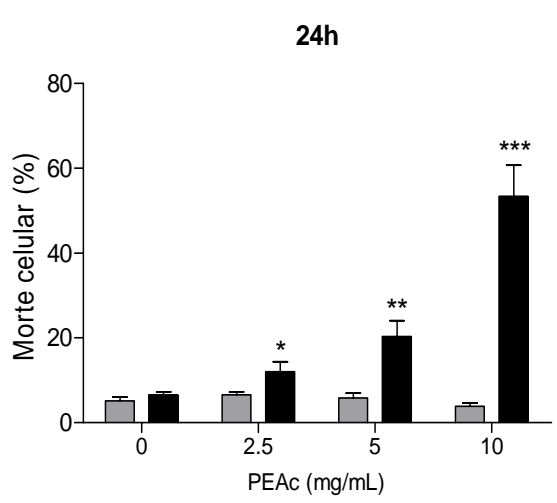

B

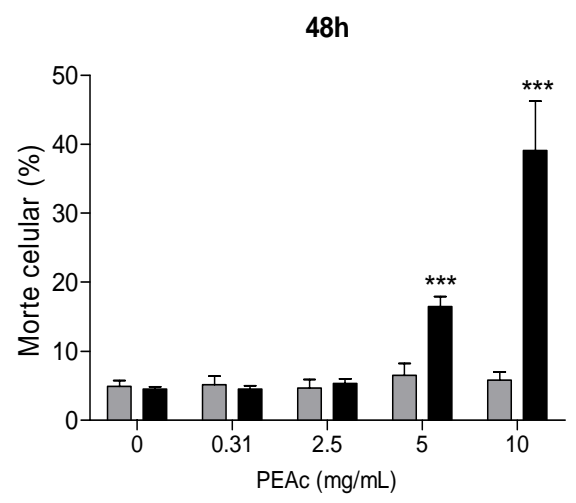

C

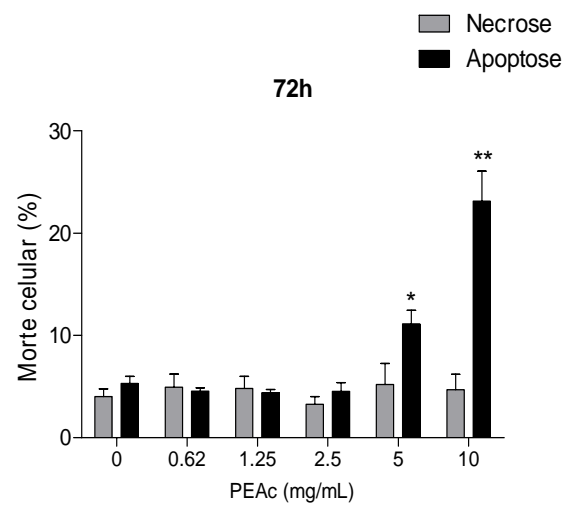

Figura 4. Quantificação de apoptose e necrose de células de melanoma murino B16F10 estimuladas com fosfoetanolamina comercial (PEAc). Células B16F10 foram estimuladas com diferentes concentrações de PEAc durante 24 (A), 48 (B) e 72 (C) horas. A porcentagem de morte celular foi avaliada através de citometria de fluxo, após marcação com anexina-V e PI. Resultados representativos de seis ensaios independentes. Amostra não paramétrica, teste estatístico MannWhitney. ${ }^{*} \mathrm{p}<0,01 ; * * \mathrm{p}<0,006 ; * * * \mathrm{p}<0,0002$.

\section{Análise de ciclo celular}

A estimulação de células B16F10 com diferentes concentrações de PEAc, nos três períodos testados (24, 48 e 72 horas), não levou a nenhuma alteração no ciclo celular das mesmas (Figura 5A, B e C). 
A

24 horas

Fase G1

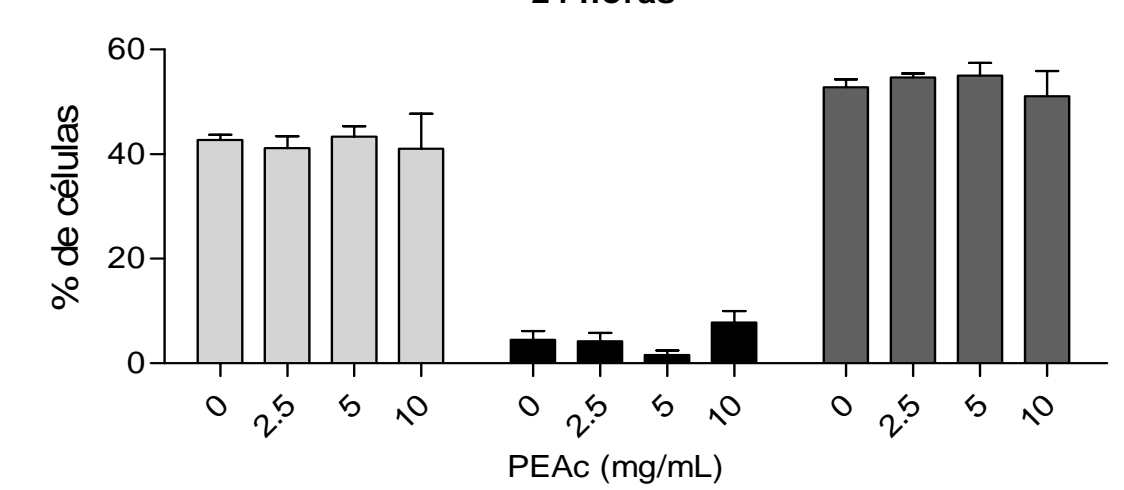

Fase G2

Fase S

B

48 horas

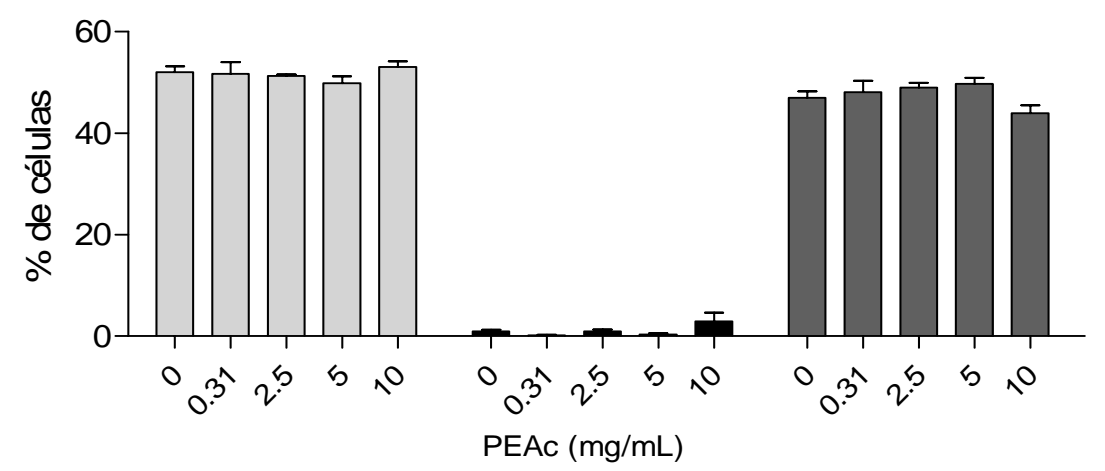

C

72 horas

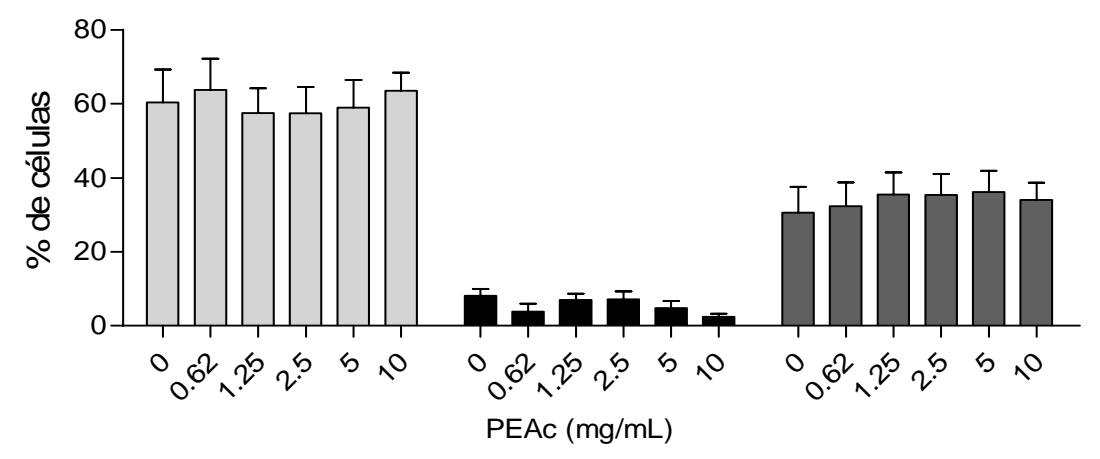

Figura 5. Análise de ciclo celular de células de animais tratados com diferentes concentrações de fosfoetanolamina sintética. Células B16F10 foram estimuladas com diferentes concentrações de PEAc durante 24 (A), 48 (B) e 72 (C) horas. A porcentagem de células nos diferentes ciclos celulares foi avaliada através de citometria de fluxo, após marcação com PI. Resultados representativos de quatro ensaios independentes. Amostra não paramétrica, teste estatístico Mann-Whitney. 


\section{Peso dos animais}

Não se observou alteração no peso dos animais tratados com PEA por 10 (Tabela 2) ou 20 dias (Tabela 3) em relação ao de animais não tratados.

Tabela 2. Peso corporal inicial e final dos animais dos sete grupos experimentais tratados por 10 dias durante o experimento. Os dados correspondem à média \pm desvio padrão da média.

\begin{tabular}{ccc}
\hline Grupos & \multicolumn{2}{c}{ Peso corporal (g) } \\
\hline & Inicial & Final \\
\hline G1 & $23,8 \pm 3,29$ & $27,9 \pm 3,64$ \\
G2 & $24,3 \pm 1,64$ & $26,5 \pm 1,87$ \\
G3 & $25,1 \pm 2,75$ & $26,5 \pm 3,21$ \\
G5 & $23,7 \pm 1,13$ & $27,5 \pm 1,27$ \\
G6 & $25,1 \pm 2,65$ & $27,2 \pm 2,86$ \\
G7 & $23,8 \pm 2,19$ & $26,0 \pm 3,26$ \\
\hline G1: controle; G2: & PEA somente; G3: não tratados; G4, G5 e \\
G6 tratados com 10, 20 e 40 mg/Kg de PEA, respectivamente; \\
G7: tratados com 20 mg/Kg de PEAc. (G3 a G7: animais com \\
tumor).
\end{tabular}

Tabela 3. Peso corporal inicial e final dos animais dos sete grupos experimentais tratados por 20 dias durante o experimento. Os dados correspondem à média \pm desvio padrão da média.

\begin{tabular}{ccc}
\hline Grupos & \multicolumn{2}{c}{ Peso corporal (g) } \\
\hline & Inicial & Final \\
\hline G1 & $24,6 \pm 2,69$ & $28,1 \pm 2,68$ \\
G2 & $25,5 \pm 2,35$ & $28,1 \pm 2,63$ \\
G3 & $27,1 \pm 1,82$ & $32,2 \pm 3,55$ \\
G4 & $25,9 \pm 2,18$ & $31 \pm 2,84$ \\
G5 & $25,5 \pm 2,86$ & $30,9 \pm 3,88$ \\
G6 & $25,5 \pm 2,88$ & $31,1 \pm 3,76$ \\
G7 & $25,4 \pm 2,71$ & $31,2 \pm 3,01$ \\
\hline
\end{tabular}

G1: controle; G2: PEA somente; G3: não tratados; G4, G5 e G6 tratados com 10, 20 e $40 \mathrm{mg} / \mathrm{Kg}$ de PEA, respectivamente; G7: tratados com $20 \mathrm{mg} / \mathrm{Kg}$ de PEAc. (G3 a G7: animais com tumor). 


\section{Análise tumoral}

Macroscopicamente, os animais do grupo não tratado (tumor + PBS) apresentavam tumores dorsais pigmentados, comumente ulcerados e com grandes áreas de necrose, neoangiogênese, volumes expressivos e massas tumorais aderidas aos músculos (Figura 6A,B e C). Em relação aos grupos tratados com PEA, de forma geral, os tumores dorsais também se apresentavam pigmentados, porém com áreas de necrose e ulcerações menos freqüentes, massa tumoral aderida à pele, embora algumas vezes também se encontrava aderida aos músculos e com menor volume (Figura 6D, E e F). Os animais inoculados com células de melanoma, independentemente de terem sido tratados ou não, exibiram grande variação individual em relação ao desenvolvimento do tumor.

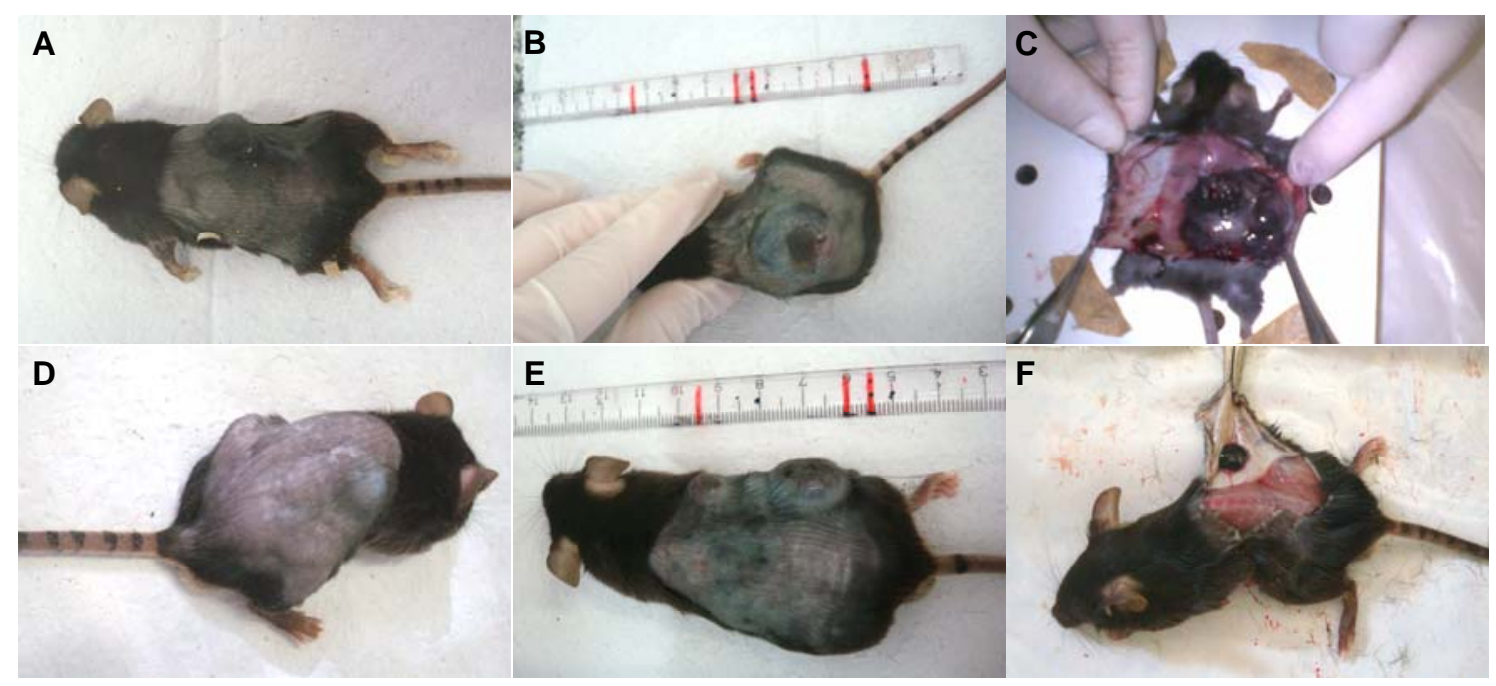

Figura 6. Aspecto macroscópico dos tumores dorsais dos animais submetidos ou não ao tratamento com fosfoetanolamina sintética. Grupo tratado com PBS (controle - A, B e C) e tratado com PEA (D, E e F). A: animal tratado durante 10 dias; B: animal com maior massa e área de necrose tumoral tratado por 20 dias; C: massa tumoral aderida à musculatura do animal controle; D: animal tratado por 10 dias com menor massa tumoral; E: animal com menor área necrótica tratado por 20 dias; F: massa tumoral aderida à pele.

Como ilustrado na Figura 7A, animais não tratados apresentaram tumores de aproximadamente $2,26 \pm 1,03$ e 9,72 $\pm 3,23 \mathrm{~cm}^{3}$ em média, após 10 e 20 dias consecutivos de administração de PBS, respectivamente.

A administração de 20 e $40 \mathrm{mg} / \mathrm{Kg}$ de PEA por apenas 10 dias já causou alterações no volume tumoral, visto que, quando comparados ao grupo de animais não tratados, tumores 82 
e $98 \%$ menores foram observados nesses grupos experimentais (Figura 7). Por outro lado, o tratamento com $10 \mathrm{mg} / \mathrm{Kg}$ de fosfoetanolamina não levou à redução tumoral (Figura 7A). A PEAc também se mostrou eficiente no tratamento do melanoma, uma vez que os volumes tumorais apresentaram-se 78\% menores após tratamento por 10 dias (Figura 7A).

Os tumores de animais cujo tratamento com PEA foi estendido por mais 10 dias (total de 20 dias), em geral, exibiram maior tamanho em relação àqueles tratados por somente 10 dias, porém ainda permaneceram menores com a administração do fosfomonoéster (Figura 7A e B). Neste caso, todas as doses de PEA $(10 ; 20 ; 40$ e comercial $20 \mathrm{mg} / \mathrm{Kg})$ impediram o crescimento da massa tumoral dorsal dos camundongos, resultando em volumes 70 a $80 \%$ menores em relação aos volumes dos tumores de animais não tratados (Figura 7B).

A

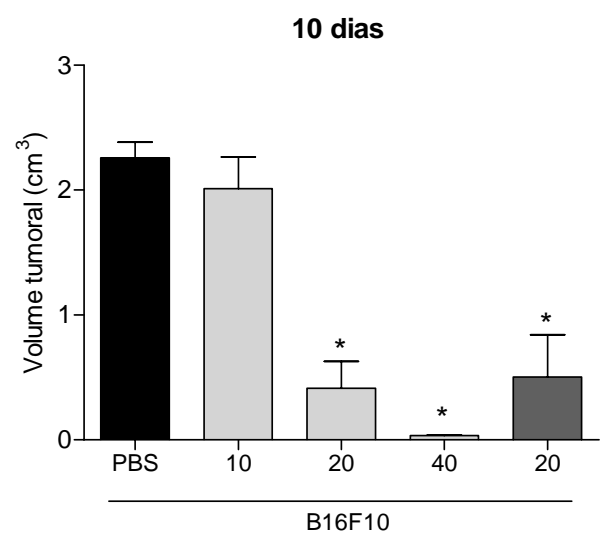

B

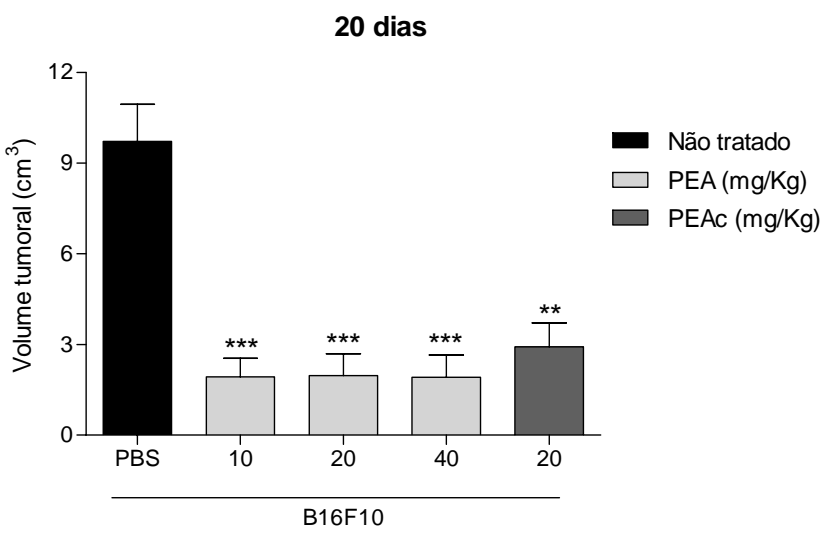

Figura 7. Efeito do tratamento com fosfoetanolamina sintética sobre o volume dos tumores dorsais de camundongos inoculados com células B16F10. Os animais foram inoculados (s.c.) com $5 \times 10^{4}$ células B16F10 e tratados com diferentes doses de PEA (10, 20 e $\left.40 \mathrm{mg} / \mathrm{Kg}\right)$, PEA comercial (PEAc, $20 \mathrm{mg} / \mathrm{Kg}$ ) ou PBS por 10 (A) ou 20 dias (B) consecutivos. Ao final dos períodos destes o volume tumoral foi determinado. Os resultados foram expressos como Média + EPM. Amostra não paramétrica, teste estatístico Mann-Whitney (*em relação ao grupo não tratado: "tumor + PBS"). *p < 0,$05 ; * * \mathrm{p}<0,001 ; * * * \mathrm{p}<0,0006$.

Através do acompanhamento do desenvolvimento dos tumores dorsais dos animais ao longo dos dois períodos de tratamento, verificamos que os grupos experimentais submetidos ao tratamento com fosfoetanolamina exibiram um crescimento tumoral mais lento quando comparados com os animais não tratados (Figura 8A e B). Em adição, animais tratados com PEA por 20 dias apresentaram maior taxa de sobrevivência ao final do experimento (Figura 8C), de 56 a 90\%, enquanto animais não tratados apresentaram taxa de sobrevivência de $40 \%$.

Não foi verificada mortalidade em nenhum dos grupos experimentais após o menor período de tratamento (10 dias - dados não mostrados). 
A

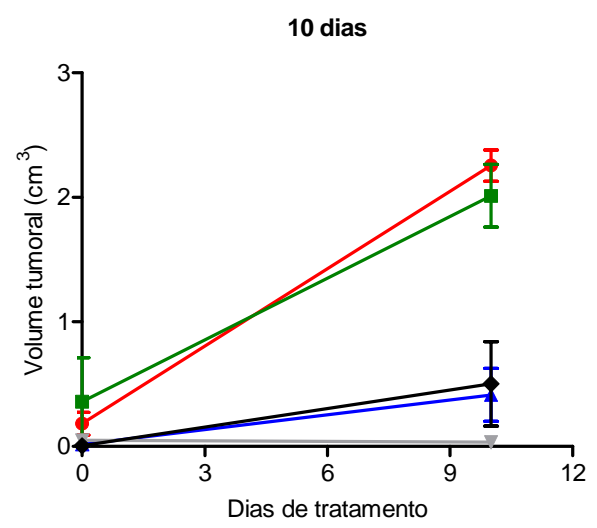

B

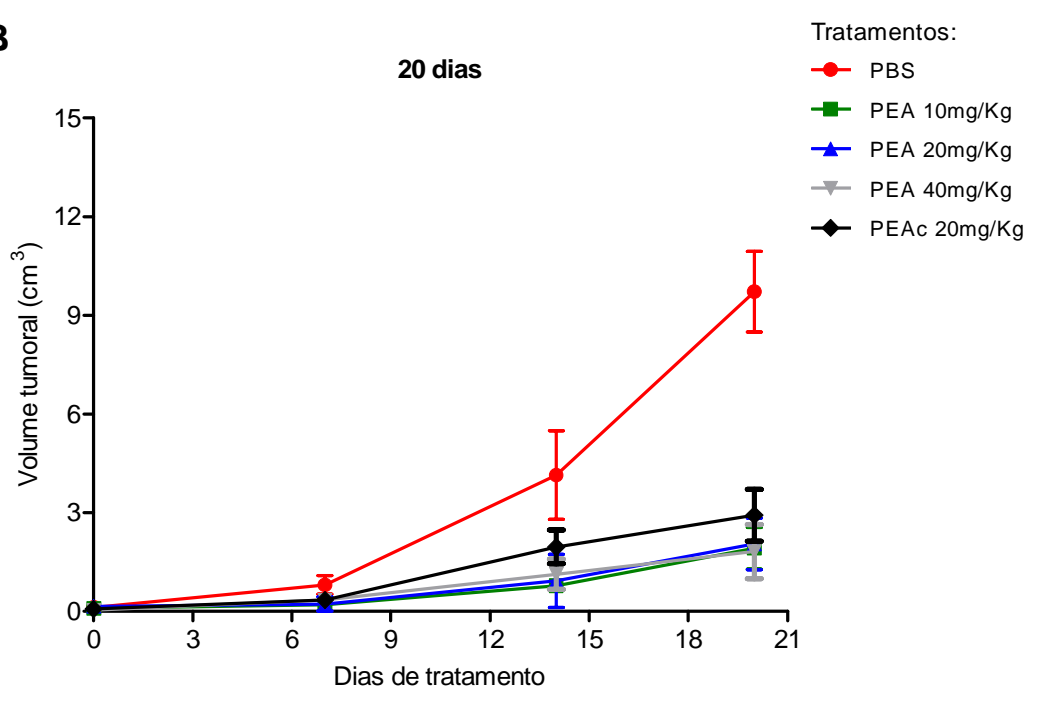

C

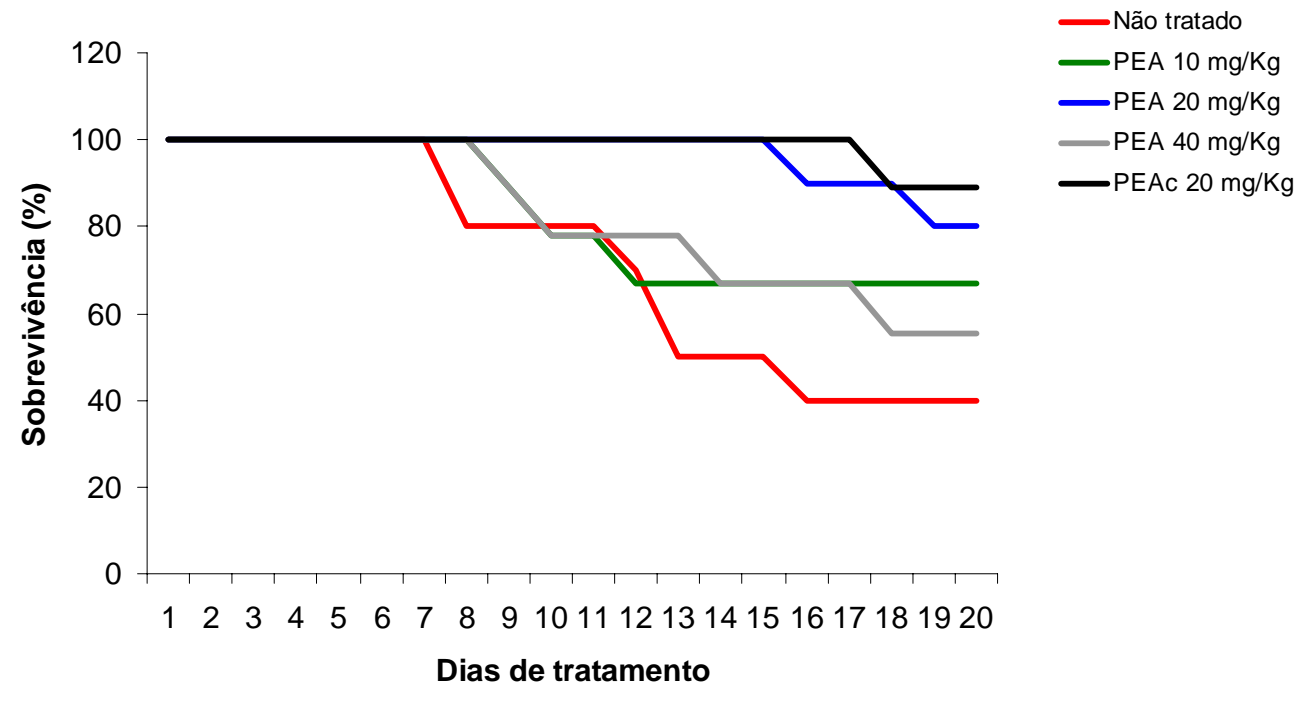

Figura 8. Perfil da progressão do volume tumoral e sobrevivência de animais inoculados com células B16F10 e tratados com fosfoetanolamina sintética. Determinação diária e semanal da sobrevivência e volume tumoral, respectivamente, ao longo de ambos os períodos de tratamento, 10 (A) e 20 dias (B e C), com diferentes doses de PEA (10, 20 e $40 \mathrm{mg} / \mathrm{Kg}$ ), PEA comercial (PEAc, 20 $\mathrm{mg} / \mathrm{Kg}$ ) ou PBS. Os resultados foram expressos como Média + EPM. 


\section{Análise imunoistoquímica de proliferação e morte das células tumorais}

A avaliação imunoistoquímica da expressão do marcador de proliferação celular PCNA no tecido tumoral revelou que o tratamento com 20 e $40 \mathrm{mg} / \mathrm{Kg}$ de PEA e $20 \mathrm{mg} / \mathrm{Kg}$ de PEAc por apenas 10 dias induziu uma diminuição de aproximadamente 27, 49 e 56\%, respectivamente, no número de células em proliferação (Figura 9A). Diminuição mais acentuada da proliferação celular, de 49, 67 e 70\%, respectivamente, foi observada após período maior de tratamento (20 dias) com as mesmas doses de PEA e PEAc (Figura 9B e Anexo A). Em ambas os períodos de tratamento, a marcação para PCNA mostrou-se inversamente proporcional à dose de fosfoetanolamina utilizada.

Os efeitos da fosfoetanolamina sobre a sobrevida das células tumorais in vivo também foram avaliados. Coerentemente com nossos resultados in vitro, verificamos que a administração de PEA resultou em aumento de apoptose das células tumorais, conforme demonstrado pela marcação positiva para caspase-3. Como se observa nas Figuras 9C e 9D, decorridos 10 e 20 dias de tratamento, todas as doses de PEA (com exceção da menor -10 $\mathrm{mg} / \mathrm{Kg}$, no período de 10 dias de tratamento), assim como PEAc, induziram apoptose das células tumorais de maneira dose dependente, havendo aumentos de 67 a 335\% no número de células apoptóticas nos tecidos tumorais (Anexo A).

Maior porcentagem de áreas de necrose nas massas tumorais dorsais (aumento de aproximadamente $72 \%$ ) foi verificada no grupo experimental tratado com a maior dose de PEA durante 20 dias (Figura 9F). Nenhuma diferença foi verificada após tratamento por menor período (10 dias; Figura 9E). 
A

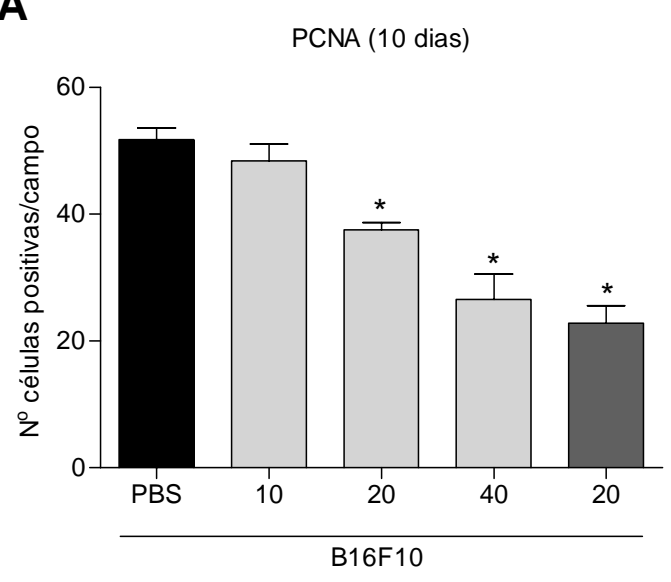

C

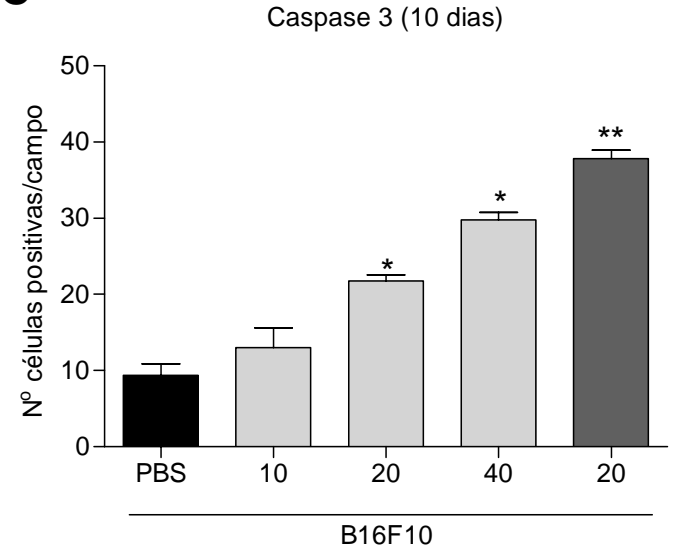

$\mathbf{E}$

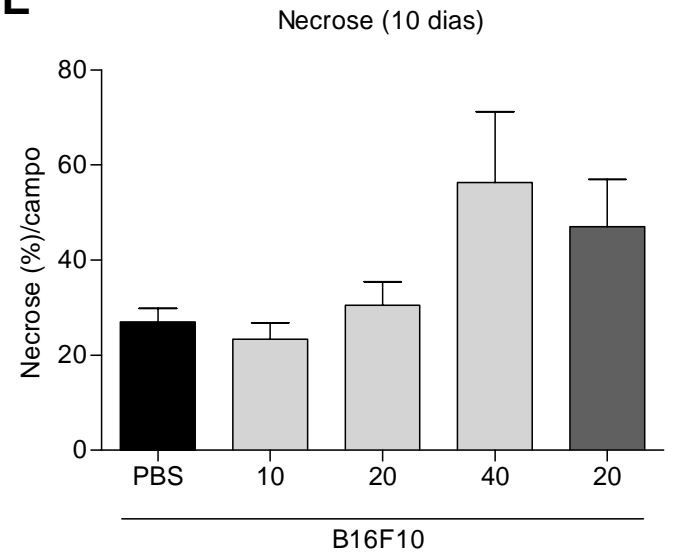

B

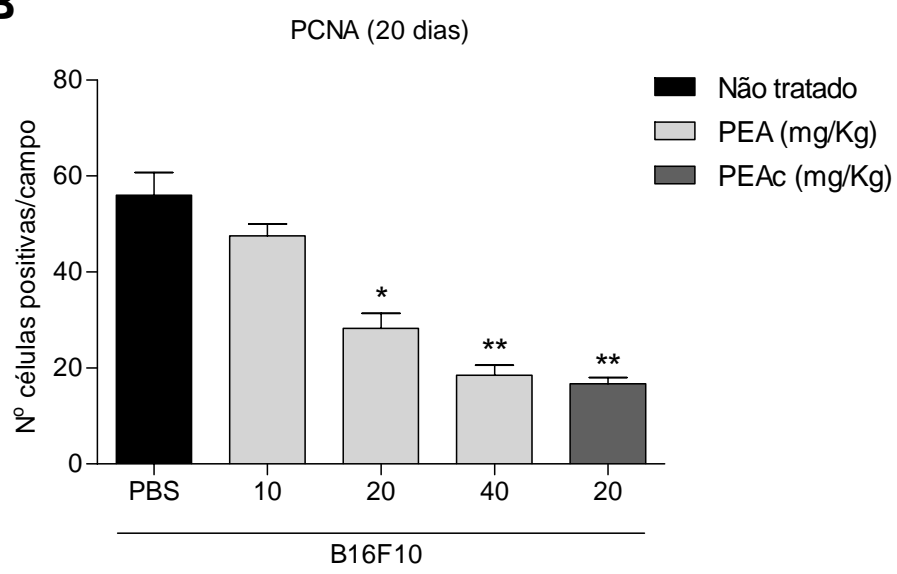

D

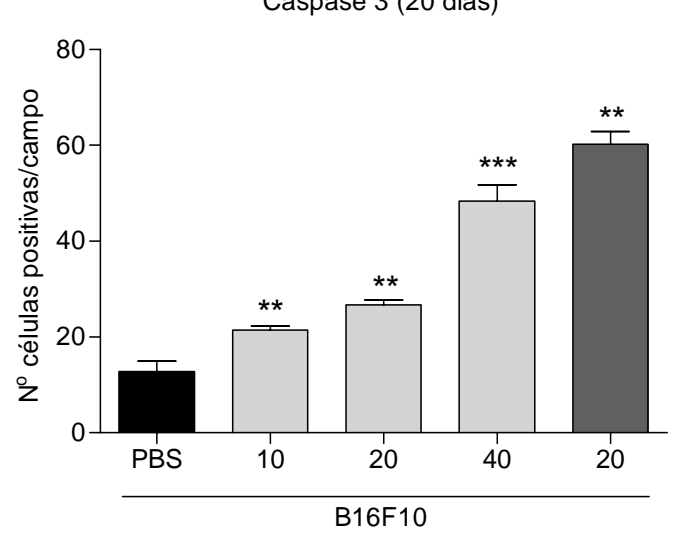

$\mathbf{F}$

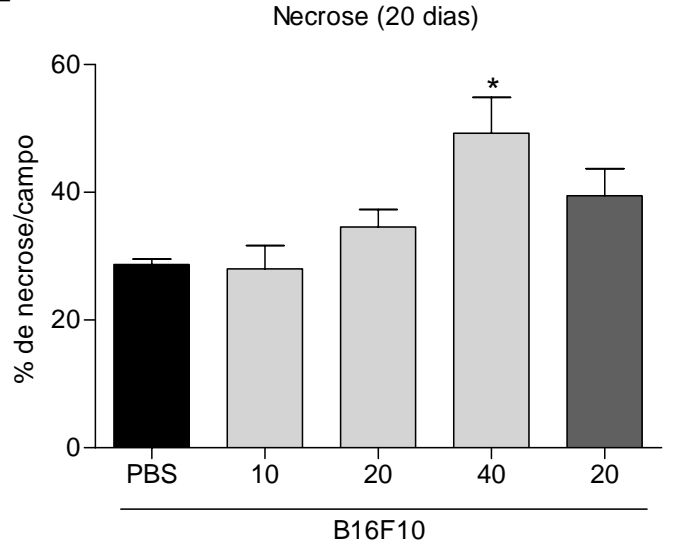

Figura 9. Proliferação e morte de células tumorais de animais tratados com diferentes doses de fosfoetanolamina sintética. Segmentos tumorais de animais tratados com PEA ou PEAc por 10 (A, C e E) ou 20 dias (B, D e F) consecutivos foram fixados em formalina tamponada e incluídos em parafina. Os blocos foram cortados serialmente e usados para coloração HE ou imunoistoquímica para marcação com anticorpos específicos para PCNA e caspase-3 ou determinação de áreas de necrose. *p $<0,03 ; * * \mathrm{p}<0,009 ; * * * \mathrm{p}<0,0007$. 


\section{Contagem de leucócitos, glóbulos vermelhos e plaquetas}

Conforme ilustrado na Figura 10A, dentre os animais que foram submetidos ao tratamento com PEA durante 10 dias, somente o grupo experimental que recebeu a maior dose $(40 \mathrm{mg} / \mathrm{Kg})$ teve o número de eritrócitos alterado, o qual aumentou 123\% em relação aos animais não tratados. Com 20 dias de tratamento, porém, as doses de 10 e $20 \mathrm{mg} / \mathrm{Kg}$ de PEA causaram um aumento de 44,8 e 64,6\% (Figura 10B), respectivamente, no número de eritrócitos do sangue em relação aos camundongos não tratados. Em adição, animais portadores de melanoma apresentaram uma redução de 30\% nos níveis de eritrócitos em relação ao grupo controle (Figura 10B). A administração somente de PEA (animais sem tumor) não interferiu no número de eritrócitos dos animais em nenhum dos períodos de tratamento.

A

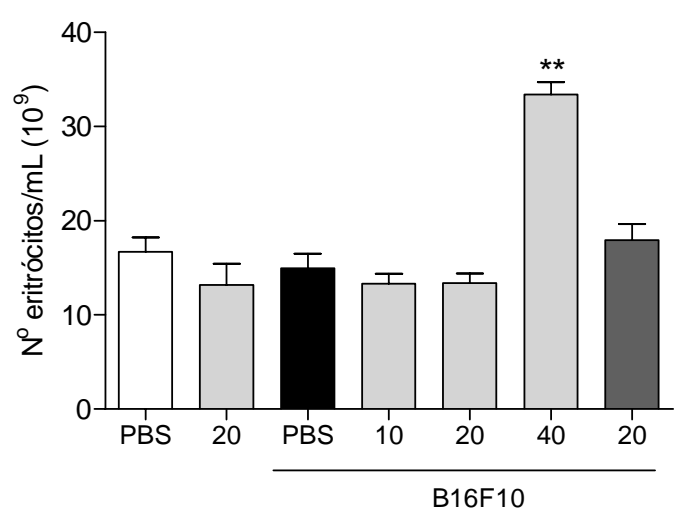

B

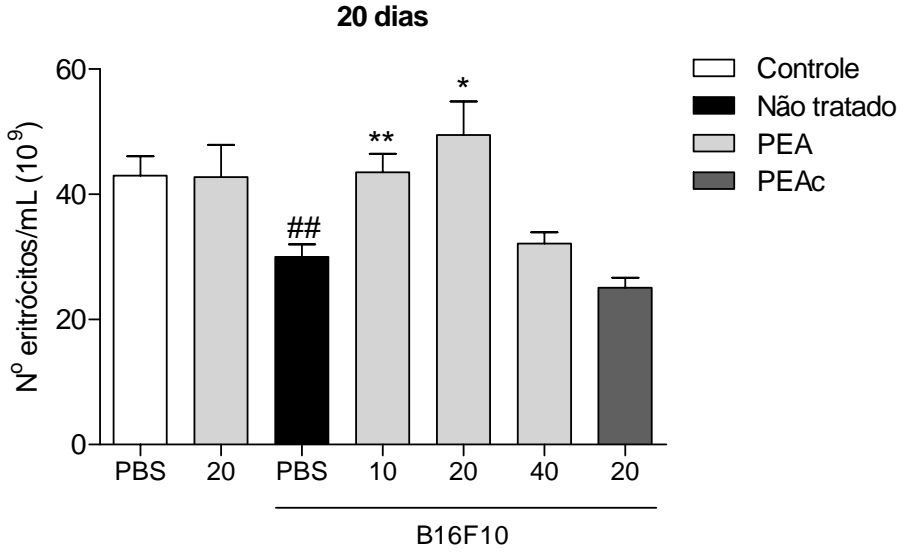

Figura 10. Níveis de eritrócitos de animais tratados com diferentes doses de fosfoetanolamina sintética. Número de eritrócitos $/ \mathrm{mL}$ de sangue de animais tratados com diferentes doses de PEA (10, 20 e $40 \mathrm{mg} / \mathrm{Kg}$ ), PEA comercial (PEAc, $20 \mathrm{mg} / \mathrm{Kg}$ ) ou PBS durante um período de 10 (A) e 20 (B) dias. Os resultados foram expressos como Média + EPM. Amostra não paramétrica, teste estatístico Mann-Whitney. (\#em relação ao controle: "PBS + PBS"; *em relação ao grupo não tratado: "tumor + PBS"). *p $<0,01 ; * * p<0,003 ; \#$; $<0,006$.

Ao término de 10 dias de tratamento com $20 \mathrm{mg} / \mathrm{Kg}$ de PEA e PEAc, a contagem de plaquetas do sangue dos animais aumentou 33 e 44\%, respectivamente, quando comparada ao grupo de animais não tratados (Figura 11A), no qual a contagem foi cerca de $30 \%$ maior em relação ao grupo controle. O mesmo não foi observado quando a menor $(10 \mathrm{mg} / \mathrm{Kg})$ e a maior (40 mg/Kg) doses de PEA foram utilizadas no tratamento, assim como quando PEA foi administrada aos animais sem tumores. 
Em relação aos resultados apresentados pelos animais tratados por um período maior (20 dias), observou-se que a administração de 20 e $40 \mathrm{mg} / \mathrm{Kg}$ de PEA, assim como de 20 $\mathrm{mg} / \mathrm{Kg}$ de PEAc, provocou um aumento de plaquetas no sangue, uma vez que números 23, 48 e $42 \%$ maiores que o de animais não tratados, respectivamente, foram observados nessas condições (Figura 11B). Os animais não tratados e aqueles sem tumores que receberam PEA não apresentaram alterações nos números de plaquetas sanguíneas.

A

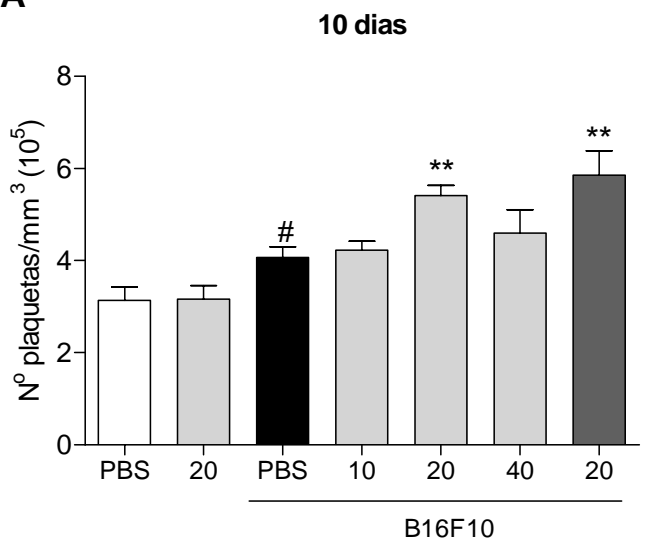

B

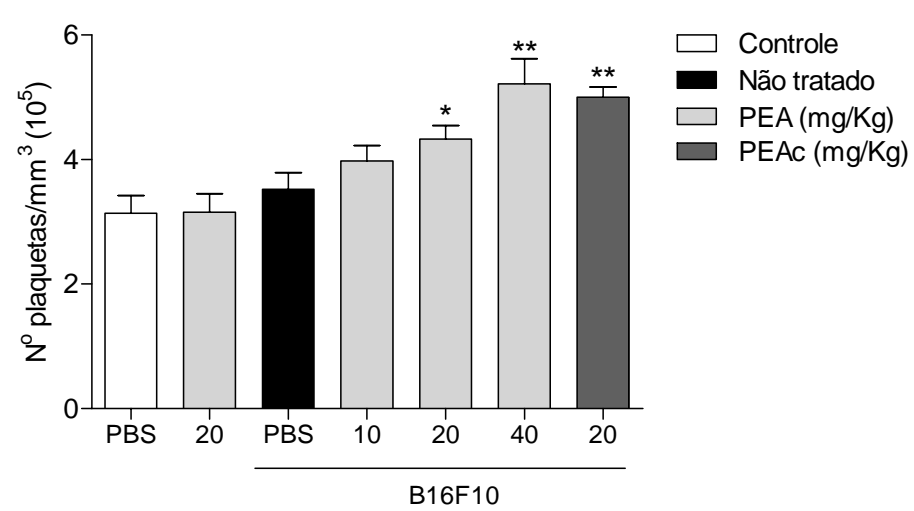

Figura 11. Níveis de plaquetas de animais tratados com diferentes doses de fosfoetanolamina sintética. Número de plaquetas $/ \mathrm{mm}^{3}$ de sangue de animais tratados com diferentes doses de PEA (10, 20 e $40 \mathrm{mg} / \mathrm{Kg}$ ), PEA comercial (PEAc, $20 \mathrm{mg} / \mathrm{Kg}$ ) ou PBS durante um período de 10 (A) e 20 (B) dias. Os resultados foram expressos como Média + EPM. Amostra não paramétrica, teste estatístico Mann-Whitney. (\#em relação ao controle: "PBS + PBS"; *em relação ao grupo não tratado: "tumor + PBS"). \#p $<0,002 ; * \mathrm{p}<0,04 ; * * \mathrm{p}<0,008$.

Em relação à contagem total de leucócitos, a indução do tumor, por si só levou a um aumento no número destas células. Após 10 e 20 dias de administração de PBS, foram observados aumentos de 89 e 36\% em relação aos animais do grupo controle, respectivamente (Figura 12A e B). A administração somente de PEA durante os dois períodos de tempo também induziu um aumento de aproximadamente 70 (10 dias) e 60\% (20 dias) no número de leucócitos no sangue dos animais em relação ao controle (Figura 12A e B). Quando os animais portadores de tumores foram submetidos à gavagem com $40 \mathrm{mg} / \mathrm{Kg}$ de PEA durante 10 dias, o número de leucócitos foi reduzido em aproximadamente 27\% (Figura 12A) em relação ao grupo não tratado. O contrário foi observado quando o período de tratamento se estendeu até 20 dias, no qual a mesma dose de PEA (40 mg/Kg) induziu um aumento de cerca de 48\% no número de leucócitos sanguíneos (Figura 12B). Metade dessa dose $(20 \mathrm{mg} / \mathrm{Kg}$ ) também levou a um aumento de aproximadamente 38\% no número de leucócitos sanguíneos, 
neste mesmo período de tratamento. $\mathrm{O}$ aumento mais expressivo no número de leucócitos foi observado quando a PEAc $(20 \mathrm{mg} / \mathrm{Kg})$ foi administrada aos animais durante 20 dias, situação em que o número dessas células aumentou $58 \%$ em relação ao apresentado por animais não tratados (Figura 12B).
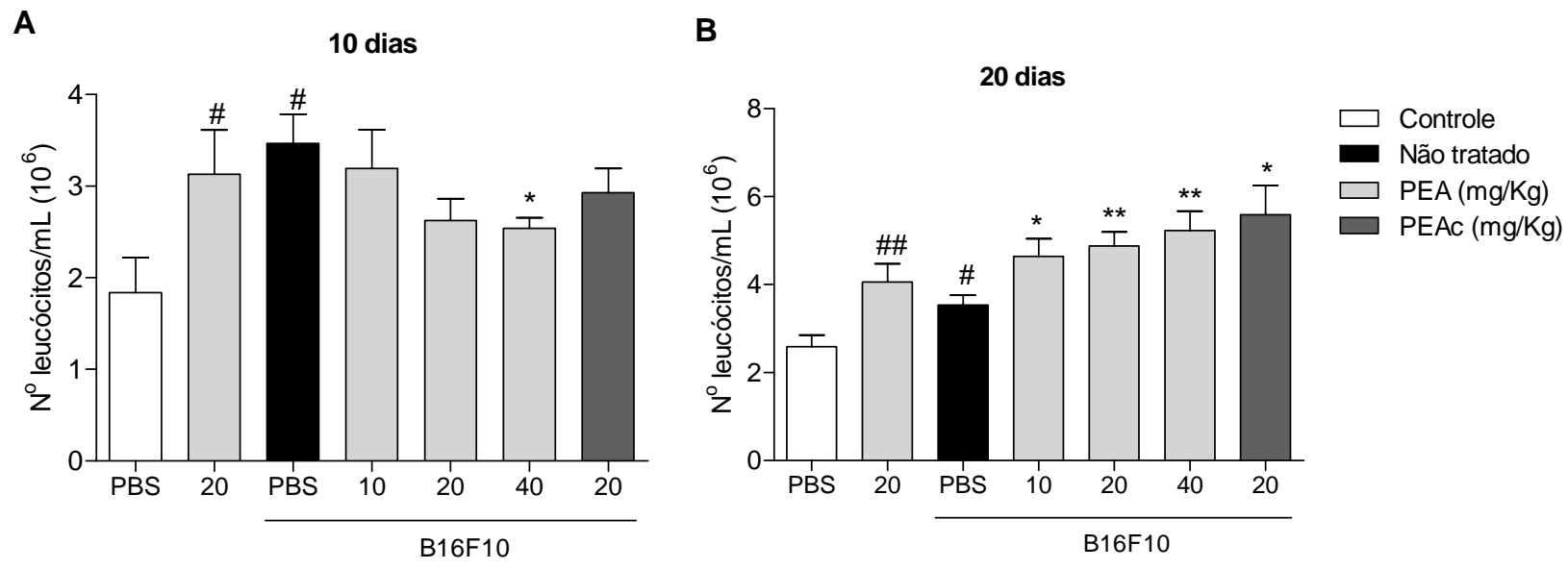

Figura 12. Níveis de leucócitos do sangue de animais tratados com diferentes doses de fosfoetanolamina sintética. Número de leucócitos $/ \mathrm{mL}$ de sangue de animais tratados com diferentes doses de PEA (10, 20 e $40 \mathrm{mg} / \mathrm{Kg}$ ), PEA comercial (PEAc, $20 \mathrm{mg} / \mathrm{Kg}$ ) ou PBS durante um período de 10 (A) e 20 (B) dias. Os resultados foram expressos como Média + EPM. Amostra não paramétrica, teste estatístico Mann-Whitney. (\#em relação ao controle: "PBS + PBS"; *em relação ao grupo não tratado: "tumor + PBS"). \#p $<0,03$; \#\# $<0,008 ; * \mathrm{p}<0,01 ; *$ * $<0,002$.

Uma vez observado que o tratamento com PEA interferiu no número de leucócitos no sangue destes animais, avaliamos, através de contagem diferencial, quais tipos celulares estavam alterados. Em ambos os períodos de tratamento e em todos os grupos experimentais, a proporção relativa de linfócitos foi sempre superior em relação aos demais tipos de leucócitos, correspondendo a mais de $60 \%$ dos leucócitos totais.

Em relação aos grupos controles, somente o grupo de animais não tratados (administração de PBS por 10 dias) apresentou uma proporção de monócitos aumentada (Figura 13A). Conforme observado na Figura 13A, o tratamento com 20 e 40 mg/Kg de PEA durante 10 dias induziu um aumento de 7,4 e 15,5\% na proporção de linfócitos, ao mesmo tempo em que reduziu 40 e 56,8\%, respectivamente, a proporção de monócitos em relação ao grupo não tratado. Nesse mesmo período de tratamento, a maior dose de PEA $(40 \mathrm{mg} / \mathrm{Kg})$ também provocou redução de $67,6 \%$ na porcentagem de neutrófilos do sangue desses animais em relação ao grupo não tratado (Figura 13A). 
O tratamento diário com PEA por período mais extenso (20 dias) não alterou a proporção relativa de neutrófilos. As maiores doses de PEA (5 e $10 \mathrm{mg} / \mathrm{mL})$, assim como PEAc, induziram um aumento no número de monócitos, de 88, 76 e 94\%, respectivamente, em relação ao grupo sem tratamento (Figura 13B). A PEAc reduziu cerca de $10 \%$ a proporção de linfócitos após 20 dias de tratamento. Não houve alteração na proporção relativa de eosinófilos em nenhum dos grupos experimentais, independentemente dos períodos de tratamento (Figuras $11 \mathrm{~A}$ e B). 
A

\section{0 dias}

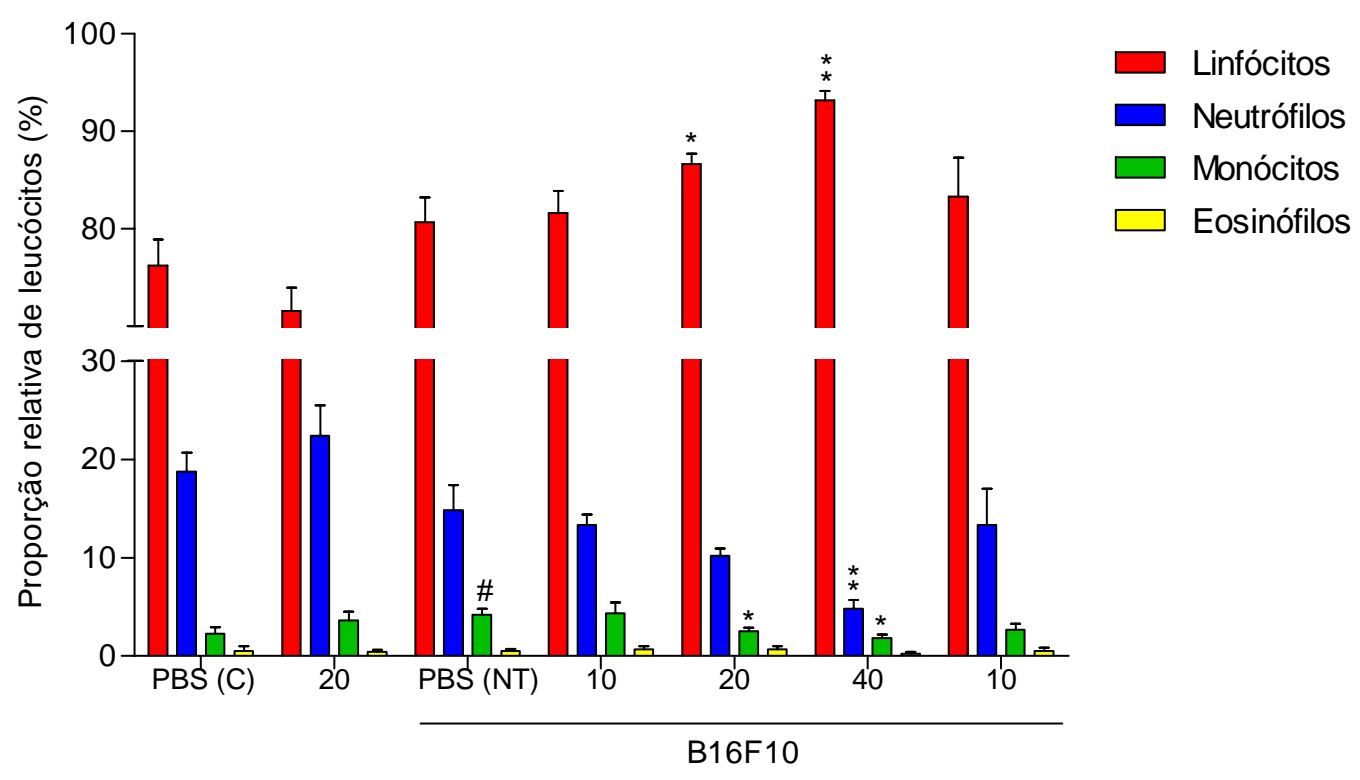

B

20 dias

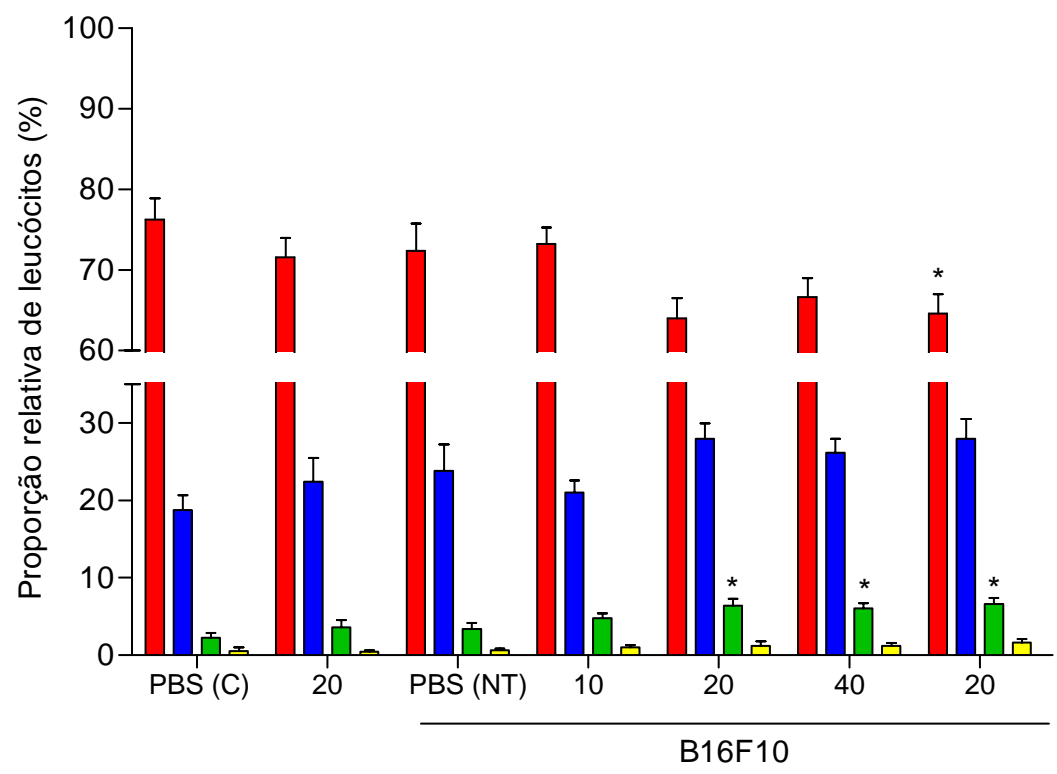

Figura 13. Proporção relativa de leucócitos do sangue de animais inoculados com células B16F10 e tratados com fosfoetanolamina sintética. Contagem diferencial de leucócitos de animais tratados com diferentes doses de PEA $(10,20$ e $40 \mathrm{mg} / \mathrm{Kg})$, PEA comercial $(20 \mathrm{mg} / \mathrm{Kg})$ ou PBS durante um período de 10 (A) e 20 (B) dias. Os resultados foram expressos como Média + EPM. Amostra não paramétrica, teste estatístico Mann-Whitney. Sendo, C: controle e NT: não tratado. (\#em relação ao controle: "PBS + PBS"; *em relação ao grupo não tratado: "tumor + PBS"). \#p $<0,04 ; * \mathrm{p}<0,04 ; * * \mathrm{p}$ $<0,008$. 


\section{Análise de citocinas in vitro}

Os efeitos da PEAc sobre produção de citocinas pelas células tumorais B16F10 também foram avaliados in vitro. Não foram observadas diferenças na produção de IL-6 e TGF- $\beta$ após 24 e 48 horas de estimulação com o fosfomonoéster (dados não mostrados). Todavia, após 72 horas, a incubação com a maior concentração de PEAc $(10 \mathrm{mg} / \mathrm{mL})$ resultou em níveis 86 e 71\% menores das citocinas IL-6 e TGB- $\beta$, respectivamente (Figura 14A e C). Redução de aproximadamente 59\% na produção de IL-6 também foi verificada após tratamento das células com $5 \mathrm{mg} / \mathrm{mL}$ de PEAc (Figura 14A). As citocinas TNF- $\alpha$ e IL-10 não foram detectadas no sobrenadante das células B16F10 estimuladas ou não com PEAc (dados não mostrados).

A

IL-6

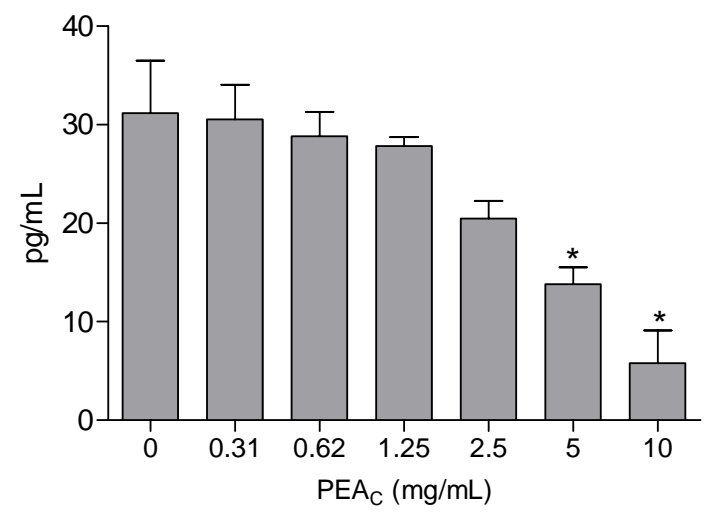

B

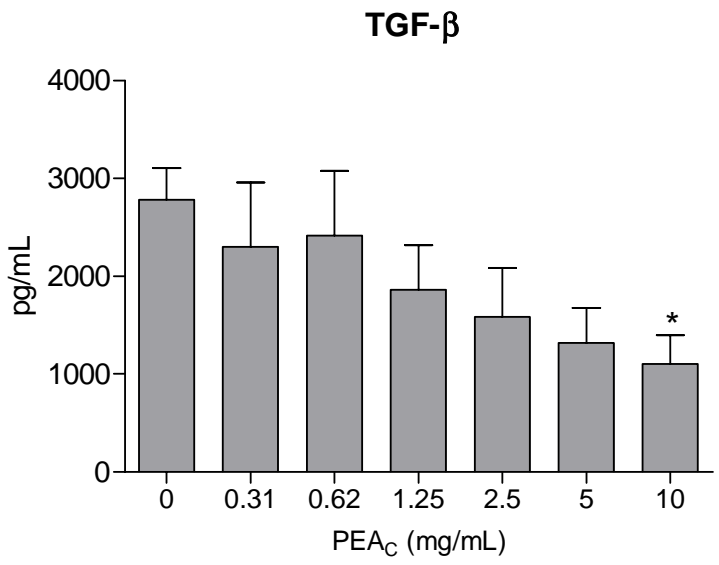

Figura 14. Determinação da produção de citocinas por células de melanoma B16F10 estimuladas com PEAc. Células B16F10 foram estimuladas com concentrações crescentes de PEAc por 72 horas e as concentrações de IL-6 e TGF- $\beta$ no sobrenadante celular determinadas por ELISA. Os resultados são expressos como Média \pm EPM. Amostras não paramétricas, teste estatístico Mann-Whitney. *p < 0,03 . 


\section{Análise de citocinas in vivo}

\subsection{Citocinas pró-inflamatórias}

Conforme observado na Figura 15, os níveis das citocinas pró-inflamatórias IL-12, TNF- $\alpha$ e IL-17 não foram alterados em nenhum dos grupos experimentais, diferentemente da produção de IFN- $\gamma$, IL-1 $\beta$ e IL-6. Animais não tratados apresentaram uma produção de IFN- $\gamma$ cerca de $85 \%$ maior quando comparados ao controle (Figura 15A). O oposto ocorreu com os grupos submetidos ao tratamento com 20 e $40 \mathrm{mg} / \mathrm{Kg}$ de PEA e $20 \mathrm{mg} / \mathrm{Kg}$ da fosfoetanolamina comercial (PEAc), os quais tiveram uma diminuição de aproximadamente 44 a 54\% nos níveis de IFN- $\gamma$ (Figura 15C) em relação aos animais não tratados.

O tratamento com 10 e $20 \mathrm{mg} / \mathrm{Kg}$ de PEA também induziu uma produção da citocina IL-6 cerca de 2 vezes maior em relação aos grupos de camundongos não tratados (Figura 15C). Níveis da citocina IL-1 $\beta$ foram alterados apenas no grupo experimental que recebeu PEA somente $(20 \mathrm{mg} / \mathrm{Kg})$, havendo, neste caso, uma diminuição de $43 \%$ em relação ao controle (Figura 15B). 
A

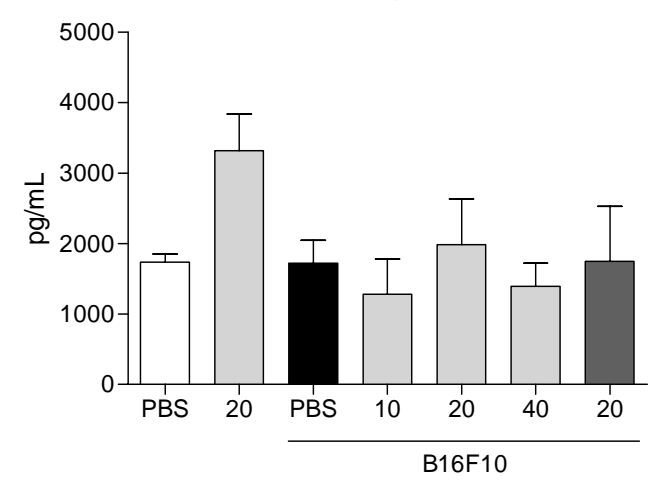

C

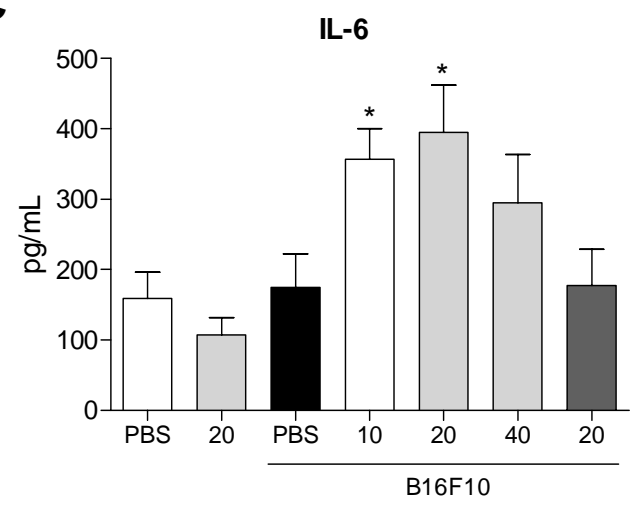

E

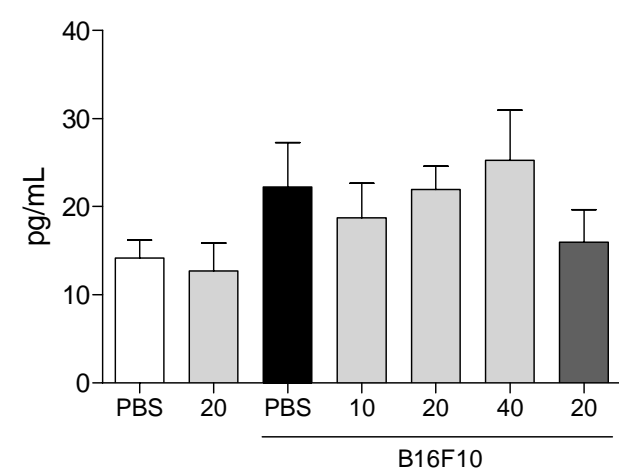

B

IL-1 $\beta$

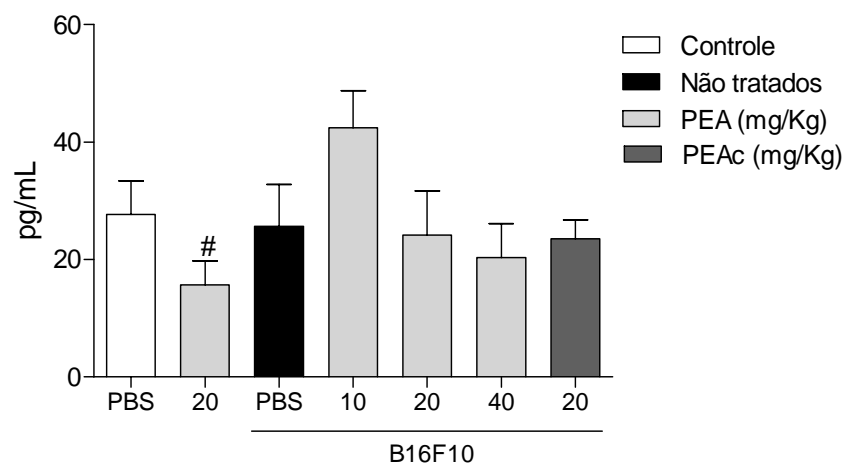

D IFN- $\gamma$

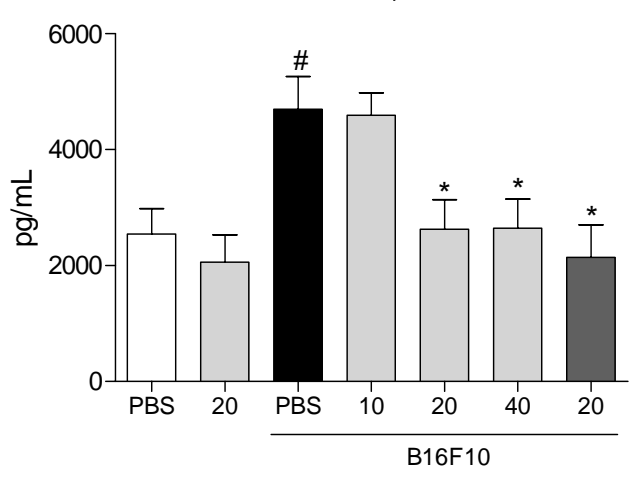

$\mathbf{F}$

IL-17

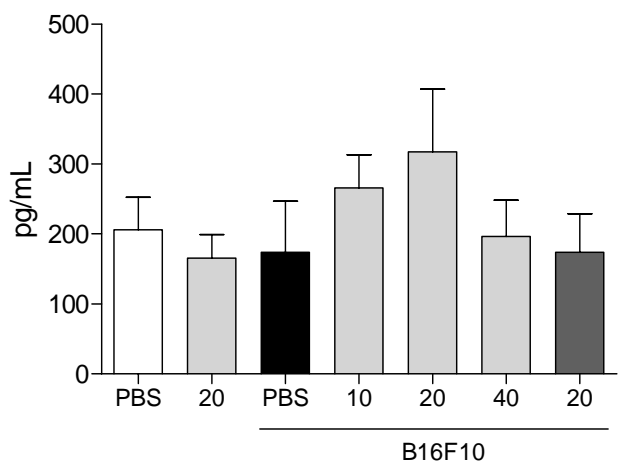

Figura 15. Determinação da produção de citocinas pró-inflamatórias por células do baço dos animais experimentais. Os baços foram removidos assepticamente e debridados, sendo as células plaqueadas $\left(2 \times 10^{6}\right.$ céls/poço), estimuladas com Con A $(5 \mu \mathrm{g} / \mathrm{mL})$ por $48 \mathrm{~h}$ e a concentração de IL-12p70, IL-1 $\beta$, TNF, IL-6, IFN- $\gamma$ e IL-17 no sobrenadante das células de cada animal determinada por ELISA. Os resultados são expressos como Média \pm EPM. Amostras não paramétricas, teste estatístico Mann-Whitney (\#em relação ao controle: "PBS + PBS"; *em relação ao grupo não tratado: "tumor + PBS"). *p $<0,01 ; * * p<0,006 ; * * \mathrm{p}<0,0002$. 


\subsection{Citocinas anti-inflamatórias}

Como ilustrado na Figura 16, a formação do tumor, na ausência de tratamento, levou a uma diminuição de $32 \%$ nos níveis da citocina TGF- $\beta$. Em relação ao tratamento, todas as doses da fosfoetanolamina $(10,20$ e $40 \mathrm{mg} / \mathrm{Kg}$ de PEA e $20 \mathrm{mg} / \mathrm{Kg}$ de PEAc) utilizadas induziram aumento (de 30 a 63\%) na produção desta citocina em relação aos animais não tratados, sendo os maiores níveis detectados nos animais que receberam a dose intermediária (20 mg/Kg) de PEA (Figura 16A). No que concerne à produção de IL-10, somente o tratamento com a menor dose de PEA $(10 \mathrm{mg} / \mathrm{Kg})$ alterou a produção dessa citocina, levando a um aumento de aproximadamente 7 vezes em relação ao grupo de animais controle (Figura 16B).

A

TGF- $\beta$

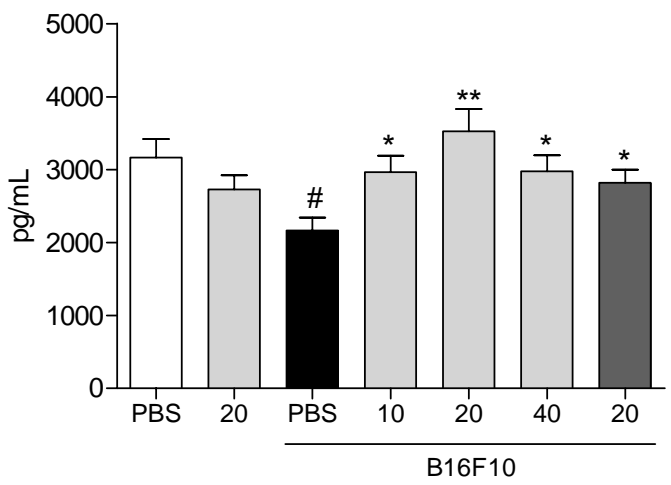

B

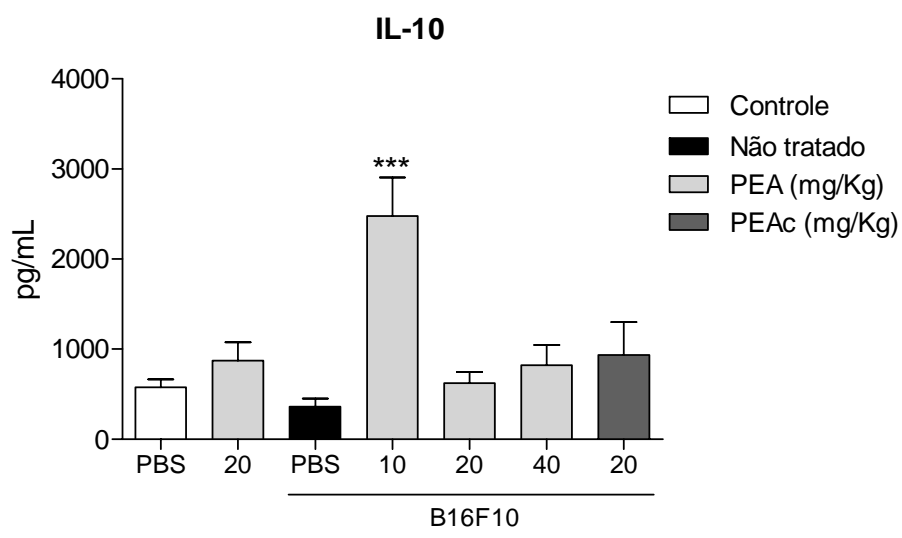

Figura 16. Determinação da produção de citocinas anti-inflamatórias por células do baço dos animais experimentais. Os baços foram removidos assepticamente e debridados, sendo as células plaqueadas $\left(2 \times 10^{6}\right.$ céls/poço), estimuladas com Con A $(5 \mu \mathrm{g} / \mathrm{mL})$ por $48 \mathrm{~h}$ e a concentração de IL-10 e TGF- $\beta$ no sobrenadante das células de cada animal determinada por ELISA. Os resultados são expressos como Média \pm EPM. Amostras não paramétricas, teste estatístico Mann-Whitney (\#em relação ao controle: "PBS + PBS"; *em relação ao grupo não tratado: "tumor + PBS"). *p < 0,01; **p $<0,005 ; * * * \mathrm{p}<0,0007$. 


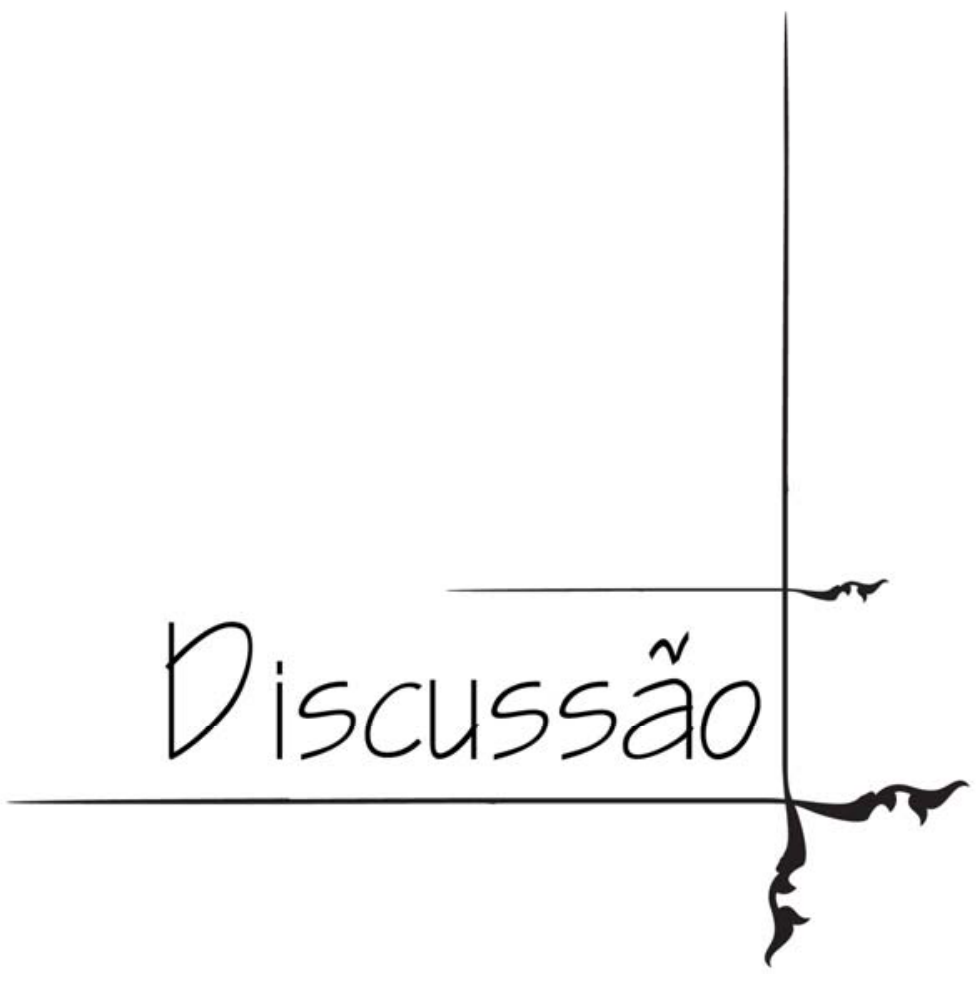




\section{DISCUSSÃO}

O elevado grau de malignidade, a crescente incidência e resistência às terapias convencionais (Ilkovitch \& Lopez, 2008; Nakayama, 2010), tem motivado a comunidade científica a buscar o desenvolvimento de novas abordagens e estratégias terapêuticas para o melanoma, o tipo de câncer de pele mais fatal. No presente trabalho, utilizamos modelo de melanoma murino experimental para estudarmos os efeitos da fosfoetanolamina (PEA) sintética sobre o desenvolvimento do melanoma. Nossos resultados in vitro demonstraram que PEA tem efeito inibitório direto sobre a viabilidade de células tumorais e que, por outro lado, afeta a viabilidade de células não tumorais de maneira menos intensa. A redução da viabilidade de células B16F10 está associada à apoptose destas células induzida por PEA. O tratamento de animais portadores de melanoma com a fosfoetanolamina resultou em redução expressiva do volume tumoral, associada a aumento de apoptose e concomitante diminuição da proliferação de células tumorais. Fosfoetanolamina induziu alterações hematológicas e interferiu sobre a produção sistêmica de citocinas por animais com melanoma. Níveis mais elevados das citocinas anti-inflamatórias IL-10 e TGF- $\beta$ e da citocina pró-inflamatória IL-6 foram detectados após o tratamento, enquanto uma menor produção de IFN- $\gamma$ foi observada.

In vitro, demonstramos redução da viabilidade de células tumorais B16F10, HT-29 e MCF-7 estimuladas com PEA, embora variações específicas para cada linhagem tenham sido verificadas. Células normais (macrófagos RAW 264.7), por sua vez, apresentaram-se menos sensíveis a estimulação com PEA. Em adição, observamos que redução da viabilidade ocorreu em função da indução de morte celular por apoptose de porcentagem significativa das células tumorais. Contudo, PEA não interferiu sobre o ciclo destas células. Estudo recente (Yao et al., 2009) demonstrou que fosfatidiletanolamina (PE), componente derivado da fosfoetanolamina, levou à diminuição do potencial de membrana mitocondrial e induziu a apoptose de células HepG2 de hepatoma humano. Em nosso trabalho, é plausível que a PEA possa ser utilizada para a síntese de PE, culminando na apoptose das células de melanoma da mesma forma como ocorre com as HepG2. A citotoxicidade apresentada por PEA é potencialmente seletiva a células cancerígenas, como demonstrado por nosso trabalho e por estudo em que a adição de outra formulação do fosfomonoéster à cultura de células normais (fibroblastos humanos) não induziu citotoxicidade e nenhuma alteração morfológica e reduziu a viabilidade de células B16F10 (Meneguelo, 2007; Ferreira et al., 2011). Tal seletividade também foi relatada para os ALPs (Mollinedo, 2007). 
Sabe-se que as células tumorais têm a capacidade de evadir a vigilância imunológica e manipular as células imunes através da produção de fatores imuno-moduladores, como citocinas e quimiocinas, criando um microambiente supressor de respostas imunológicas (Ilkovitch \& Lopez, 2008). Em nosso estudo, ao investigarmos os efeitos de fosfoetanolamina sobre a produção de citocinas pelas células B16F10 in vitro, observamos que a molécula inibiu, de maneira direta, a produção de TGF- $\beta$ e IL-6. Tal diminuição pode, em parte, ser devido à indução da morte de parte das células, também verificada em nossos ensaios. No entanto, ela foi ainda mais acentuada em relação à proporção de células mortas. IL-6 e TGF$\beta$, por suprimirem respostas imunológicas e/ou estimularem a angiogênese e a proliferação de células transformadas, são consideradas citocinas tipicamente pró-tumorais (Yue et al., 1997; Yan et al., 2002; Sethi et al., 2012). Portanto, a menor produção de IL-6 e TGF- $\beta$ em resposta à estimulação com PEA pode contribuir, pelo menos em parte, para a formação de um microambiente adequado à ativação de respostas imunes anti-tumorais.

In vivo, o tratamento com PEA induziu diferenças tumorais macroscópicas consideráveis, incluindo uma redução expressiva do volume tumoral. De maneira dosedependente, o fosfomonoéster também induziu aumento da apoptose e diminuição da proliferação de células da massa tumoral, evidenciando assim, um papel inibidor da progressão tumoral exercido por PEA. Alterações hematológicas referentes ao número de eritrócitos, leucócitos e plaquetas do sangue de animais que receberam o fosfomonoéster diariamente também foram verificadas.

Proporcionalmente ao número total de leucócitos, verificamos que a porcentagem de linfócitos do sangue de animais tratados com PEA durante 10 dias consecutivos foi aumentada em até $15 \%$. Os linfócitos T são considerados atualmente o principal mecanismo de imunidade a tumores (Mantovani et al., 2008) e, em virtude de tal habilidade, muitas das novas estratégias imunoterapêuticas de combate a tumores são baseadas na expansão do número de linfócitos, principalmente daqueles específicos aos tumores (Koebel et al., 2007; Russ et al., 2011). O processo carcinogênico usualmente resulta na inibição da proliferação de linfócitos T. De fato, como demonstrado por Russ e colaboradores (2011), na presença de melanoma $\mathrm{B} 16 \mathrm{~F} 10$, camundongos $\mathrm{C} 57 \mathrm{BL} / 6$ apresentaram uma supressão da expansão proliferativa de linfócitos $\mathrm{T}$ de forma global, independente da sua reatividade ao tumor.

Maiores níveis das citocinas anti-inflamatórias IL-10 e TGF- $\beta$ produzidas por células do baço de animais com tumores submetidos ao tratamento com PEA também foram verificados. Embora a produção elevada de TGF- $\beta$ sugira uma resposta promotora de tumor devido à inibição do sistema imune, principalmente de células T (Byrne et al., 2008), 
evidências crescentes sugerem que uma resposta Th17, induzida pela combinação de TGF- $\beta$ com a IL-6 (Wang et al.,2009), seria capaz de regular a progressão tumoral (Benchetrit et al., 2002; Martin-Orozco et al., 2009), inclusive em modelos de melanoma murino (Muranski, et al.; 2008). Hirahara e colaboradores (2001) demonstraram que células de fibrosarcoma MethA transfectadas com o gene para IL-17, através do aumento da expressão de moléculas classe I e II do MHC, foram capazes de induzir imunidade tumor-específica. Em outro trabalho, camundongos deficientes em IL-17 exibiram acelerado crescimento tumoral e metástases pulmonares (Kryczek et al., 2009). Nesse sentido e tendo em vista indícios de uma atividade antitumoral (indução de apoptose e menor progressão tumoral) da fosfoetanolamina, avaliamos se assim como os níveis de TGF- $\beta$, ela também induziria maior produção de IL-6, o que poderia sugerir uma possível participação de células Th17 em nosso modelo. No presente trabalho, verificamos uma maior produção de IL-6 nos mesmos grupos experimentais em que elevados níveis de TGF- $\beta$ foram induzidos. Entretanto, não houve diferença estatística na produção de IL-17 pelos diferentes grupos de animais. Possivelmente, dispondo de um maior tamanho amostral, tais diferenças seriam detectadas, uma vez que o perfil da produção de IL-17 pelos grupos experimentais foi semelhante aos de TGF- $\beta$ e IL-6, fato que indica fortemente uma resposta mediada por células Th17.

Contrariamente ao que foi observado em relação à produção de citocinas antiinflamatórias, os níveis de IFN- $\gamma$ apresentaram-se diminuídos em resposta ao tratamento com PEA. Embora também possa derivar de outros tipos celulares, tais como células T CD8+, T $\gamma \delta$, NKT e NK, essa é a citocina de assinatura produzida por células Th1 (Martin-Foncheca et al., 2004; Li et al., 2007) cujas funções principais incluem a ativação de respostas imunes inata e adaptativa (Ikeda et al., 2002) e a coordenação de respostas anti-tumorais (Alshaker \& Matalka, 2011). Contrariando o pensamento de que altos níveis de IFN- $\gamma$ tenham função antitumoral, estudos têm demonstrado que essa citocina pode promover a evasão do tumor ao sistema imunológico (He et al., 2005), o que, em nosso trabalho, seria concernente. 


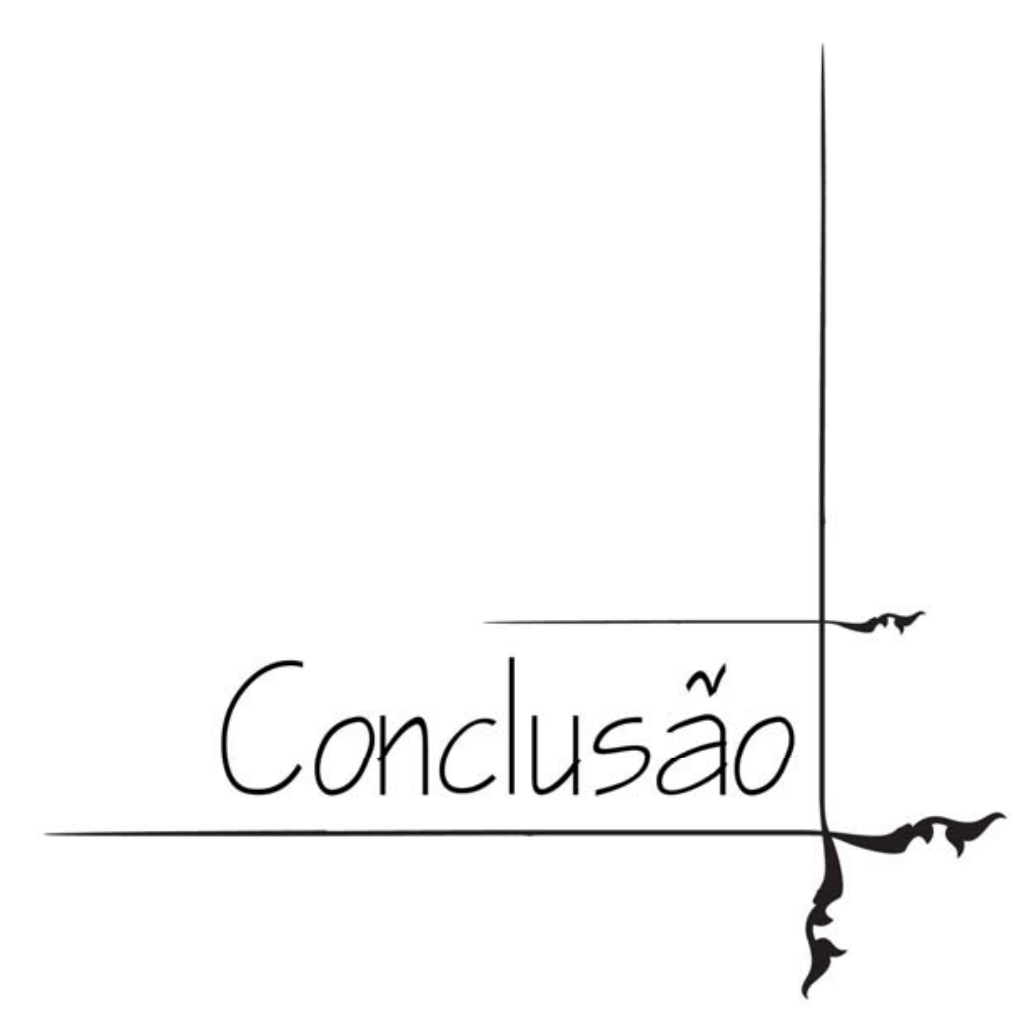




\section{CONCLUSÃO}

O conjunto dos nossos resultados obtidos até o presente reflete um papel promissor da fosfoetanolamina no tratamento de tumores de melanoma $\mathrm{B} 16 \mathrm{~F} 10$, visto que tanto in vitro, quanto in vivo, encontramos evidências de que a mesma iniba a proliferação/crescimento tumoral. Embora essa molécula possa atuar diretamente sobre as células tumorais, outros mecanismos possivelmente estão envolvidos no controle da progressão carcinogênica, tais como a ativação de respostas imunes anti-tumorais. A identificação dos mediadores químicos produzidos no microambiente tumoral, assim como do fenótipo das células imunes infiltrantes do tumor, poderá contribuir ao entendimento dos mecanismos envolvidos na atividade antitumoral de PEA. 


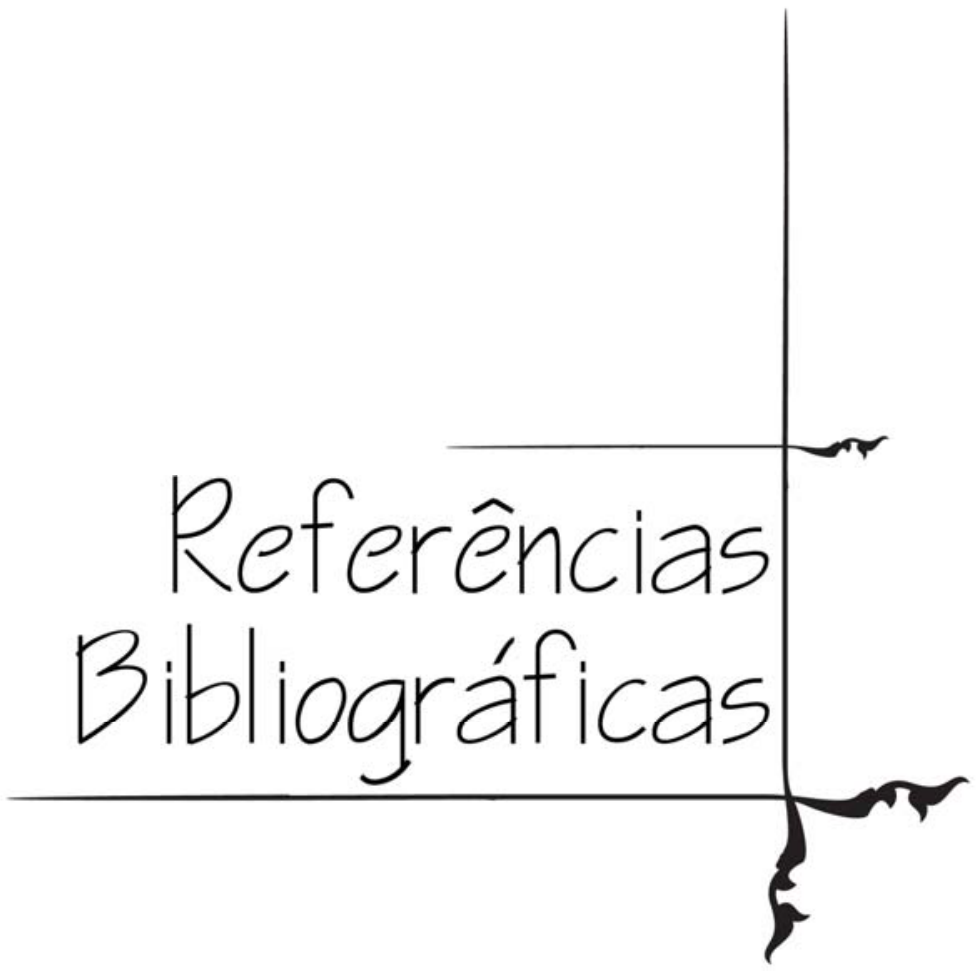




\section{REFERÊNCIAS BIBLIOGRÁFICAS}

Alderliesten, M.C.; Klarenbeek, J. B.; van der Luit, A. H.; van Lummel, M.; Jones, D. R.; Zerp, S. et al. Phosphoinositide phosphatase SHIP-1 regulates apoptosis induced by edelfosine, Fas ligation and DNA damage in mouse lymphoma cells. Biochem J., 440(1):12735. $-202,2011$.

Alb, M.; Sie, C.; Adam, C.; Chen, S.; Becker, J., C.; Schrama, D. Cellular and cytokinedependent immunosuppressive mechanisms of grm1-transgenic murine melanoma. Cancer Immunol Immunother, 2012.

Algarra I, Cabrera T, Garrido F. The HLA crossroad in tumor immunology. Hum Immunol.61(1):65-73, 2000.

Alshaker, H. A.; Matalka, K. Z.; IFN- $\gamma$, IL-17 and TGF- $\beta$ involvement in shaping the tumor microenvironment: the significance of modulating such cytokines in treating malignant solid tumors. Cancer Cell International, 11: 33, 2011.

Andersen MH, Keikavoussi P, Bröcker EB, Schuler-Thurner B, Jonassen M, Søndergaard I, Straten PT, Becker JC, Kämpgen E. Induction of systemic CTL responses in melanoma patients by dendritic cell vaccination: cessation of CTL responses is associated with disease progression. Int J Cancer. 94(6):820-4, 2001.

Bakovic, M.; Fullerton M.D.; Michel, V. Metabolic and molecular aspects of ethanolamine phospholipid biosynthesis: the role of CTP: phosphoethanolamine cytidyltransferase (Pcyt2). Biochem. Cell Biol., 85: 283-200, 2007.

Balasubramanian, K. Mirnikjoo, B.; Schroit, A.J.; Regulated externalizationof phosphatidylserine at the cell surface: implications for apoptosis. J. Biol. Chem., 282: 1835718364, 2007.

Becker JC, Brabletz T, Czerny C, Termeer C, Bröcker EB Tumor escape mechanisms from immunosurveillance: induction of unresponsiveness in a specific MHC-restricted CD4+ human $\mathrm{T}$ cell clone by the autologous MHC class II+ melanoma. Int Immunol. 5(12):1501-8, 1993.

Benchetrit, F.; Ciree, A; Vives, V.; Warnier, G.; Gey, A.; Sautes-Fridman, C.; Fossiez, F.; Haicheur, N.; Fridman, W. H.; Tartour, E. Interleukin-17 inhibits tumor cell growth by means of a T-cell-dependent mechanism. Blood, 114: 357-359, 2009. 
Biassoni R, Coligan JE, Moretta L. Natural killer cells in healthy and diseased subjects. $J$ Biomed Biotechnol. 2011.

Biswas, S. K.; Sica, A.; Lewis, C. E. Plasticity of macrophage function during tumor progression: regulation by distinct molecular mechanisms. J. Immunol., 180: 2011-2017, 2008.

Borisenko, G.G.; Matsura, T.; Liu, S.X.; Tyurin, V.A.; Jianfei, J.; Serinkan, F.B.; Kagan, V.E. Macrophage recognition of externalized phosphatidylserine and phagocytosis of apoptotic Jurkat cells - existence of a threshold. Arch. Biochem. Biophys., 413: 41-52, 2003.

Brocker, E.B.; Zwadlo, G.; Holzmann, B.; Macher, E; Sorg, C. Inflammatory cell infiltrates in human melanoma at different stages of tumor progression. Int. J. Cancer, 41: $562-7,1988$.

Brouckaert, G.; Kalai, M.; Krysko, D.V.; Saelens, X.; Vercammen, D.; Ndlovu, M.; Haegeman, G.; D'Herde, K.; Vandenabeele, P. Phagocytosis of necrotic cells by macrophages is phosphatidylserine dependent and does not induce inflammatory cytokine production. Mol. Biol. Cell, 15: 1089-1100, 2004.

Burnet, F.M. Cancer - A Biological Approach: I. The Processes Of Control. II. The Significance of Somatic Mutation. Brit. Med. Jour. 1 (5022): 779-786, 1957.

Burnet, F.M. The concept of immunological surveillance. Prog Exp Tumor Res. 13:1-27, 1970.

Burnet, F.M. Immunological surveillance in neoplasia. Transplant Rev. 7:3-25, 1971.

Byrne, S. N.; Knox, M. C.; Halliday, G. M. TGFbeta is responsible for skin tumour infiltration by macrophages enabling the tumours to scape immune destruction. Immunol. Cell Biol., 86: 92-97, 2008.

Chudnovsky, Y.; Khavari, P.A.; Adams, A.E. Melanoma genetics and the development of rational therapeutics. J. Clin. Invest, 115(4): 813-824, 2005.

Corthay A, Skovseth DK, Lundin KU et al. Primary antitumor immune response mediated by CD4+ T cells. Immunity 22: 371-383, 2005.

Coussens, L.M.; Werb, Z. Inflammation and cancer. Nature, 420: 860-867, 2002. 
Czene, K.; Lichtenstein, P.; Hemminki, K. Environmental and heritable causes of cancer among 9.6 million individuals in the swedish family-cancer database. Int. J. Cancer, 99: 260266, 2002.

Danial, NN; Korsmeye, SJ. Cell death: critical control points. Cell, 116: 205-219, 2004.

Dinarello, C.A. Proinflammatory cytokines. Chest. 118(2):503-8, 2000.

Dobrosotskaya, I.Y.; Seegmiller, A.C.; Brown, M.S.; Goldstein, J.L.; Rawson, R.B. Regulation of SREBP processing and membrane lipid production by phospholipids in Drosophila. Science, 296: 879-883, 2002.

Du JW, Xu KY, Fang LY, Qi XL. Interleukin-17, produced by lymphocytes, promotes tumor growth and angiogenesis in a mouse model of breast cancer. Mol Med Report. 6(5):1099-102, 2012 .

Dummer W, Becker JC, Schwaaf A, Leverkus M, Moll T, Brocker EB. Elevated serum levels of interleukin-10 in patients with metastatic malignant melanoma. Melanoma Res, 5:67-68, 1995.

Dunn, G.P.; Old, L.J.; Schreiber, R.D. The Three Es of Cancer Immunoediting. Annual Review of Immunology 22: 329-360, 2004.

Dunn GP, Bruce AT, Sheehan KC, Shankaran V, Uppaluri R, Bui JD, Diamond MS, Koebel CM, Arthur C, White JM, Schreiber RD. A critical function for type I interferons in cancer immunoediting. Nat Immunol, 6(7):722-9, 2005.

Ferreira AK, Meneguelo R, Claro Neto S, Chierice GO, Maria DA. Synthetic phosphoethanolamine induces apoptosis through caspase-3 pathway by decreasing expression of Bax/Bad protein and changes cell cycle in melanoma. J. Cancer Sci. Ther. 3(3): 053-059, 2011.

Ferreira AK, Meneguelo R, Marques FL, Radin A, Filho OM, Neto SC, Chierice, GO, Maria DA.

Synthetic phosphoethanolamine a precursor of membrane phospholipids reduce tumor growth in mice bearing melanoma B16-F10 and in vitro induce apoptosis and arrest in G2/M phase. Biomed Pharmacother. 2012.

Fesik, SW. Promoting apoptosis as a strategy for cancer drug discovery. Nat Rev Cancer, 5: $053-059,2011$. 
Finn AV, Saeed O, Virmani R. Circ Res. Macrophage subsets in human atherosclerosis. 110(9):e64, 2012.

Fossiez F, Djossou O, Chomarat P, Flores-Romo L, Ait-Yahia S, Maat C, Pin JJ, Garrone P, Garcia E, Saeland S, Blanchard D, Gaillard C, Das Mahapatra B,Rouvier E, Golstein $\mathrm{P}$, Banchereau J, Lebecque S. T cell interleukin-17 induces stromal cells to produce proinflammatory and hematopoietic cytokines. J Exp Med. 183(6):2593-603, 1996.

Fujiwara K, Higashi T, Nouso K, Nakatsukasa H, Kobayashi Y, Uemura M, Nakamura S, Sato S, Hanafusa T, Yumoto Y, Naito I, Shiratori Y. Decreased expression of B7 costimulatory molecules and major histocompatibility complex class-I in human hepatocellular carcinoma. J Gastroenterol Hepatol. 19(10):1121-7, 2004.

Gajate, C.; Matos-da-Silva, M.; Dakir, E.L.; Fonteriz, R. I.; Alvarez, J.; Mollinedo, F. Antitumor alkyl-lysophospholipid analog edelfosine induces apoptosis in pancreatic cancer by targeting endoplasmic reticulum. Oncogene 2011.

Ghobrial IM, Witzig TE, Adjei, AA. Targeting apoptosis pathways in câncer therapy. CA Cancer J Clin, 55: 178-194, 2005.

Gout, S.; Hout, J. Role of cancer microenvironment in metastasis: Focus on colon cancer. Cancer Microenvironment, 1: 69-83, 2008.

Grivennikov, S.I.; Greten, F.R.; Karin, M. Immunity, inflammation, and cancer. Cell, 140: 883-899, 2010.

Hagemann, T.; Wilson, J.; Kulbe, H.; Li, N.F.; Leinster, D.A.; Charles, K.; Klemm, F.; Pukrop, T.; Binder, C.; Balkwill, F.R. Macrophages induce invasiveness of epithelial cancer cells via NF- $\kappa$ B and JNK. J. Immunol., 175, 1197-1205, 2005.

Hanahan, D.; Weinberg, R.A. The hallmarks of cancer. Cell, 100: 57-70, 2000.

Hao, N. B.; Lu, M. H.; Fan, Y. H.; Cao, Y. L.; Zhank, Z. R.; Yang, S. M. Machophages in tumor microenvironments and the progression of tumors. Clin. Dev. Immunol., 2012.

Harrington LE, Mangan PR, Weaver CT. Expanding the effector CD4 T-cell repertoire: the Th17 lineage. Curr Opin Immunol. 18(3):349-56, 2006.

He Y, Wang X, Zhang G, Chen H, Zhang H, Feng Z. Sustained low-level expression of interferon- $\gamma$ promotes tumor development: potential insights in tumor prevention and tumor immunotherapy. Cancer Immunol. Immunother. 54: 891-897, 2005. 
Hirahara, N.; Nio, Y; Sasaki, S.; Minari, Y.; Takamura, M.; Iguchi, C.; Dong, M.; Yamasawa, K.; Tamura, K. Inoculation of human interleukin-17 gene-transfected Meth-A fibrosarcoma cells induces T cell-dependent tumor-specific immunity in mice. Oncology, 61:79 - 89, 2001.

Hold, G.L.; El-Omar, E.M. Genetic aspects of inflammation and cancer. Biochem. J., 410: 225-235, 2008.

Horibata, Y.; Hirabayashi, Y. Identification and characterization of human ethanolamine phosphotransferase 1. J. Lipid. Res., 48: 503-508, 2006.

Houghton AN. Cancer antigens: immune recognition of self and altered self. $J$ Exp Med. 180(1):1-4, 1994.

Ikeda, H.; Old, L. J.; Schreiber, R. D. The roles of IFN gamma in protection against tumor development and cancer immunoediting. Cytokine Growth Factor Rev., 13 (2): 95-109, 2002.

Ilkovitch, D.; Lopez, D.M. Immune modulation by melanoma-derived factors. Exp. Dermatol., 17: 977-985, 2008.

Instituto Nacional do Câncer; Ministério da Saúde. Estimativas da incidência e mortalidade por câncer no Brasil. Disponível em: http://www.inca.gov.br. Acesso em: 01 out. 2012.

Ivanović V, Demajo M, Krtolica K, Krajnović M, Konstantinović M, Baltić V, Prtenjak G, Stojiljković B, Breberina M, Nesković-Konstantinović $\quad$ Z, Nikolić-Vukosavljević D, Dimitrijević B. Elevated plasma TGF-beta1 levels correlate with decreased survival of metastatic breast cancer patients. Clin Chim Acta. 371(1-2):191-3, 2006.

Jilaveanu, L.B.; Aziz, S.A.; Kluger, H.M. Chemotherapy and biologic therapies for melanoma: do they work? Clin. Dermatol., 27(6): 614-25, 2009.

Jovanovic DV, Di Battista JA, Martel-Pelletier J, Jolicoeur FC, He Y, Zhang M, Mineau F, Pelletier JP.IL-17 stimulates the production and expression of proinflammatory cytokines, IL-beta and TNF-alpha, by human macrophages. J Immunol. 160(7):3513-21, 1998.

Kim, R.; Emi, M.; Tanabe, K. Cancer immunoediting from immune surveillance to immune escape. Journal of Immunology 121 (1): 1-14, 2007.

Koebel CM, W. Vermi, J.B. Swann, et al., Adaptive immunity maintains occult cancer in an equilibrium state, Nature 450: 903-907, 2007. 
Krasagakis K, Thölke D, Farthmann B, Eberle J, Mansmann U, Orfanos CE. Elevated plasma levels of transforming growth factor (TGF)-beta1 and TGF-beta2 in patients with disseminated malignant melanoma. Br J Cancer. 77(9):1492-4, 1998.

Krueger, A.; Baumann, S.; Krammer, P.H.; Kirchhoff, S. FLICE-Inhibitory proteins: Regulators of death receptor-mediated apoptosis. Mol. Cell Biol., 21: 8247-8254, 2001.

Kryczek I, Banerjee M, Cheng P, Vatan L, Szeliga W, et al. (2009) Phenotype, distribution, generation, and functional and clinical relevance of Th17 cells in the human tumor environments. Blood, 114: 1141-1149, 2009.

Kusmartsev, S.; Gabrilovich, D. I. STAT1 signaling regulates tumor-associated macrophagemediated T cell deletion. J. Immunol., 174: 4880-4891, 2005.

Lanier LL. Activating and inhibitory NK cell receptors. Adv Exp Med Biol. 452:13-8, 1998.

Lee, W. S.; Baek, J. H; You, D. H.; Nam, M. J. Prognostic value of circulating cytokines for stage III colon cancer. J. Surg. Res., 2012.

Li, Z.; Pradera, F.; Kammertoens, T.; Li, B.; Liu, S.; Qin, Z. Cross-talk between T cells and innate immune cells is crucial for IFN- $\gamma$-dependent tumor rejection. J. Immunol. 179: 15681576, 2007.

Lin, W.W.; Karin, M. A cytokine-mediated link between innate immunity, inflammation, and cancer. J. Clin. Invest., 117: 1175-1183, 2007.

Liu VC, Wong LY, Jang T, Shah AH, Park I, Yang X, Zhang Q, Lonning S, Teicher BA, Lee C. Tumor evasion of the immune system by converting CD4+CD25-T cells into CD4+CD25+ Tregulatory cells: role of tumor-derived TGF-beta. J Immunol. 178(5):2883-92, 2007.

Long EO. Regulation of immune responses by inhibitory receptors. Adv Exp Med Biol. 452:19-28, 1998.

Lorusso, G.; Ruegg, C. The tumor microenvironment and its contribution to tumor evolution toward metastasis. Histochem. Cell Biol., 130: 1091-1103, 2008.

Luo, J.L., Maeda, S., Hsu, L.C., Yagita, H., and Karin, M. Inhibition of NF-kB in cancer cells converts inflammation-induced tumor growth mediated by TNF- $\alpha$ to TRAIL-mediated tumor regression. Cancer Cell. 6:297-305, 2004. 
Lykidis, A.; Wang, J.; Karim, M.A.; Jackowski, S. Over-expression of a mammalian ethanolamine-specific kinase accelerates the CDP-ethanolamine pathway. J. Biol. Chem., 276: 2174-2179, 2001.

Mantovani A.; Bottazzi, B.; Colotta, F.; Sozzani, S.; Ruco, L. The origin and function of tumor-associated macrophages. Immunol. Today, 13: 265-270, 1992.

Mantovani,A.; Allavena, P.; Sica, A.; Balkwill, F. Cancer-related inflammation. Nature, 454: 436-444, 2008.

Mantovani, A.; Sica, A.; Allavena, P.; Garlanda, C.; Locati, M. Tumor-associated macrophages and the related myeloid-derived suppressor cells as a paradigm of the diversity of macrophage activation. Hum Immunol. 70, 325-30, 2009.

Martin-Foncheca, A.; Thomsen, L. L.; Brett, S.; Gerard, C.; Lipp, M.; Lanzavecchia, A.; Sallusto, F. Induced recruitment of NK cells to lymph nodes provides IFN-gamma for $\mathrm{T}(\mathrm{H}) 1$ priming. Nat. Immunol., 5: 1260-1265, 2004.

Martin-Orozco N, Muranski P, Chung Y, Yang XO, Yamazaki T, et al. T helper 17 cells promote cytotoxic T cell activation in tumor immunity. Immunity 31: 787-798, 2009.

Matte I, Lane D, Laplante C, Rancourt C, Piché A. Profiling of cytokines in human epithelial ovarian cancer ascites. Am J Cancer Res. 2(5):566-80, 2012.

Meister, A. Biochemistry of the amino acids. Academic, New York, 1: 111, 1965.

Meneguelo, R. Efeitos antiproliferativos e apoptóticos da fosfoetanolamina sintética no melanoma B16F10. 106 f. Dissertação (Mestrado) - Programa de Pós-graduação da Interunidades em Bioengenharia (EESC/FMRP/IQSC), Universidade de São Paulo, São Carlos, 2007.

Mentor-Marcel RA, Bobe G, Sardo C, Wang LS, Kuo CT, Stoner G, Colburn NH. Plasma cytokines as potential response indicators to dietary freeze-

dried black raspberries incolorectal cancer patients. Nutr Cancer. 64(6):820-5, 2012.

Mollinedo, F.; Antitumour ether liquids: proapoptotic agents with multiple therapeutic indications, Expert Opin. Ther. Pat. 17: 385-405, 2007.

Morandi B, Mortara L, Chiossone L, Accolla RS, Mingari MC, Moretta L, Moretta A, Ferlazzo G Dendritic cell editing by activated natural killer cells results in a more protective cancer-specific immune response. PLoS One. 7(6):e39170, 2012. 
Muranski, P., A. Boni, P.A. Antony, L. Cassard, K.R. Irvine, A. Kaiser, C.M. Paulos, D.C. Palmer, C.E. Touloukian, K. Ptak, et al. Tumor-specific Th17-polarized cells eradicate large established melanoma. Blood. 112:362-373, 2008.

Nakayama, K. Growth and progression of melanoma and non-melanoma skin cancers regulated by ubiquitination. Pigment Cell Melanoma Res., 23:338-351, 2010.

Numasaki M, Watanabe M, Suzuki T, Takahashi H, Nakamura A, McAllister F, Hishinuma T, Goto J, Lotze MT, Kolls JK, Sasaki H. IL-17 enhances the net angiogenic activity and in vivo growth of human non-small cell lung cancer in SCID mice through promoting CXCR-2dependent angiogenesis. J Immunol. 175(9):6177-89, 2005.

Papadakis K. A.; Targan S. R. Role of cytokines in the pathogenesis of inflammatory bowel disease, Annual Review of Medicine, vol. 51, pp. 289-298, 2000.

Qian, B. Z.; Pollard, J. W. Macrophage diversity enhances tumor progression and metastasis. Cell, 141: 39-51, 2010.

Ramirez-Montagut T, Turk MJ, Wolchok JD, Guevara-Patino JA, Houghton AN. Immunity to melanoma: unraveling the relation of tumor immunity and autoimmunity. Oncogene. 22(20):3180-7, 2003.

Ricotti, C.; Bouzari, N.; Agadi, A.; Cockerell, C.J. Malignant skin neoplasms. Med. Clin. North Am., 93: 1241-1264, 2009.

Russ AJ, Wentworth L, Xu K, Rakhmilevich A, Seroogy CM, Sondel PM, Suresh M, Cho CS. Suppression of T-Cell Expansion by Melanoma is Exerted on Resting Cells. Ann. Surg. Oncol. Apr 5, 2011.

Shankaran, V.; Ikeda, H.; Bruce, A,T.; White, J.M.; Swanson, P.E.; Old, L.J.; Schreiber, R.D. IFN gamma and lymphocytes prevent primary tumour development and shape tumour immunogenicity. Nature, 410: 1107-1111, 2001.

Sethi, G.; Shanmugam, M. K.; Ramachandran, L;, Kumar, A. P.; Tergaonkar, V. Multifaceted link between cancer and inflammation. Biosci Rep., 32(1):1-15, 2012.

Silveira D. S. C. Papel functional dos leucotrienos na resposta imunológica ao melanoma B16-F0 experimental em camundongos. Dissertação (Mestrado) - Programa de Pósgraduação em Biociências Aplicadas à Farmácia (FCFRP), Universidade de São Paulo, 2012.

Swann JB, Smyth MJ. Immune surveillance of tumors. J Clin Invest. 117(5):1137-46, 2007. 
Tang, DG; Porter, AT. Target to apoptosis: a hopeful weapon for prostate cancer. The prostate, 32: 284-293, 1997.

Tartour E, Fossiez F, Joyeux I, Galinha A, Gey A, Claret E, Sastre-Garau X, Couturier J, Mosseri V, Vives V, Banchereau J, Fridman WH, Wijdenes J, Lebecque S, Sautès-Fridman C. Interleukin 17, a T-cell-derived cytokine, promotes tumorigenicity of human cervical tumors in nude mice. Cancer Res. 59(15):3698-704, 1999.

Thejass P, Kuttan G. Modulation of cell-mediated immune response in B16F-10 melanomainduced metastatic tumor-bearing $\mathrm{C} 57 \mathrm{BL} / 6$ mice by sulforaphane. Immunopharmacol Immunotoxicol. 29(2):173-86, 2007.

Thomas, L. On immunosurveillance in human cancer. Yale J Biol Med. 55(3-4): 329-333, 1982.

Torezzini, T.; Athanazio, D. A. Imunovigilância e Imunoedição de Neoplasias: Implicações Clínicas e Potencial Terapêutico. Res. Bras. Cancerologia, 54(1): 63-77, 2008.

Trinchieri G. Interleukin-12 and the regulation of innate resistance and adaptive immunity. Nat Rev Immunol. 3(2):133-46, 2003.

Tsai, C. S.; Chen, F. H.; Wang, C. C.; Huang, H. L.; Jung, S. M.; Wu, C. J.; Lee, C. C.; McBride, W. H.; Chiang, C. S.; Hong, J. H. Macrophages from irradiated tumors express high levels of iNOS, arginase-I and COX-2, and promote tumor growth. Int. J. Radiat. Oncol. Biol. Phys. 68: 499-507, 2007.

Vakkila, J.; Lotze, M.T. Inflammation and necrosis promote tumour growth. Nature Rev. Immunology, 4: 641-647, 2004.

van Houdt IS, Sluijter BJ, Moesbergen LM, Vos WM, de Gruij1 TD, Molenkamp BG, van den Eertwegh AJ, Hooijberg E, van Leeuwen PA, Meijer CJ, Oudejans JJ. Favorable outcome in clinically stage II melanoma patients is associated with the presence of activated tumor infiltrating T-lymphocytes and preserved MHC class $\mathrm{I}$ antigen expression. Int $J$ Cancer. 123(3):609-15, 2008.

Vance, J.E. Phosphatidylserine and phosphatidylethanolamine in mammalian cells: two metabolically related aminophospholipids. J. Lipid. Res., 49: 1377-1387, 2008.

Vink, S.R.; van Blitterswijk, W.; Schellens, J.H.M.; Verheij, M. Rationale and clinical application of alkylphospholipid analogues in combination with radiotherapy. Cancer Treat. Rev. 33: 191, 2007. 
Vuoristo MS. The polymorphisms of interleukin-10 gene influence the prognosis of patients with advanced melanoma. Cancer Genet Cytogenet. 176(1):54-7, 2007.

Wagner, M.; Bjerkvig, R.; Wing, H.; Melero-Martin, J. M.; Lin, R. Z.; Klagsbrun, M.. Dudley, A. C. Inflamed tumor-associated adipose is a depot for machophages tha stimulate tumor growth and angiogenesis. Angiogenesis, 15: 481-495, 2012.

Wang L, Yi T, Kortylewski M, Pardoll DM, Zeng D, Yu H. IL-17 can promote tumor growth through an IL-6-Stat3 signaling pathway. J. Exp. Med., 206 (7): 1457-1464, 2009.

Yamada, Y.; Saito, H.; Ikeguchi, M. Prevalence and clinical relevance of Th17 cells in patients with gastric cancer. J. Surg. Res., 2012.

Yan Z, Kim GY, Deng X, Friedman E. Transforming growth factor beta 1 induces proliferation in colon carcinoma cells by Ras-dependent, smad-independent down-regulation of p21cip1. J Biol Chem, 277:9870-9879, 2002.

Yao, Y.; Huang, C.; Li, Z.F.; Wang, A.Y.; Liu, L.Y.; Zhao, X.G.; Luo, Y.; Ni, L.; Zhang, W.G.; Song, T.S. Exogenous phosphatidylethanolamine induces apoptosis of human hepatoma HepG2 cells via the bcl-2/bax pathway. World J. Gastroenterol., 15: 1751-1758, 2009.

Yu, P.; Fu, Y.X. Tumor-infiltrating T lymphocytes: friends or foes? Lab. Invest., 86: 231-245, 2006.

Yu JJ, Ruddy MJ, Wong GC, Sfintescu C, Baker PJ, Smith JB, Evans RT, Gaffen SL. An essential role for IL-17 in preventing pathogen-initiated bone destruction: recruitment of neutrophils to inflamed bone requires IL-17 receptor-dependent signals. Blood.109(9):3794$802,2007$.

Yue FY, Dummer R, Geertsen R, Hofbauer G, Laine E, Manolio S, Burg G. Interleukin-10 is a growth factor for human melanoma cells and down-regulates HLA class-I, HLA class-II and ICAM-1 molecules. Int J Cancer. 16;71(4):630-7, 1997.

Zhang XH, Xia LH, Liu ZP, Wei WN, Hu Y, Song SJ. Experimental study on activating antileukemic $T$ cells by vaccination with dendritic cells pulsed with survivin. Zhongguo Shi Yan Xue Ye Xue Za Zhi. 11(1):66-9, 2003. 
ANEXOS 


\section{ANEXOS}

Anexo A - Imagens de secções de tumores de melanoma registradas com aumento de 40X.
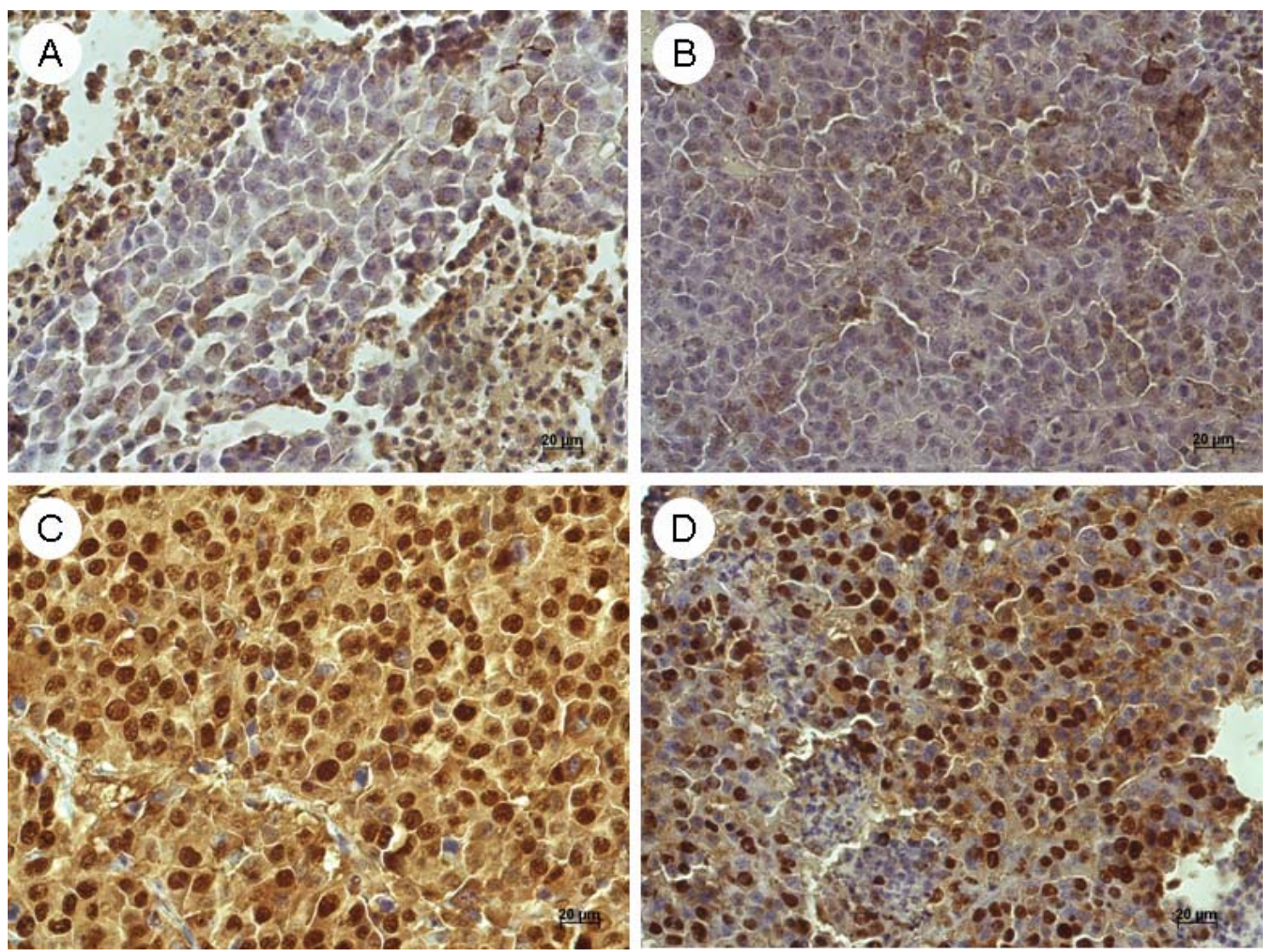

Anexo A - Imagens de secções de tumores de melanoma registradas com aumento de 40X. Imunoistoquímica para detecção de apoptose (caspase-3) na massa tumoral de animais não tratados (A) e que receberam $40 \mathrm{mg} / \mathrm{Kg}$ de PEA por 20 dias consecutivos (B). Imunoistoquímica para marcação do antígeno de proliferação celular - PCNA nos tumores de animais não tratados (C) e tratados com $40 \mathrm{mg} / \mathrm{Kg}$ de PEA por 20 dias(D). 
Anexo B - “Nanoassisted Laser Desorption-Ionization-MS Imaging of Tumors”.

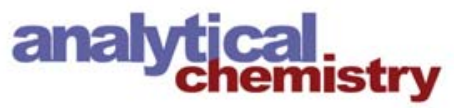

\section{Nanoassisted Laser Desorption-Ionization-MS Imaging of Tumors}

Alessandra Tata, ${ }^{\dagger}$ Anna Maria A. P. Fernandes, ${ }^{\dagger}$ Vanessa G. Santos, ${ }^{\dagger}$ Rosana M. Alberici, ${ }^{\dagger}$ Dioneia Araldi, ${ }^{\dagger}$ Carlos A. Parada, Wellington Braguini, ${ }^{\S}$ Luciana Veronez, ${ }^{\S}$ Gabriela Silva Bisson, ${ }^{\S}$ Felippe H. Z. Reis, ${ }^{\perp}$ Luciane C. Alberici, ${ }^{\perp}$ and Marcos N. Eberlin*,

ThoMSon Mass Spectrometry Laboratory, Institute of Chemistry, University of Campinas-UNICAMP, Campinas, SP, Brazil

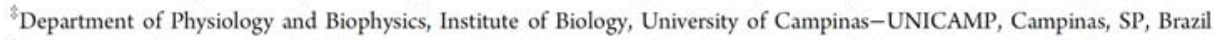
${ }^{8}$ Department of Maternal and Child Nursing and Public Health, School of Nursing of Ribeirão Preto, SP, Brazil ${ }^{\perp}$ Department of Physics and Chemistry, Faculty of Pharmaceutical Sciences of Ribeirão Preto, University of São Paulo, Ribeirão Preto, SP, Brazil

ABSTRACT: The ability of nanoassisted laser desorption-ionization mass spectrometry (NALDI-MS) imaging to provide selective chemical monitoring with proper spatial distribution of lipid profiles from tumor tissues after plate imprinting has been tested. NALDI-MS imaging identified and mapped several potential lipid biomarkers in a murine model of melanoma tumor (inoculation of B16/F10 cells). It also confirmed that the in vivo treatment of tumor bearing mice with synthetic supplement containing phosphoethanolamine (PHO-S) promoted an accentuated decrease in relative abundance of the tumor biomarkers. NALDI-MS imaging is a matrix-free LDI protocol based on the selective imprinting of lipids in the NALDI plate followed by the removal of the tissue. It therefore provides good quality and selective chemical images with preservation of spatial distribution and

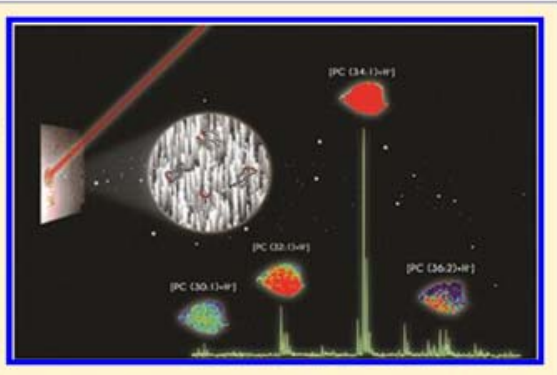
less interference from tissue material. The test case described herein illustrates the potential of chemically selective NALDI-MS imaging for biomarker discovery.

Phospholipids are the main components of biological 1 membranes and are therefore key players in cancer growth. $^{1,2}$ For instance, in breast, prostate, and different types of brain cancers, the tumor progression is accompanied by adaptive metabolic changes showing high levels of phosphatidylcholines (PC) and phosphatidylethanolamines (PE). ${ }^{3} \mathrm{~A}$ class of synthetic antineoplastic phospholipids such as alkylphospholipids, generally termed as "ether lipids", acting specifically on the phospholipid metabolism, has therefore been established as promising drugs for cancer. Ether lipids, such as phosphoethanolamine, have been found to reduce the synthesis of PC in cancer cells interfering with turnover of the phospholipids of the membrane. ${ }^{4-6}$

Imaging $\mathrm{MS}^{7}$ has been recently introduced as a powerful analytical tool able to provide $2 \mathrm{D}$ and $3 \mathrm{D}^{8}$ visualization of molecular variations in biological tissues. Its capability to follow spatial changes in biological samples and organisms at the molecular level has pointed to many key applications in life sciences. Secondary ion mass spectrometry (SIMS),, 10 matrixassisted laser desorption ionization (MALDI)-MS, ${ }^{11-13}$ and desorption electrospray ionization (DESI)-MS ${ }^{14}$ have been the major techniques used for MS imaging. In MALDI, sample preparation is more laborious and consists of several steps: tissue collection, storage, sectioning, and transfer onto MALD plate, followed by matrix deposition. The homogeneity of the matrix deposition is crucial for a good quality MALDI-MS image. Matrix-free laser desorption ionization (LDI) techniques that simplify sample preparation and eliminate matrix noise have therefore been developed. ${ }^{15,16}$ Silicon ${ }^{17}$ and more recently silicon nanowires ${ }^{18,19}$ have been one of the first materials to be used as a suitable support for matrix-free LDI. Silica with silicon nanowires in association with lithium hydroxide and diamond like carbon has also been applied to assist LDI for lipid analysis. ${ }^{20,21}$ Nanostructures such as carbon nanotubes have also shown low signal background and effectiveness as LDI surfaces. $^{22,23}$ Particularly interesting as LDI surfaces are the nanoassited LDI plates (NALDI). ${ }^{24}$ They are produced using semiconductor nanowires of zinc oxide $(\mathrm{ZnO})$, tin oxide $\left(\mathrm{SnO}_{2}\right)$, gallium nitride $(\mathrm{GaN})$, and silicon carbide $(\mathrm{SiC})$ usually grown on a $\mathrm{Si}$ substrate. A variety of physical and chemical methods have been described to synthesize different semiconductor nanorods or nanowires ${ }^{25-27}$ Such semiconductor nanowire surfaces have been demonstrated to be efficient energy-transfer materials for LDI. The disposable and ready to use NALDI targets (Bruker Daltonics) have been applied for the high-throughput quantitative analysis of small molecules and to quantify phospholipids in phototriggerable liposomes. ${ }^{28}$ NALDI-MS has been tested and compared to MALDI-MS for

Received: May 4, 2012

Accepted: June 28, 2012

Published: June 28, 2012 
Analytical Chemistry

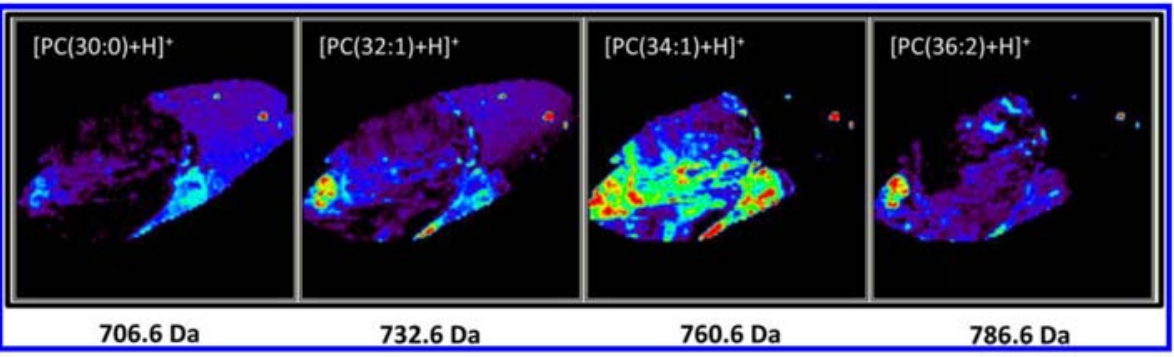

Figure 1. Chemically selective NALDI-MS images for PC ions of human melanoma grown in control mice.

direct lipids analysis in mice kidney tissue imaging, ${ }^{29}$ and a slightly higher number of lipids were identified. NALDI-MS has also been applied for the analysis of phospholipids for gecko footprints. ${ }^{30}$ In this study, we tested the ability of NALDI-MS to provide chemical selective imaging of lipids after imprinting of the lipid content using B16/F10 melanotic murine melanoma as a test case.

\section{EXPERIMENTAL SECTION}

Amino-ethyl phosphoric ester (synthetic phosphoethanolamine, PHO-S) was prepared according to a reported procedure $^{31}$ with purity over $(99 \%)$ analyzed by highperformance liquid chromatography (HPLC). A stock solution of phosphoethanolamine $5 \mathrm{mg} / \mathrm{mL}$ was dissolved in water and used for in vivo experiments.

The murine melanoma cell line $\mathrm{B} 16 / \mathrm{F} 10$ was maintained as monolayer cultures in RPMI 1640 medium (Gibco, Invitrogen) supplemented with $10 \%$ fetal calf serum (Gibco, Invitrogen), $100 \mu \mathrm{g} / \mathrm{mL}$ streptomycin, and 100 units $/ \mathrm{mL}$ penicillin at $37^{\circ} \mathrm{C}$ in $5 \% \mathrm{CO}_{2}$. When $80 \%$ confluence was reached, cells were removed from culture flasks by adding $0.05 \%$ trypsin solution. For inoculation in animals, the cell suspension was centrifuged and then resuspended in sterile PBS to obtain a solution containing $5 \times 10^{5}$ cells $\mathrm{mL}^{-1}$. Cell viability was determined by $0.2 \%$ trypan blue exclusion and was $>95 \%$ in all experiments.

The B16/F10 cells were injected subcutaneously (sc) in the dorsal region of C57/BL6 mice $\left(5 \times 10^{4}\right.$ cells/animal). Within 20 days after inoculation of cells, the tumors measured approximately $1 \mathrm{~cm}^{3}$, and the animals were sacrificed for tumor removal, cryosectioning, and NALDI imaging.

PHO-S $(20 \mathrm{mg} / \mathrm{kg})$ was administered daily by gavage for 10 days, beginning 10 days after the inoculation of tumor cells. The animals were divided in two groups: the control group consisted of 30 animals that received $100 \mu \mathrm{L}$ of water by gavage, and the treated group, consisting of 30 animals that received $100 \mu \mathrm{L}$ of PHO-S solution. All experiments were conducted according to the ethical principles for animal research and approved by the Ethics Committee for Animal Experimentation of the School of Medicine of Ribeirão Preto, University of São Paulo (USP).

For sample preparation, the guidelines for the "thaw mounting" procedure reported by Vidova and co-workers ${ }^{27}$ were followed. The tumors were frozen in liquid nitrogen, stored at $-80^{\circ} \mathrm{C}$, and subsequently cut in $30 \mu \mathrm{m}$ sections using a cryo-microtome (CM1850, Leica, Germany). After cutting, the tissue was carefully transferred onto a cold NALDI surface $\left(-20^{\circ} \mathrm{C}\right.$; the temperature inside the Leica microtome $)$ by the standard surgical tweezers/pincers. After positioning the tissue section on a NALDI surface, the operator touched the surface with a finger from the other side opposite to the place where the tissue is located. The rapid heating results in "thaw mounting"; that is, a melting and imprinting process that transfers the lipid species that were present on the tissue section. The rest of the tissue was washed off mechanically by a water rinse (approximately $5 \mathrm{~mL}$ ), but the imprint of phospholipids stayed on the NALDI surface. The NALDIimaging was performed using an Autoflex III MALDI-TOF/ TOF (Bruker Daltonics, Germany) equipped with smartbeam $(337 \mathrm{~nm})$ laser desorption imaging ion source in the positive ion mode. The NALDI imaging experiment was controlled by the program FlexImaging 3.0 (BrukerDaltonics, Germany). The laser diameter was set to $\sim 50 \mu \mathrm{m}$ and rastered along the $x$ - and $y$-axis of selected regions at $150 \mu \mathrm{m}$ resolution. Each spectrum was acquired from 500 laser shots on a single spot. The range over which ions were detected was $m / z 700$ to 950 . The laser power range was adjusted to $30-50 \%$ before the imaging experiment to yield optimal results. NALDI imaging measurements were done in operating conditions as follows: ion source $1=19.00 \mathrm{kV}$, ion source $2=16.72 \mathrm{kV}$, lens voltage $=8.30 \mathrm{kV}$, reflector voltage $=21.00 \mathrm{kV}$, reflector voltage $2=9.70 \mathrm{kV}$, pulsed ion extraction time $=10 \mathrm{~ns}$, and suppression $=500 \mathrm{Da}$. Images were created and normalized using the FlexImaging software. Images were replicated three times on consecutive tissues. One parallel slice of each tumor (control and treated) was cut in $10 \mu \mathrm{m}$ sections and subjected to hematoxylin and eosin staining according to the standard protocol.

Data Processing. The 2D images of lipids were created using on line free Biomap software, a free comprehensive medical image analysis software developed by Novartis Institutes for BioMedical Research. It allows the ion images to be reconstructed, the process of the mass spectral data for creation of two-dimensional coordinates of the surface versus intensity. ${ }^{32}$ Mapping the abundance of the observed ions allowed one to evaluate the differences between the control tissues and the treated tissues. The most significant ions that showed differences in abundance between the two tissues were characterized by LIFT-MS fragmentation and lipid searches performed through the online database (www.lipidmaps.org).

\section{RESULTS AND DISCUSSION}

Direct tissue profiling was performed on the melanoma tumor tissues grown in the nontreated animals (control tumors) and on the tumors grown in the PHO-S treated animals. The NALDI images generated by Flexlmaging were imported into Biomap and processed to tentatively identify species as candidates for lipid biomarkers. The lipid ions observed in 
Analytical Chemistry

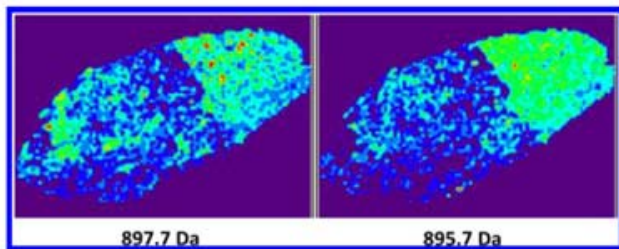

Figure 2. Chemically selective NALDI-MS images for [TAG $+\mathrm{H}]$ ions of human melanoma grown in control mice.

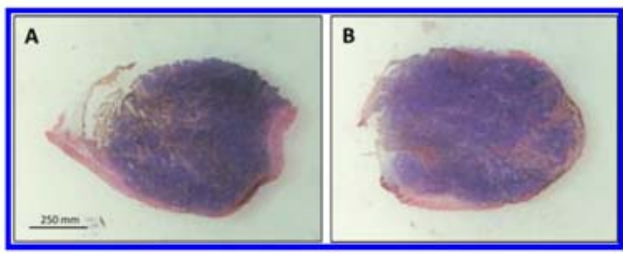

Figure 3. Histological images of the (A) control and (B) the PHOS-S treated tumor tissue.

the tissues were labeled by class abbreviation followed by the total number of carbons and double bounds in the acyl-residues attached to the glycerol backbone (in parentheses). Figure 1 shows NALDI-MS images of the tumor tissue which were removed from a control animal. Note that the tumor is encapsulated into an adipose tissue and some of this material remained attached to it. The presence of this adipose tissue is interesting since it functions as a reference tissue for comparison of the abundances in the tumor of phospholipids (major PC) and triacylglycerols (TAG). The mapping of different PC ions made possible to clearly identify lipid biomarkers of the two types of tissues on the same slice. Higher abundances of protonated phosphatidylcholine [PC $(30: 0)+$ $\mathrm{H}]^{+}$of $\mathrm{m} / z 706.6$ and phosphatidylglycerol of $\mathrm{m} / z$ 747.5 [PG $(34: 2)+\mathrm{H}]^{+}$(image not shown) are observed only in the fatty portion, and its selective image clearly shows the border between the tumor and the adipose tissue. The monounsatu-

rated phosphatidylcholine ion of $m / z 732.6[\mathrm{PC}(32: 1)+\mathrm{H}]$ is homogeneously distributed in the entire slice, as well as the saturated $[\mathrm{PC}(32: 0)+\mathrm{H}]^{+}$ion of $m / z 734.6$ (image not shown). Although found throughout the slice, these unsaturated phospholipids are slightly more abundant in the tumor tissue, concentrating in vesicles that appear red and yellow in the NALDI images. The monounsaturated phosphatidylcholine ion $[\mathrm{PC}(34: 1)+\mathrm{H}]^{+}$of $m / z 760.6$ and the polyunsaturated ion $[\mathrm{PC}(36: 2)+\mathrm{H}]^{+}$of $m / z 786.6$ are by far the most characteristic and predominate in the tumor. Another marker ion for the tumor was [PC $(36: 1)+\mathrm{H}]^{+}$of $m / z 788.6$ (data not shown). These observations indicate that whereas saturated PCs are almost equally distributed in both tumor and fatty tissues, the mono- and polyunsaturated lipids are more abundant in the tumor tissue.

For breast cancer, it has been found that the phospholipid (PL) content is 4-fold higher in tumor tissue whereas the triacylglycerol (TAG) content tended to be $65 \%$ lower. ${ }^{1,33}$ The presence and the distribution of TAG ions were therefore investigated in the tumor tissue by NALDI-MS imaging. [TAG $+\mathrm{H}]^{+}$ions of $m / z 895.7$ and $m / z 897.7$ are observed to be more abundant in the adipose tissue than in the tumor tissue (Figure 2).

Figure 3 shows histological images $(A, B)$ and Figure 4 shows NALDI-MS images $(A, B)$ of the $(A)$ control and $(B)$ treated tumors. Note that only subtle differences in the morphology of both treated and untreated tumors are seen in the histological images that require the help of a trained pathologist to be recognized. The NALDI images (Figure 4) show, however, very contrasting distributions of $\mathrm{PC}$ tumor marker ions with different relative abundances between treated and control tissue, although relative intensities of the spectra of the marker ions remain nearly the same for the treated and untreated tissues (Figure 5). Data obtained by the NALDI image seem to demonstrate the efficacy of PHO-S treatment inhibiting the PC biosynthesis. Alkylphospholipids are known to interfere with the PC metabolism and turnover by inhibition of CTP phosphocholine cytidyltransferase, the key enzyme controlling the PC synthesis. These phospholipids are crucial for the maintenance of membrane integrity and, therefore, for cell survival. These molecules seem to kill tumor cells by induction

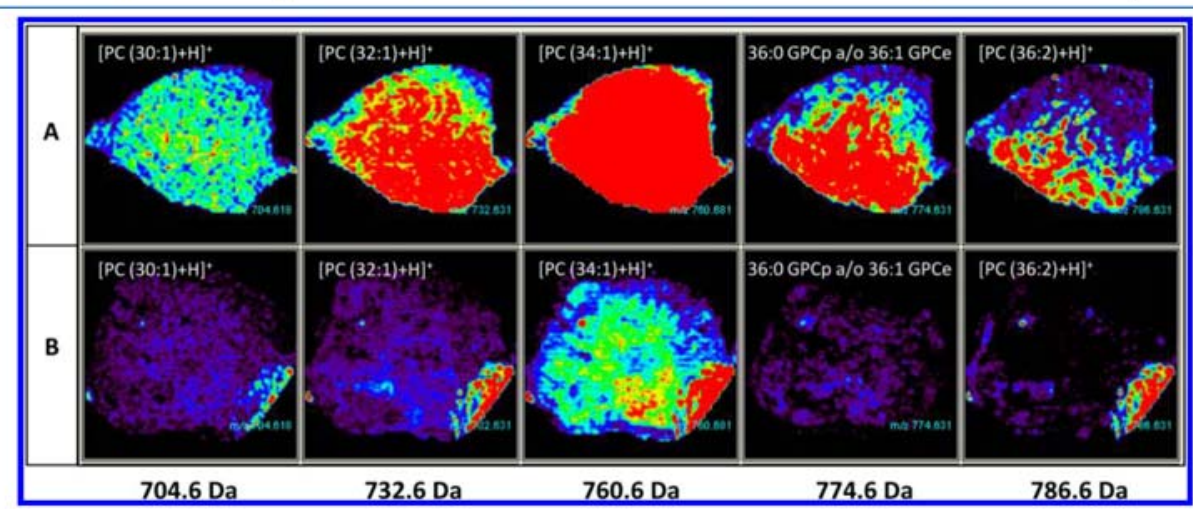

Figure 4. (A) NALDI image of control tumor tissue. (B) NALDI image of PHOS-S treated tumor tissue. Note that the reference adipose tissue was removed from the tumors. 


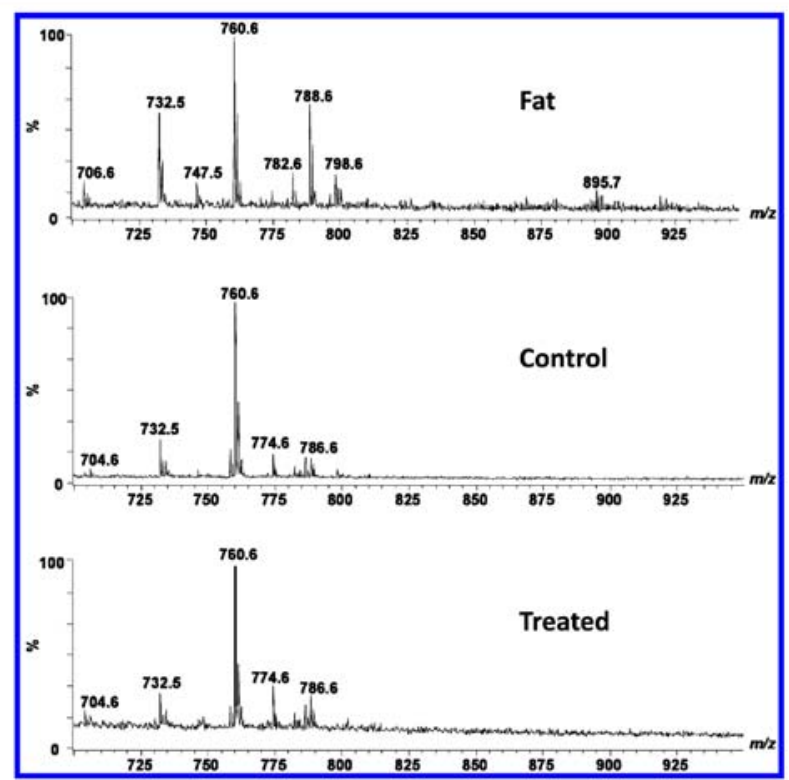

Figure 5. Typical NALDI-MS of the fatty region, the control tumor, and PHOS-S treated tumor.

of both apoptotic and nonapoptotic cell death. ${ }^{34}$ Alkylphospholipids are already subjected to clinical tests as promising antineoplastic drugs, but analytical protocols to test their efficacy have employed laborious procedures and/or radioactive compounds.

Note also that, whereas some markers are quite homogenously distributed throughout the tumor, some others seem to be more concentrated on specific vesicles or areas within the tumor and that the imprinting process used in NALDI is able to preserve adequate spatial distribution to detect this heterogeneity. Note that the ion of $m / z 774.6$ may correspond to a alkenyl (GPCp) and/or alkyl ether phosphatidylcholines species (GPCe), respectively, 36:0 and/or 36:1. The NALDIMS trends observed in Figure 4 are therefore in accordance with previous observations that PC synthesis is inhibited by PHO-S intake. Note in the treated tumor an area in the low right part that still displays high abundances of marker ions, particularly for $[\mathrm{PC}(32: 1)+\mathrm{H}]^{+},[\mathrm{PC}(34: 1)+\mathrm{H}]^{+}$, and $[\mathrm{PC}(36: 2)+\mathrm{H}]^{+}$. It may represent a region with differen cellular architecture and higher phospholipids content much similar to the control. It has been demonstrated that, after 14 days of PHOS-S treatment on mice, the morphology of the tumor changes, revealing better cell organization accompanied by the lipid hydrolysis. Note that the morphological aspect of this region looks quite similar to the untreated tumor, and the still high abundances of the biomarkers indicate that the PHOS-S treatment was not so effective in this area.

Interesting, phosphatidylcholines have only been detected by NALDI-MS as protonated molecules. In MALDI, they are detected in various forms including $[\mathrm{PC}+\mathrm{H}]^{*},[\mathrm{PC}+\mathrm{Na}]^{+}$, and $[\mathrm{PC}+\mathrm{K}]^{*}$ ions which may cause isobaric interferences. ${ }^{29}$ The NALDI preparative washing process removes salts and therefore eliminates these cationized species that may overlap with other isobaric species hence simplifying spectra interpretation. This shows another beneficial aspect of NALDI-MS imaging of lipids. Protonated molecules have also been favored in MALDI using 9-aminoacridine (9-AA) as the matrix. $^{3 s}$

\section{CONCLUSION}

Selective NALDI-MS images of tumors, focusing on lipids analysis, could be obtained after lipid imprinting on the NALDI plate with suitable sensitivity and conserved spatial distribution. Characteristic lipid profiles of melanoma tumors were obtained, and tumors treated with PHO-S (drug intake) showed a substantial reduction in the abundance of phospholipid biomarkers. NALDI-MS is performed on the imprinted lipids; hence, it avoids interferences from other tissue components. The reduced salt content of the imprinted material also simplifies the ionization by eliminating the $\left[\mathrm{PC}+\mathrm{Na}^{+}\right.$and $[\mathrm{PC}+\mathrm{K}]^{+}$species and their isobaric interferences directing the ionization nearly exclusively to a single species: the protonated molecules $[\mathrm{PC}+\mathrm{H}]^{+}$and $[\mathrm{TAG}+\mathrm{H}]^{+}$. NALDI-MS seems therefore to offer an attractive matrix-free, selective, and simplified LDI protocol for tissue imaging and biomarker discovery.

\section{AUTHOR INFORMATION}

\section{Corresponding Author}

*Address: ThoMSon Mass Spectrometry Laboratory, Institute of Chemistry, University of Campinas-UNICAMP, 13084-971, Campinas SP, Brazil. E-mail: eberlin@iqm.unicamp.br.

\section{Notes}

The authors declare no competing financial interest. 


\section{ACKNOWLEDGMENTS}

The authors thank the Brazilian science foundations FAPESP, $\mathrm{CNPq}$, and CAPES for financial assistance.

\section{REFERENCES}

(1) Sakai, K.; Okuyama, H.; Yura, J.; Takeyama, H.; Shinagawa, N.; Tsuruga, N.; Kato, K.; Miura, K.; Kawase, K.; Tsujimura, T. Carcinocencsis 1992, 13, 579-584.

(2) Ackerstaff, E.; Glunde, K.; Bhujwalla, Z. M. J. Cell Biochem. 2003, $90,525-533$.

(3) Negendvak, W. NMR Biomed 1992, 5, 303-324.

(4) Ferreira, A. K.; Meneguelo, R.; Claro Neto, S.; Chierice, O. G. (4) Ferreira, A. K.; Meneguelo, R.; Claro Neto, S.;
Durvanei, A. M. J. Cancer Sci. Ther. 2011, 3, 53-59.

(5) Luit, A. H; Vink, S. R.; Klarenbeek, Jeffrey B.; Perrissoud, D Solary, E.; Verheij, M.; Blitterswijk, W. J. Mol. Cancer Ther. 2007, 6 2337-2345.

(6) Danker, K; Reutter, W.; Semini, G. Br.L.Pharmacel. 2010, 160 $36-47$

(7) (a) Schwamborn, K, Caprioli, R. M. Nat_Rev. Cancer 2010, 10 , 639-646. (b) Amstalden Van Hove, E, R.; Smith, D, F; Heering, R.

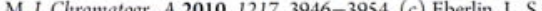
M. Chem. 2011, 83, 8366-8371, S; Agar, N. Y. R; Cooks, R. G. And. Chem. 2011, 83, 8366-8371.

(8) Eberlin, L. S.; Ifa, R. D.; Wu, C.; Cooks, R. G. Angew, Chem., Int. Ed. 2010, 49, 873-876.

(9) Nygren, H.; Malmberg, P.; Kriegeskotte, C.; Arlinghaus, H. F. EEBS Latt, 2004, 566, 291-293.

(10) Brunelle, A; Touboul, D; Laprevote, O. J. Mass Spectrom. 2005 $40,985-999$.

(11) Karas, M.; Hillenkamp, F. Anal Chem. 1988, 60, 2299-2301. (12) Caprioli, R. M.; Farmer, T. B.; Gile, J. Anal. Chem. 1997, 69 , 4751-4760.

(13) Stoecki, M.; Chaurand, P.; Hallahan, D. E.; Caprioli, R. M. Nat (13) Stoecki, M.; Chaur
Med. 2001, 7, 493-496.

Med. 2001, 7, 493-496.
(14) (a) Wiseman, J. M.; Ifa, D. R; Zhu, Y.; Kissinger, C. B.; Manicke, N. E.; Kissinger, P. T; Cooks, R. G. Proc, Natl. Acad. Sci. U.S.A. 2008, 105, 18120-18125. (b) Eberlin, L. S.; Norton, I; Dill, A L.; Golby, A. J.; Ligon, K. L.; Santagata, S; Cooks, R. G. Cancer Res. $2012,72,645-654$

(15) Northen, T. R, Yanes, O, Northen, M. T. Marrinucci, D, Uritboonthai, W.; Apon, J.; Golledge, S. L.; Nordstrom, A.; Siuzdak, G. Uritboonthai, W.; Apon, J; Golled
Naturs 2007, 449, 1033-U1033.

(16) Nemes, P.; Woods, A. S.; Vertes, A. Anal. Chem, 2010, 82, $982-$ 988.

(17) Wei, J.; Buriak, J. M.; Siuzdak, G. Naturs 1999, 399, 243-246 (18) Go, E. P.; Apon, J. V.; Luo, G.; Saghatelian, A.; Daniels, R. H. Sahi, V; Dubrow, R.; Cravatt, B. F.; Vertes, A.; Siuzdak., G. Anal. Chem. 2005, 77, 1641-1646.

(19) Muck, A.; Stelzner, T.; Hubner, U.; Christiansen, S.; Svatos, A. Lab Chin 2010, 10, 320-325.

(20) Budimir, N.; Blais, J. C.; Fournier, F.; Tabet, J. C. Rapid. Commun. Mass Suectrom, 2006, 20,680-684.

(21) Najam-ul-Haq, M.; Rainer, M.; Huck, C. W.; Hausberger, P. mal. Chem. 2008, 80, 7467-7472

(22) Xu, S.; Li, Y.; Zou, H.; Qju, J. Anal. Chem, 2003, 75, 6191-6195. (23) Ren, S. F.; Zhang, L.; Cheng, Z. H.; Guo, Y. L. J. Am. Soc. Mass Sectrom. 2005, 16, 333-339.

(24) Kang, M. J.; Pyun, J. C.; Lee, J. C.; Choi, Y. J.; Park, J. H.; Park, J. G.; Lee, J. G.; Choi, H. J. Rapid Commun. Mass Spectrom. 2005, 19, 3166-3170.

(25) Seong, H. K.; Lee, S. K; Choi, H. J.; Lee, J. L.; Choi, D. J. Appl Phys Lett. 2004, 85, 1256-1258.

(26) Choi, H. J.; Seong, H. K.; Park, J. H.; ParkJ., G.; Cho, B. W. here. Cham. Commun. 2004, 7, 809-811.

(27) Johnson, J.; Choi, H. J.; Knutsen, K. P.; Schaller, R. D.; Yang, P.; Saykally, R L L Nat_Mater. 2002, 1, 106-110.

(28) Colantonio, S.; Simpson, J. T.; Fisher, R. J.; Yavlovich, A. Belanger, J. M.; Puri, A.; Blumenthal, R. Livids 2011, 46, 469-477.
(29) Vidova, V.; Novak, P.; Strohalm, M.; Pol, J.; Havlicek, V.; Volný, M. Anal. Chem. 2010, 82, 4994-4997.

(30) Hsu, P. Y.; Ge, L; Li, X.; Stark, A. Y.; Wesdemiotis, C. Niewiarowski, P. H.; Dhinojwala, A. J. R. Sec.Jnterfacs 2011, 9, 657 664.

31) Outhouse, E. L. Biochem. J. 1936, 30, 197-201.

32) Hosokawa, N.; Sugiura, Y.; Setou, M. Imaging Mass Spectrom. 2010, No. Part V, 113-126.

(33) Szachowicz-Petelska, B.; Dobrzynska, L.; Sulkowski, S.; Figaszewski, Z. J. Environ. Biol. 2010, 31, 845-850.

(34) Vink, S. R; Blitterswijk, W. J.; Schellens, J. H. M.; Verheij, M. Cancer Treat Rev. 2007, 33, 191-202.

(35) Fuch, S.; Süss, R; Schiller, J. Pros_Linid Res 2010, 49, 450-475. 